\title{
AVALIAÇÃO DOSIMÉTRICA DE DETECTORES SEMICONDUTORES PARA APLICAÇÃO NA DOSIMETRIA E MICRODOSIMETRIA DE NÊUTRONS EM REATORES NUCLEARES E INSTALAÇÕES DE RADIOCIRURGIA
}

JOSÉ PATRICIO NÁHUEL CÁRDENAS

Tese apresentada como parte dos requisitos para obtenção do grau de Doutor em Ciências na Área de Tecnologia Nuclear - Aplicações

Orientadora:

Dra. Letícia Lucente Campos Rodrigues

\section{São Paulo}




\section{DEDICATÓRIA}

En Memória de: mi señora Madre Chelita mi señor Padre Juan “Lagui” y mis hermanos Rubén Casimiro y John Isaias. 
À minha esposa Ivani e ao meu filho Andrés Esteban

A meu Deus 


\section{AGRADECIMENTOS}

Gostaria de expressar meus agradecimentos para as pessoas que permitiram o desenvolvimento deste trabalho:

Ao Instituto de Pesquisas Energéticas e Nucleares pela oportunidade do desenvolvimento deste trabalho.

Ao Professor M.Sc. Joel Alvarenga e ao Eng. M.Sc. Heinz Hoppe de Souza pela oportunidade de ingresso no Instituto de Energia Atômica (IEA-1978).

À Dra. Letícia Lucente Campos Rodrigues pela oportunidade da orientação e o desenvolvimento do trabalho na Área de Dosimetria.

Ao Eng M.Sc. Roberto Franjdlich e M.Sc. Walter Ricci na Chefia do reator IEA-R1, grupo de operação, supervisores e técnicos de proteção radiológica.

Ao Dr. Ulisses Bitelli Chefe do reator IPEN/MB-01, aos operadores, ao Físico (Operador Sênior) Rogério Jerez e técnicos de proteção radiológica.

Aos Drs Reynaldo Pugliese e Marcos Pereira pelo apoio e supervisão no uso da instalação de Neutrongrafia.

À Dra. Brigitte Pecequilo pelo empréstimo da fonte mista de calibração.

Ao Dr. Tufic Madi Filho pela cessão do Laboratório CENF para o desenvolvimento da maior parte das experiências e pela sua paciência nas inúmeras discussões sobre o assunto desenvolvido. 
Ao Projetista Operador do Reator IEA-R1 Sr. Edno Lenhatti pelo projeto e desenhos mecânicos necessários para o desenvolvimento do trabalho.

Ao Sr José Carlos Sabino (OM) pela execução dos componentes mecânicos utilizados no trabalho desenvolvido.

À Professora Élide Mastena e ao Professor Ítalo Salzano pela colaboração no idioma inglês.

A toda equipe de Nefrologia do Instituto Central da Faculdade de Medicina da Universidade de São Paulo (ICFMUSP) na pessoa da Ilma. Sra. Dra. Maria Cristina Ribeiro de Castro pelos cuidados e dedicação com minha saúde desde 12 de Junho de 1994.

Un agradecimiento especial a Carlitos Montero (in memoriam) por todos "los empujones" dados y su insistência para que me viniera al Brasil. 


\title{
AVALIAÇÃO DOSIMÉTRICA DE DETECTORES SEMICONDUTORES PARA APLICAÇÃO NA DOSIMETRIA E MICRODOSIMETRIA DE NÊUTRONS EM REATORES NUCLEARES E INSTALAÇÕES DE RADIOCIRURGIA
}

\section{JOSÉ PATRICIO NÁHUEL CÁRDENAS}

\begin{abstract}
RESUMO
Este trabalho tem como objetivo a avaliação dosimétrica de componentes semicondutores (detectores Barreira de Superfície e fotodiodos PIN) para aplicação em medições de dose equivalente em campos de baixo fluxo de nêutrons (rápidos e térmicos), utilizando uma fonte de AmBe de alto fluxo, a instalação de Neutrongrafia do reator IEA-R1 (fluxos térmicos/epitérmicos) e fluxo de nêutrons rápidos do núcleo do reator IPEN/MB-01 (UCRI Unidade Crítica). Para a detecção de nêutrons (térmicos, epitérmicos e rápidos) foram usados componentes moderadores e conversores (parafina, boro e polietileno). Os fluxos resultantes da moderação e conversão foram utilizados para a irradiação de componentes semicondutores (SSB - Barreira de Superfície e fotodiodos). Foi utilizado também um conversor misto constituído de uma folha de polietileno borado (marca Kodak).

O método de simulação por Monte Carlo foi utilizado para avaliar de forma analítica a espessura ótima da parafina. O resultado obtido foi similar ao verificado experimentalmente e serviu para avaliar o fluxo de nêutrons emergentes do moderador (parafina). Da mesma forma, através de simulação, foi avaliado também o fluxo de nêutrons rápidos que atinge o conversor de polietileno que cobre a face sensível dos semicondutores.

O nível de radiação gama foi avaliado cobrindo o detector por inteiro com uma folha de cádmio de $1 \mathrm{~mm}$ de espessura.

O reator IPEN/MB-01 foi usado para avaliar a resposta dos detectores para nêutrons rápidos de alto fluxo.

Os resultados, de uma forma geral, mostraram concordância e similaridade com os trabalhos desenvolvidos por outros grupos de pesquisas.

Foi também estabelecida uma abordagem para o cálculo de dose equivalente utilizando os espectros obtidos nas experiências.
\end{abstract}




\title{
DOSIMETRIC EVALUATION OF SEMICONDUCTOR DETECTORS FOR APPLICATION IN NEUTRON DOSIMETRY AND MICRODOSIMETRY IN NUCLEAR REACTOR AND RADIOSURGICAL FACILITIES
}

\section{JOSÉ PATRICIO NÁHUEL CÁRDENAS}

\begin{abstract}
The main objetive of this research is the dosimetric evaluation of semiconductor componentes (surface barrier detectors and PIN photodiodes) for applications in dose equivalent measurements on low dose fields (fast and thermal fluxes) using an AmBe neutron source, the IEA-R1 reactor neutrongraphy facility (epithermal and thermal fluxes) and the Critical Unit facility IPEN/MB-01 (fast fluxes).

As moderator compound to fast neutrons flux from the AmBe source was used paraffin and boron and polyethylene as converter for thermal and fast neutrons measurements. The resulting fluxes were used to the irradiation of semiconductor components (SSB - Surface Barrier Detector and PIN photodiodes). A mixed converter made of a borated polyethylene foil (Kodak) was also used.

Monte Carlo simulation metodology was employed to evaluate analytically the optimal paraffin thickness. The obtained results were similar to the experimental data and allowed the evaluation of emerging neutron flux from moderator, as well as the fast neutron flux reaching the polyethylene covering the semiconductor sensitive surface.

Gamma radiation levels were evaluated covering the whole detector with cadmium foil $1 \mathrm{~mm}$ thick, allowing thermal neutrons blockage and gamma radiation measurements.

The IPEN/MB-01 facility was employed to evaluate the detector response for high neutron flux. The results were in good agreement with other studies published.

Using the obtained spectra an approach to dose equivalent calculation was established.
\end{abstract}




\section{SUMÁRIO}

1.- INTRODUÇÃO

Página

2.- OBJETIVOS

Gerais

Específicos

3. FUNDAMENTOS TEÓRICOS

3.1 Interações radiobiológicas

3.1.1 Interações dos raios gamas com a matéria ………………………………........ 6

3.1.2 Interação dos nêutrons com a matéria …………………………………….....

3.2 Classificação dos nêutrons segundo sua energia …………………………….....

3.3 Dosimetria - definições básicas ......................................................................... 11

3.3.1 Qualidade da radiação e Equivalente de Dose ................................................ 11

3.3.2 Dose Absorvida ...................................................................................... 12

3.3.3 Fator de Qualidade (QF-Quality Factor) e Tranferência Linear de Energia (LET - Linear Energy Transfer) ………………………………………………... 12

3.3.4 Dose Equivalente .................................................................................... 13

3.3.5 Conversão da Fluência em Equivalente de Dose ............................................... 13

3.4 Dosimetria de nêutrons ..................................................................................

3.5 Conversores de nêutrons .................................................................................. 15

3.5.1 Tipos de conversores ................................................................................ 17

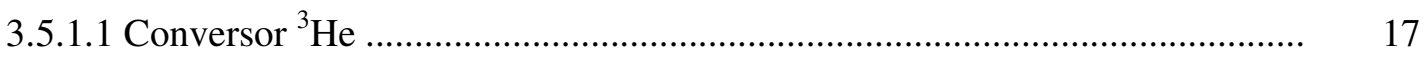

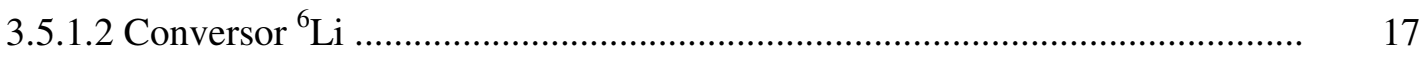

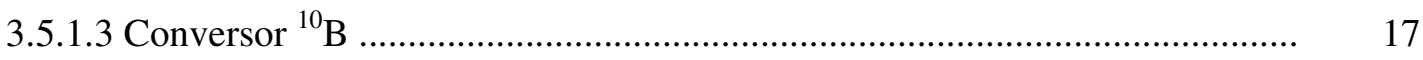

3.5.1.4 Conversores hidrogenados (geradores ou radiadores de prótons de recuo).... 18

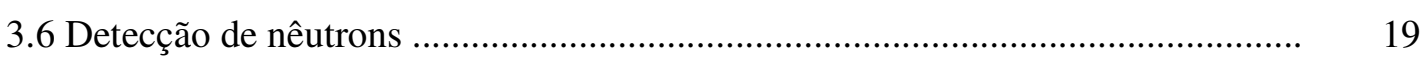

3.6.1 Detecção por meio de prótons e partículas alfa ................................................... 19

3.7 Os semicondutores - generalidades .............................................................. 24

3.7.1 Estrutura cristalina ……………………………………………………....

3.7.2 Diodos semicondutores .........................................................................

3.7.3 Dopagem de semicondutores ........................................................................ 28

3.7.4 Dependência da resposta de semicondutores ……………………………...... 28

3.7.5 Vantagens e desvantagens dos detectores de silício ........................................ 29 
3.8 Semicondutores em dosimetria e detecção de partículas - Estado da Arte ......... $\quad 32$

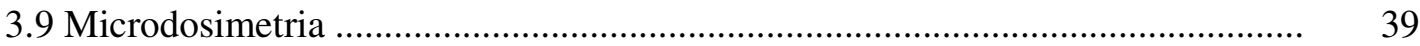

3.9.1 Equivalência ao tecido ................................................................................... 39

3.9.2 Semicondutores em Microdosimetria ........................................................... $\quad 40$

3.10 Simulação usando o código de Monte Carlo .................................................... 43

4.- MATERIAIS E MÉTODOS ….................................................................... 44

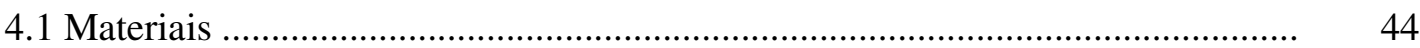

4.1.1 Diodos semicondutores de Barreira de Superfície (SSBD - Silicon Surface

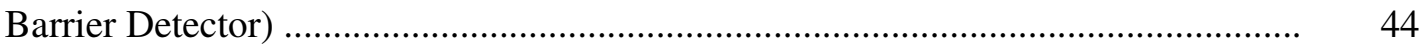

4.1.1.1 Detectores Barreira de Superfície da ORTEC ….......................................... 44

4.1.1.2 Detector de silício TMF-1 de Barreira de superfície ..................................... 44

4.1.1.3 Fotodiodos PIN da HAMAMATSU .......................................................... 44

4.1.2 Componentes moderadores .......................................................................... 46

4.1.3 Componentes conversores ....................................................................... 46

4.1.3.1 Conversor de Boro ............................................................................... 47

4.1.3.2 Conversor de Polietileno .......................................................................... 47

4.1.3.3 Conversor de Polietileno-Borado .................................................................. 47

4.1.4 Emissores alfa utilizados para calibração em energia ..................................... 47

4.1.4.1. Fontes de calibração ..................................................................................... 47

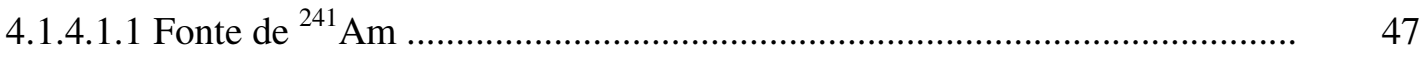

4.1.4.1.2 Fonte de nuclídeos mista $\left({ }^{239} \mathrm{Pu}+{ }^{241} \mathrm{Am}+{ }^{244} \mathrm{Cm}\right)$..................................... 48

4.1.5 Módulos preamplificadores sensíveis à carga (PSC) ..................................... 48

4.1.5.1 Módulo Pré-amplificador Sensível à Carga da Sochin Incorporated,............

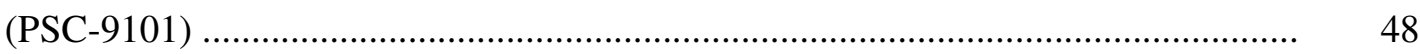

4.1.5.2 Módulo préamplificador sensível à carga ORTEC 142AH …...................... 48

4.1.6 Eletrônica associada e sistema de aquisição de dados utilizados na avaliação dos semicondutores (Arranjo experimental) ........................................................... 49

4.1.7 Fontes de nêutrons ...................................................................................... 50

4.1.7.1 Fonte de AmBe - Bancada Experimental no Laboratório CENF ................. $\quad 50$

4.1.7.2 Reatores nucleares de pesquisas .................................................................. 51

4.1.7.2.1 Reator nuclear IEA-R1 .................................................................. 51

4.1.7.2.1.1 Instalação de Neutrongrafia, nêutrons térmicos e epitérmicos ................ 52

4.1.7.2.2 Reator IPEN/MB-01 (Unidade Crítica) ................................................... 53 
4.2.1 Método para testes preliminares de componentes (Laboratório CENF ) .......... $\quad 54$

4.2.1.1 Teste de "Rise Time" dos preamplificadores SOSHIN 9101 e ORTEC 142. 54

4.2.1.2 Testes de pré-amplificadores sensíveis à carga (PSC) .................................. 55

4.2.1.2.1 Módulo Preamplificador SOSHIN 9101 …................................................. $\quad 55$

4.2.1.2.2 Módulo Preamplificador ORTEC 142AH ….......................................... 55

4.2.1.2.3 Testes comparativos dos detectores tipo barreira de superfície (SSB-

Silicon Surface Barrier) .................................................................................. 56

4.2.2 Método de calibração do sistema para detecção e processamento ................... 56

4.2.2.1 Calibração utilizando fonte $\mathrm{de}^{241} \mathrm{Am}$......................................................... 56

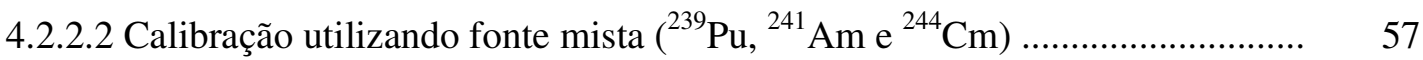

4.3 Método de detecção de nêutrons térmicos ......................................................... 57

4.4 Método de detecção de nêutrons rápidos ............................................................ 57

4.5 Método de simulação por Monte Carlo para definir o fluxo de nêutrons emergentes do moderador a parafina ................................................................... 58

4.7 Método para a determinação da espessura otimizada da película (ou lamina) de polietileno................................................................................................... 58

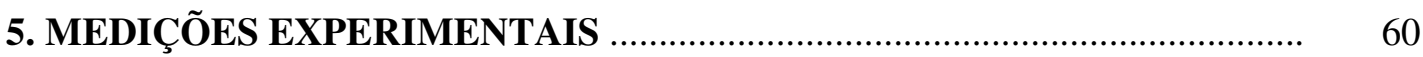

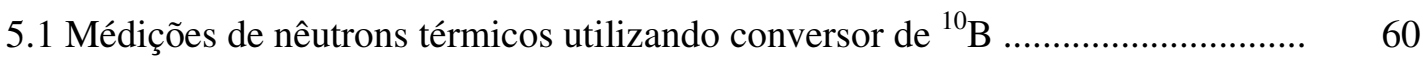

5.2 Medição de nêutrons térmicos utilizando conversor de polietileno borado .......... 61

5.3 Medição de nêutrons rápidos usando polietileno .................................................. 61

5.4 Medições na instalação de Neutrongrafia - Detecção de nêutrons térmicos e epitérmicos

5.5 Medições no núcleo do reator IPEN/MB-01 (UCRI) - Detecção de nêutrons rápidos

6. RESULTADOS E DISCUSSÕES .................................................................. 64

6.1 Teste de "Rise Time" dos preamplificadores SOSHIN 9101 e ORTEC 142...... $\quad 64$

6.2 Detectores SSBs TMF-1 e ORTEC com os preamplificadores 142AH e

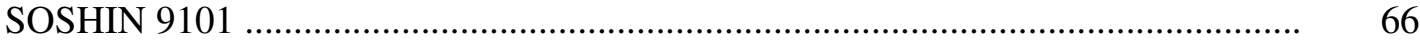

6.3 Teste dos detectores SSB com preamplificador SOSHIN 9101........................ 68

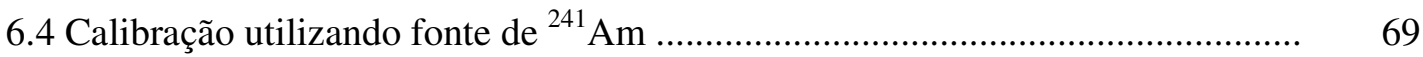

6.5 Calibração - Testes de linearidade do canal de aquisição .................................. $\quad 70$

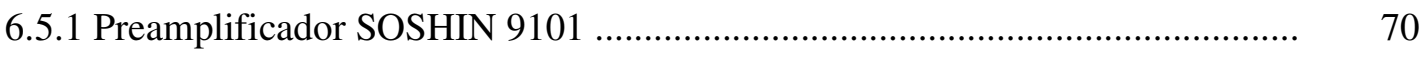


6.6 Resposta dos fotodiodos PIN, S3590-04(A) e S1223-01, para a calibração com

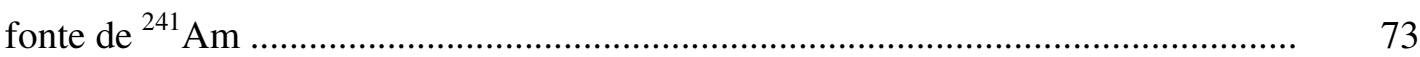

6.7 Calibração utilizando fonte mista $\left({ }^{239} \mathrm{Pu},{ }^{241} \mathrm{Am}\right.$ e $\left.{ }^{244} \mathrm{Cm}\right)$............................... 74

6.8 Detecção de nêutrons térmicos (fonte AmBe) ....................................................... 77

6.8.1 Resposta do fotodiodo S3590-04(A) para nêutrons térmicos (Laboratório

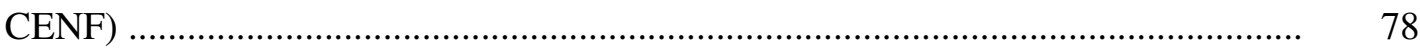

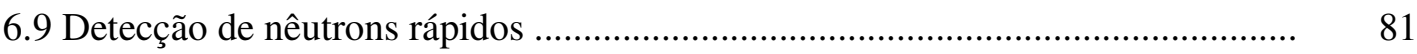

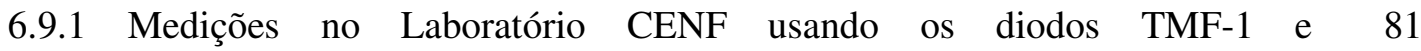
S3590-04

6.9.2 Medições no Reator IPEN/MB-01 (UCRI) ................................................... 83

6.9.3 Medições na Instalação de Neutrongrafia - nêutrons térmicos e epitérmicos . $\quad 86$

6.9.3.1 Resposta dos detectores para nêutrons térmicos e epitérmicos com o reator operando a uma potencia de 2 MW térmicos ........................................................... 86

6.9.3.2 Resposta do detector S3590-04(B) para uma potencia do reator de 3,5 MW

6.10 Cálculo de um fator de conversão Contagens para Dose para dosimetria utilizando um diodo

6.10.1 Dados necessários para o cálculo de fator de conversão Contagens para Dose (fonte AmBe)

6.10.2 Dados necessários para o cálculo de fator de conversão Contagens para Dose (instalação de Neutrongrafia) 91

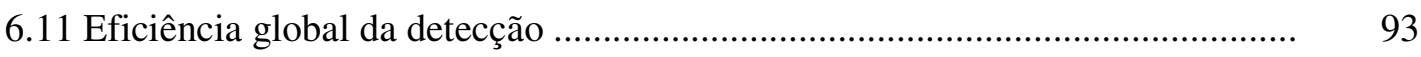

6.12 Análise de incertezas ................................................................................... 94

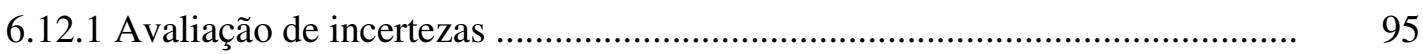

6.12.2 Resultado das incertezas ................................................................... 98

6.13 Dosimetria de nêutrons .............................................................................. 98

6.13.1 Dosimetria utilizando dois fotodiodos "pareados" ....................................... 98

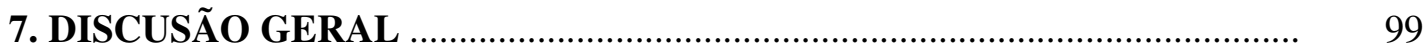

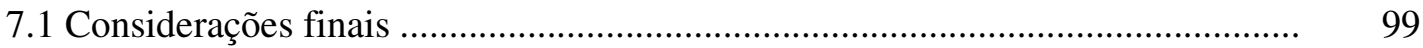


9.1 Sistema de detecção diferencial a ser aplicado em dosimetria de nêutrons térmicos utilizando dois fotodiodos "pareados"

9.2 Sistema dosimétrico para determinar o equivalente de dose usando fotodiodo como elemento primário de detecção e instrumento rastreado (padrão de Calibração

9.3 Desenvolvimento de uma metodologia para a obtenção de uma estimativa de equivalente de dose (dosímetro individual) utilizando os dados de detecção de nêutrons obtidos com semicondutores fotodiodos

9.4 Caracterização completa de um elemento sensor (semicondutor), moderadores e conversores sob campos mistos nêutron-gama usando simulação por código de Monte Carlo

9.5 Módulo de monitoração de nêutrons de área utilizando fotodiodos e comunicação de dados via Ethernet e sem fio (wireless)

9.6. Desenvolvimento de medições eletrônicas na detecção da radiação em campos mistos nêutrons-gama utilizando a técnica de discriminação por forma de pulso

9.77. Projeto de Medidor de Rotina (Survey Meter) baseado em componentes semicondutores para aplicações em proteção radiológica

APÊNDICE A

Modelagem da fonte de AmBe e do moderador (parafina) utilizado para os cálculos de fluxo térmico usando o código de Monte Carlo.

APÊNDICE B

Dados referentes às medições de fluxo na instalação de Neutrongrafia

APÊNDICE C

Medições dosimétricas com instrumento Medidor Portátil (Survey meter) fabricado pela LUDLUM MEASUREMENTS modelo 2363

APENDICE D

Metodologia para a definição do Fator de Conversão Contagens para Dose (Neutrongrafia).

APÊNDICE E

Considerações na aquisição de dados utilizando o software Maestro. 


\section{APÊNDICE F}

Parâmetros de detecção dos semicondutores utilizados (TMF-1 e S3590-04) obtidos através da análise das curvas obtidas usando o software Maestro..

\section{APÊNDICE G}

Dosimetria utilizando dois fotodiodos "pareados".

APÊNDICE H

Metodologia para a obtenção de uma estimativa de equivalente de dose (dosímetro

individual) utilizando os dados de detecção de nêutrons obtidos com semicondutores fotodiodos

REFERÊNCIAS BIBLIOGRÁFICAS 


\section{LISTA DE TABELAS}

Tabela

Página

1 Interações dos nêutrons com os elementos componentes do tecido biológico .................................................................................... 10

2 Valores de Fatores de Qualidade para diferentes radiações....................... 13

3 Reações para a detecção de nêutrons ....................................................... 19

4 Características básicas dos detectores e fotodiodos utilizados nas

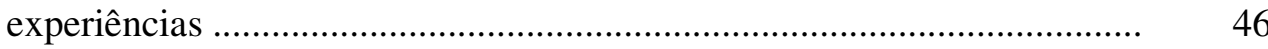

5 Resumo do cálculo da energia e fluxo incidentes na superfície ativa do detector .

6 Resumo do cálculo da energia e fluxo incidentes na superfície ativa do detector sem qualquer moderação a uma distância fonte-detector de $30 \mathrm{~mm}$

7 Valores utilizados para a obtenção do fator de conversão Contagens para Dose

8 Resumo dos valores de desvio padrão e eficiência para o detector TMF-1 e o fotodiodo S3590-04(A) e (B) para nêutrons térmicos e rápidos procedentes da fonte de $\mathrm{AmBe}$, e nêutrons térmicos $\mathrm{e}$ epitérmicos da instalação de Neutrongrafia

9 Resultado da média, desvio padrão (DP) e incerteza para as medições realizadas na instalação de Neutrongrafia usando o detector TMF-1 e o fotodiodo S3590-04(A) com conversor de polietileno de 0,12 $\mathrm{mm}$

10 Parâmetros obtidos usando o software de aquisição de dados Maestro (ORTEC) na detecção de nêutrons térmicos e rápidos usando os semicondutores TMF-1 e S3590-04(A)

11 Valores de contagens por segundo (cps), intervalos de energia de nêutrons, fluxo correspondente a cada tipo de medição e a eficiência do detector com conversor 


\section{LISTA DE FIGURAS}

Figura

Página

1 Ilustração dos três efeitos mais importantes da interação da radiação gama com a matéria.

2 Intervalos de energia para as principais interações dos raios gama com a matéria.

3 Esquema do princípio de operação de um sensor composto de um sensor (camada ativa) e de um detector de silício (camada sensível)..

4 Espectro de impulsos de um contador proporcional ${ }^{3} \mathrm{He}$ com pronunciado efeito de parede

5 Estrutura cristalina tipo diamante ( $\mathrm{Si} \mathrm{e} \mathrm{Ge),a} \mathrm{é} \mathrm{a} \mathrm{constante} \mathrm{de} \mathrm{rede.}$

6 Representação esquemática de uma junção P-N [39]

7 Esquema da polarização reversa do diodo

8 Detectores de Barreira de Superfície produzidos pela ORTEC e IPEN.

9 Fotodiodo HAMAMATSU S3590-04(A) e detector IPEN TMF-1 e a fonte $\mathrm{de}^{241} \mathrm{Am}$

10 Preamplificador sensível à carga SOSHIN 9101

11 Preamplificador ORTEC 142 e conectores utilizados

12 Configuração da instrumentação usada para os testes e medições .....

13 Exemplo do espectro da energia dos nêutrons emitidos por uma fonte de AmBe (adaptada de Thompson e Taylor) [97].

14 Núcleo do reator IEA-R1 com a indicação dos Tubos de Experimentação (BHs) para desenvolvimento de pesquisas em BNCT, Neutrongrafia e Gama

15 Instalação para Neutrongrafia (reator IEA-R1)

16 Núcleo do reator IPEN/MB-01 e os detectores nucleares para sua operação

17 Bancada experimental e arranjo de proteção radiológica

18 Arranjo experimental para nêutrons térmicos

19 Arranjo experimental (configuração) para medições de nêutrons rápidos 
20 Configuração física do detector TMF-01 e preamplificador ORTEC 142AH para medições de nêutrons térmicos e epitérmicos

21 Núcleo do reator IPEN/MB-01 e o arranjo do detector para as medições

22 Resposta do PSC SOSHIN para tempos de "Rise Time" do detector TMF-1 a partículas alfa (fonte ${ }^{241} \mathrm{Am}$ )

23 Resposta do PSC ORTEC para tempos de "Rise Time" do detector TMF-1 a partículas alfa (fonte ${ }^{241} \mathrm{Am}$ )

24 Resposta do detector TMF-1 conectado ao PSC ORTEC 142AH a uma fonte de ${ }^{241} \mathrm{Am}$

25 Resposta do detector TMF-1 conectado ao PSC SOSHIN 9101

26 Resposta do detector SSB ORTEC ( $\mathrm{Au})$ com fonte de ${ }^{241} \mathrm{Am}$.

27 Resposta do detector SSB ORTEC (Ag) conectado ao preamplificador ORTEC 142AH (fonte de ${ }^{241} \mathrm{Am}$ )

28 Resposta do detector ORTEC (Au) conectado ao preamplificador SOSHIN 9101 (fonte ${ }^{241} \mathrm{Am}$ )

29 Resposta do detector ORTEC $(\mathrm{Au})$ conectado ao preamplificador SOSHIN 9101 (fonte de ${ }^{241} \mathrm{Am}$ )

30 Resposta do fotodiodo S3590-04(A) a uma fonte de ${ }^{241} \mathrm{Am}$ 70

31 Distribuição para o PSC SOSHIN 9101 (pulsos 1 a 10 Volts)

32 Resposta do sistema a uma varredura de pulsos com amplitude de 0 a 10 Volts

33 Ajuste da curva de Energia vs. Canal

34 Exemplo do espectro de Energia vs Contagens para o fotodiodo S3590-04(A)

35 Resposta do fotodiodo S3590-04 a uma fonte de ${ }^{241} \mathrm{Am}$. 73

36 Resposta do fotodiodo S1223-01 a uma fonte de ${ }^{241} \mathrm{Am}$

37 Resposta dos fotodiodos S3590-04, S1223-01 e S1336-18BU utilizados para a fonte mista $\left({ }^{239} \mathrm{Pu}+{ }^{241} \mathrm{Am}+{ }^{244} \mathrm{Cm}\right)$.

38 Resposta do fotodiodo S1336-18BU utilizado para a fonte mista $\left({ }^{239} \mathrm{Pu}+{ }^{241} \mathrm{Am}+{ }^{244} \mathrm{Cm}\right)$

39 Resposta do fotodiodo S3590-04(A) para uma polarização de 0 e 60 $\mathrm{V}$ e conversor de polietileno de $1 \mathrm{~mm}$ 
40 Resposta do fotodiodo $\mathrm{S} 3590-04(\mathrm{~A})$ à radiação gama $\left({ }^{60} \mathrm{Co}\right)$ para uma polarização de $0,15,24,40$ e $60 \mathrm{~V}$ e conversor de polietileno de $1 \mathrm{~mm}$

41 Esquema de detecção de nêutrons térmicos utilizando conversor de ${ }^{10} \mathrm{~B}[25]$

42 Resposta do fotodiodo S3590-04(A) para medições com nêutrons térmicos utilizando conversor de ${ }^{10} \mathrm{~B}$ e polarizado com 15 Volts ....... 78

43 Resposta do fotodiodo para nêutrons térmicos (polarização reversa de $15 \mathrm{~V}$ ), sinal da radiação gama e a diferença destes sinais

44 Resposta do fotodiodo (sem polarização reversa) para nêutrons térmicos, à radiação gama (detector coberto por cádmio) e a diferença dos dois sinais

45 Reposta do fotodiodo aos nêutrons moderados utilizando uma lamina de polietileno borada, com uma polarização de $15 \mathrm{~V}$

46 Resposta do fotodiodo nu (sem conversor) aos nêutrons térmicos, a resposta do detector coberto com cádmio e a diferença destes sinais.

47 Espectro de nêutrons para o detector TMF-1 com conversor de polietileno $(0,12 \mathrm{~mm})$ para fonte de $\mathrm{AmBe}$

48 Espectro de nêutrons para o fotodiodo S3590-04(A) com conversor de polietileno $(1 \mathrm{~mm})$ para fonte de AmBe

49 Resposta do fotodiodo S1223-01 para nêutrons rápidos utilizando conversor de polietileno e polietileno borado e polarização de 0 e $24 \mathrm{~V}$

50 Resposta (espectro) do detector TMF-1 na Unidade Critica para potencias de 1, 2, 4 e $10 \mathrm{~W}$

51 Resposta (espectro) do fotodiodo S3590-04 (A) na Unidade Critica para potencias de $1,2,5$ e $10 \mathrm{~W}$

52 Espectro de nêutrons térmicos e epitérmicos para o detector TMF-1 e fotodiodo S3590-04 para uma potencia térmica do reator de $2 \mathrm{MW}$....

53 Resposta do fotodiodo S3590-04(B) para um fluxo de nêutrons térmicos e epitérmicos usando conversor de ${ }^{10} \mathrm{~B}$

54 Resposta do fotodiodo S3590-04(B) para um fluxo de nêutrons térmicos e epitérmicos usando conversor de polietileno $(1 \mathrm{~mm})$ 
55 Resposta do fotodiodo S3590-04(B) para um fluxo de nêutrons térmicos e epitérmicos usando conversor de polietileno borado ..........

56 Resposta do detector S3590-04(B) para um fluxo de nêutrons térmicos e epitérmicos usando os três tipos de conversores sem o sinal de radiação gama (subtraído)

57 Resposta do detector S3590-04(B) para um fluxo de nêutrons térmicos e epitérmicos usando os três tipos de conversores com o sinal de radiação gama incluído

58 Exemplo da janela operacional do Software Maestro mostrando o número bruto de contagens (GA), o número real de contagens (NA) e a taxa de contagens em cps

A1 Esquema da modelagem (MCNP) da fonte de nêutrons e o moderador (parafina)

A2 Esquema da modelagem (MCNP) da fonte de nêutrons sem o moderador

G1 Esquema da proposta de dosímetro usando a técnica de detecção diferencial 


\section{1.- INTRODUÇÃO}

Os detectores de radiação, de germânio e silício, têm sido utilizados principalmente para espectrometria gama, e têm substituído os detectores cintiladores de estado sólido em aplicações onde se requer uma alta resolução energética. $\mathrm{O}$ uso de diodos de silício como detectores de fótons de energia alta e feixes de elétrons, principalmente no campo da radiocirurgia, começou na década dos 60. Os dosímetros de germânio foram excluídos devido ao seu número atômico efetivo muito alto, especialmente para medições de radiação de energia baixa, além da necessidade do componente permanecer refrigerado quando das medições.

Este efeito não é restritivo para sua utilização em espectrometria, onde toda a energia da partícula incidente é depositada no detector. Este não é o caso na dosimetria de fótons ou elétrons e, com maior razão, de nêutrons.

Os componentes de silício tem sido utilizados extensivamente em espectrometria nuclear, como descrito na literatura nas ultimas três décadas [1, 2, 3, 4 e 5].

Um dos mais importantes interesses em se utilizar semicondutores em dosimetria é o da sua elevada sensibilidade em relação ao volume ionizante, comparado com a câmara de ionização (preenchida com gás). Geralmente é encontrado um fator de 1800 entre a resposta de um diodo semicondutor de silício e uma câmara de ionização do mesmo volume, permitindo a redução do volume sensível a umas poucas dezenas de milímetros cúbicos. Isto reduz drasticamente a necessidade de requisitos rígidos referente à parte eletrônica de condicionamento do sinal produzido por estes sensores e da amplificação ou integração da corrente e permite o desenvolvimento de um detector ideal para o mapeamento de campos de radiação. No caso dos diodos, para um melhor desempenho, eles são normalmente usados com uma polarização reversa para obter uma depleção mais profunda, menor ruído e tempo de transito mais curto.

Apesar da sua excessiva resposta aos fótons de energia baixa, os detectores semicondutores de silício apresentam características que os fazem atrativos para medições de dose ou taxa de dose em relação às câmaras gás-ionizantes [6]. 
A relevância do trabalho desenvolvido reside na utilidade que sistemas dosimétricos e microdosimétricos podem trazer para as rotinas operacionais nos centros médicos, no uso clínico para dosimetria de fótons de energia alta ou para radiações neutrônicas normalmente encontradas em campos mistos (aceleradores, reatores nucleares, fabricação de combustíveis e descomissionamento), até o momento, com pouco ou quase nenhum desenvolvimento no país. A possibilidade de utilização de rotinas computacionais simples proporcionará um melhor controle de qualidade da radiação quando dos tratamentos. Devido à sua aplicabilidade, o trabalho propõe uma interação maior entre os centros de pesquisas nucleares do país.

Atualmente, em nosso país, existe um grande interesse pela dosimetria e microdosimetria devido a seu vasto campo de aplicação (radiocirurgia, microeletrônica, usinas nucleares, etc.). Entretanto, sua aplicação no campo da radiocirurgia em particular, sempre teve o problema da sua praticidade quanto ao tipo de detector a ser utilizado como elemento primário de um sistema dosimétrico. A utilização de câmaras de ionização resulta impraticável para medidas in-vivo, devido a seu tamanho e ao risco que representa sua alimentação de operação em alta voltagem. Assim também, os contadores proporcionais sofrem destas desvantagens. Por outro lado, a utilização de diodos semicondutores representa uma boa opção para estes entraves.

Existem poucos trabalhos sobre aplicação de diodos semicondutores na área radioterapêutica e os projetos nacionais de aplicação realizados se restringiram à sua aplicação em controle de qualidade nos tratamentos In-Vivo em radiocirurgia ou para avaliação de feixes de raios-X [7-9]. Por outro lado, a cada ano que passa, o câncer se configura e se consolida como um problema de saúde pública no âmbito nacional e internacional.

Nos últimos anos da década passada o Brasil obteve um avanço considerável no que tange às fontes de informações sobre morbidade por câncer, acompanhando o progresso já observado no sistema de informações sobre mortalidade.

Segundo o relatório da Agência Internacional para Pesquisa em Câncer (IARC)/OMS (World Cancer Report 2008), a estimativa para o ano de 2008 era de 12,4 milhões de casos novos de câncer e 7,6 milhões de óbitos. O contínuo crescimento populacional, bem como seu envelhecimento, afetará de forma significativa o impacto do câncer no mundo. Esse impacto 
será maior nos países com médio e baixo desenvolvimento. A IARC/OMS estimou que, em 2008, metade dos casos novos e em torno de dois terços dos óbitos por câncer ocorreriam nessas localidades. Destes, os mais incidentes foram o câncer de pulmão (1,52 milhões de casos novos), mama (1,29 milhões) e cólon e reto (1,15 milhões). Devido ao mau prognóstico, o câncer de pulmão foi a principal causa de morte (1,31 milhões), seguido pelo câncer de estômago (780 mil óbitos) e pelo câncer de fígado (699 mil óbitos). Para América do Sul, Central e Caribe, estimou-se em 2008 cerca de 1 milhão de casos novos de câncer e 589 mil óbitos. Em homens, o mais comum foi o câncer de próstata, seguido por pulmão, estômago e cólon e reto. Nas mulheres, o mais frequente foi o câncer de mama, seguido do colo do útero, cólon e reto, estômago e pulmão (WORLD CANCER REPORT, 2008).

No Brasil, as estimativas, para o ano de 2010 serão válidas também para o ano de 2011, indicando uma previsão de 489.270 casos novos de câncer. Os tipos mais incidentes, à exceção do câncer de pele do tipo não melanoma, serão os cânceres de próstata e de pulmão no sexo masculino e os cânceres de mama e do colo do útero no sexo feminino, acompanhando o mesmo perfil da magnitude observada para a América Latina. Para 2010, há uma previsão de 236.240 casos novos para o sexo masculino e 253.030 para sexo feminino. As estimativas indicam que o câncer de pele do tipo não melanoma (114 mil casos novos) será o mais incidente na população brasileira, seguido pelos tumores de próstata (52 mil), mama feminina (49 mil), cólon e reto (28 mil), pulmão (28 mil), estômago (21 mil) e colo do útero (18 mil) [10].

Estes dados ilustram a importância do problema social, e para enfrentá-lo são utilizadas diversas modalidades de terapias, ou seja, cirurgia, quimioterapia e terapia utilizando radiação.

Para o tratamento de pacientes por meio de radiocirurgia utilizam-se aceleradores lineares ou unidades de Co-60 e para estes procedimentos é realizado um estudo de dosimetria para estabelecer o tipo, energia, dose e direcionamento dos feixes para que a irradiação do tecido afetado seja homogênea e o dano em órgãos críticos seja mínimo [11].

Com referência à microdosimetria, embora esta já possua certo desenvolvimento e aplicações nos países desenvolvidos, no Brasil ainda é uma área incipiente dentro das aplicações da Física Médica e nas instalações relacionadas com a energia nuclear. 
Cientistas e pesquisadores tem procurado compreender, com rara dedicação, os aspectos microscópicos da interação da radiação ionizante com a matéria, especialmente em materiais equivalentes ao tecido humano, para melhor compreensão dos efeitos biológicos resultantes no ser humano [12-13].

Por outro lado, existe um aumento gradual dentro de programas de saúde de Centros de Tratamento (Terapêuticos) onde se utilizam fontes de radiação de energia alta (aceleradores clínicos). Em 2002 existiam no Brasil 156 Serviços de Radiocirurgia com um parque de 113 Unidades (Bombas) de Co-60 e 102 Aceleradores Lineares (LINAC) instalados, sendo que 59 destes aceleradores estavam localizados na região sudeste [11].

Nos países desenvolvidos são diagnosticados 30.000 novos casos de câncer por ano e por milhão de habitantes. Isto significa que dos 750.000 a 1.000 .000 de novos casos por ano em Estados Unidos ou na Comunidade Européia, entre 40.000 a 50.000 se beneficiariam de tratamento com radiação de alto LET (Transferência Linear de Energia). Estes dados ilustram a importância do problema [14].

A relevância maior deste trabalho reside na necessidade de resolver uma reivindicação antiga do grupo de Proteção Radiológica do reator IEA-R1. Isto diz respeito da monitoração individual de nêutrons, pois devido à presença de tubos colimadores (Beam Holes) que fornecem feixes de nêutrons apesar de estarem blindados, os nêutrons espalhados de várias energias fornecem uma dose de radiação às pessoas que trabalham em estas áreas. Atualmente o controle das doses de nêutrons é realizado através de monitoração rotineira com detectores portáteis, porém o ideal seria monitorar cada trabalhador individualmente. No presente momento o reator IEA-R1 não possui qualquer sistema de monitoração de nêutrons, de área ou individual. 


\section{2.- OBJETIVOS}

Gerais.

Avaliação de componentes semicondutores que possam ser utilizados no desenvolvimento de um protótipo dosimétrico, constituindo um sistema de dosimetria e microdosimetria, visando a determinação da dose equivalente devida à radiação de nêutrons. Estabelecer as características operacionais do sistema dosimétrico que possibilite sua aplicação como um instrumento de apoio nas rotinas operacionais em radiocirurgia e na proteção radiológica de instalações nucleares.

Específicos.

- Pesquisar diversos tipos de diodos de diferentes fabricantes para testes de desempenho sob irradiação, para especificar um modelo que cumpra com os requisitos de monitoração de nêutrons em rotinas de proteção radiológica.

- Estudar e avaliar o desempenho de componentes conversores de nêutrons, tais como o ${ }^{10} \mathrm{~B}$ e o polietileno.

- Utilizar, quando necessário e conforme a aplicação, técnicas de simulação empregando o método de Monte Carlo.

- Avaliar o desempenho dos diodos semicondutores escolhidos, para estabelecer as características operacionais de um sistema dosimétrico que possibilite sua aplicação (prática) em medições de campos mistos nêutron-gama e estabelecer uma abordagem para o cálculo de equivalente de dose a partir dos espectros obtidos nas experiências.

- Efetuar a comparação dos resultados experimentais com os obtidos por outros autores.

- Descrever os critérios (metodologia) para o cálculo de equivalente de dose a partir dos espectros de Bragg obtidos na parte experimental.

- Propor trabalhos futuros para a continuação da pesquisa de monitoração de campos mistos nêutrons-gama. 


\section{3. - FUNDAMENTOS TEÓRICOS}

\subsection{Interações radiobiológicas.}

O conhecimento das interações básicas da radiação com a matéria é essencial para a compreensão do espectro dosimétrico e microdosimétrico. A radiação de nêutrons sempre vem acompanhada por radiação gama, seja ela proveniente de estados excitados do alvo ou pelos raios gama de captura produzidos no colimador e na blindagem. Por esta razão, as interações da radiação gama (primária) com a matéria biológica devem ser consideradas.

\subsubsection{Interações da radiação gama com a matéria.}

A radiação gama transfere energia ao material alvo principalmente por três processos:

- Efeito fotoelétrico - as interações acontecem com os elétrons ligados, e a maior parte da energia gama é transferida a um único elétron.

- Espalhamento Compton - a radiação gama transfere uma fração da sua energia a um único elétron, que é conhecido como elétron de recuo emitindo um raio gama, sendo sua direção e energia determinadas pela lei da conservação relativística momentum-energia.

- Produção de Pares - a energia mínima necessária para este processo é de 1,02 MeV (duas vezes a energia da massa do eletrôn em repouso). Na interação, o raio gama desaparece sendo substituído por um par elétron-pósitron. A Figura 1 ilustra a interação dos três processos [16].

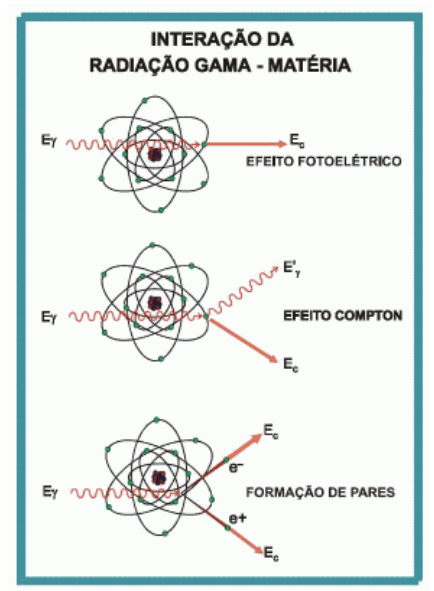

Figura 1: Ilustração dos três efeitos mais importantes da interação da radiação gama com a matéria. 
Para os constituintes, relativamente leves, do tecido biológico, o efeito fotoelétrico predomina na região de energia baixa e o efeito Compton é o mecanismo de interação predominante até umas dezenas de $\mathrm{MeV}$. A produção de pares não é um processo importante para materiais de interesse biológico [15]. A Figura 2 ilustra os intervalos de energia das interações da radiação gama com a matéria [16].

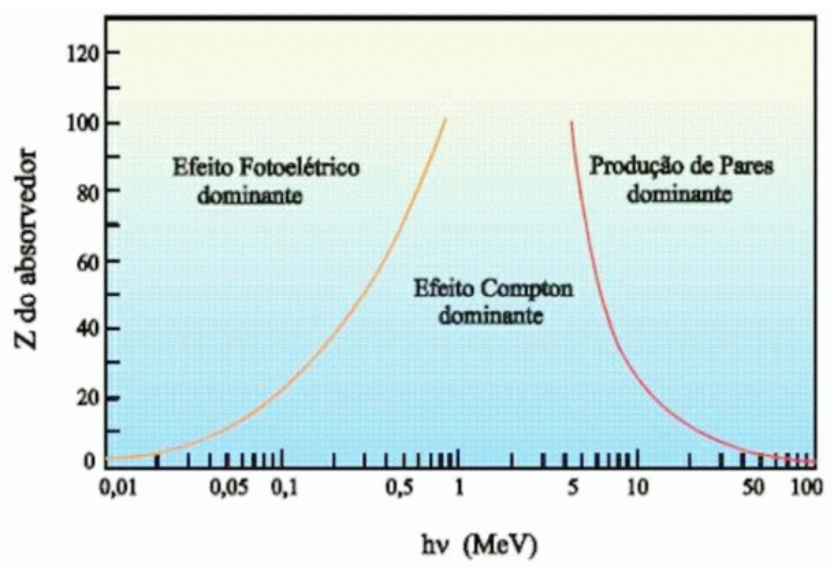

Figura 2: Intervalos de energia para as principais interações da radiação gama com a matéria.

\subsubsection{Interação dos nêutrons com a matéria [13].}

O nêutron é uma partícula não carregada cujo principal meio de interação é através de colisões com núcleos, pois ele não pode causar ionização diretamente. A probabilidade de interação entre um nêutron e um elétron é extremamente pequena, sendo normalmente desprezada. Os principais processos de interação dos nêutrons com os núcleos são:

- Espalhamento elástico $(n, n)$ - o nêutron ao colidir com o núcleo perde energia que aparece como a energia cinética do núcleo de recuo. A soma das energias cinéticas de todas as partículas do sistema permanece constante;

- Espalhamento inelástico $\left(n, n^{`}\right)$ - o nêutron ao colidir com o núcleo é espalhado com uma fração de sua energia de incidência, uma vez que parte dela é usada em um processo de excitação nuclear;

- Captura radioativa $(n, \gamma)$ - o nêutron é capturado pelo núcleo, formando um núcleo composto excitado que emite radiação gama para voltar ao estado fundamental; 
- Fissão - a captura do nêutron por um núcleo pode induzir à divisão do mesmo em dois fragmentos com massas, raramente, da mesma ordem de grandeza, e que é acompanhada pela emissão de radiação gama, beta e de nêutrons;

- Espalação - é o processo em que um nêutron de energia alta incide sobre um núcleo e provoca a emissão de grande número de nêutrons e prótons e a formação de um novo núcleo com massa muito inferior à do original. A espalação do ${ }^{238} \mathrm{U}$ é um bom exemplo. Nela pode ocorrer a produção de mais de 50 prótons e nêutrons. Esse tipo de interação é significativo para energias de nêutrons $\geq 10 \mathrm{MeV}$;

- Reações que produzem outras partículas - o nêutron pode atingir um núcleo produzindo a emissão de outras partículas tais como prótons ou partículas alfa. Para altas energias reações do tipo (n, 2n) e (n, 3n) ou outras combinações podem ocorrer.

\subsection{Classificação dos nêutrons segundo sua energia [13].}

Em qualquer discussão sobre a interação de nêutrons com a matéria, é conveniente enfatizar alguns intervalos de energia:

- Nêutrons térmicos - Esses nêutrons possuem energia inferior a $0,2 \mathrm{eV}$, sendo representados por uma distribuição Maxwelliana com a energia mais provável a $0,025 \mathrm{eV}$ a $20{ }^{\circ} \mathrm{C}$, correspondendo a uma velocidade de $2200 \mathrm{~m} . \mathrm{s}^{-1}$.

A sua principal interação com a matéria é a captura. As reações tipo (n, p), (n, $\alpha)$, ou fissão também podem ocorrer. Muitos nuclídeos nessa faixa de energia possuem uma seção de choque proporcional a $1 / \mathrm{v}$, ou seja, inversamente proporcional à velocidade do nêutron. No tecido, as reações importantes a energias baixas são; ${ }^{1} \mathrm{H}(\mathrm{n}, \gamma)^{2} \mathrm{H}$, que produz um raio gama de 2,2 $\mathrm{MeV}, \mathrm{e},{ }^{14} \mathrm{~N}(\mathrm{n}, \mathrm{p}){ }^{14} \mathrm{C}$, que resulta num próton de $0,6 \mathrm{MeV}$. A reação ${ }^{10} \mathrm{~B}(\mathrm{n}, \alpha){ }^{7} \mathrm{Li}$ é muito usada em detectores de nêutrons de energia baixa;

- Nêutrons intermediários - esta classificação se refere aos nêutrons com energias que vão de 0,5 eV até $200 \mathrm{keV}$, aproximadamente. Nêutrons de energias intermediarias geralmente são obtidos pela perda de energia dos nêutrons rápidos em um material moderador. A distribuição do fluxo de nêutrons é, normalmente, inversamente proporcional à energia. Porém, a região abaixo dos $100 \mathrm{eV}$ pode conter um número de ressonâncias onde as seções de choque podem aumentar ou diminuir por varias ordens de grandeza em um intervalo de energia estreito. 
Nêutrons com energias que correspondem às absorções de ressonância são classificados como nêutrons de ressonância.

Estes nêutrons são geralmente de pouco interesse para estudos radiobiológicos, exceto na obtenção de feixes epitérmicos para uso em radiocirurgia. Os nêutrons epitérmicos utilizados nesse contexto estão no intervalo de $0,2 \mathrm{eV}$ até $1 \mathrm{keV}$. É importante salientar que os limites que separam as categorias não são precisos, indicando apenas ordens de grandeza.

- Nêutrons rápidos - correspondem aos nêutrons com energias no intervalo de $500 \mathrm{keV}$ a $20 \mathrm{MeV}$. A interação mais importante desses nêutrons com a matéria é o espalhamento elástico. Porém, por volta dos $10 \mathrm{MeV}$ uma parte considerável da seção de choque corresponde ao espalhamento inelástico.

A interação mais importante dos nêutrons rápidos com o tecido é o espalhamento elástico com o hidrogênio.

Apesar da maior parte da transferência de energia dos nêutrons rápidos para o tecido biológico e materiais equivalentes a tecido ser através de prótons de recuo, a contribuição relativa de vários processos de reação na deposição de energia no tecido depende da abundância relativa dos elementos constituintes. Portanto, para a análise da interação dos nêutrons com plásticos e gases equivalentes ao tecido, o teor de hidrogênio é o principal fator determinante na forma do espectro de perda de energia em um Contador Proporcional Equivalente Tecido (TEPC - Tissue Equivalent Proportional Counter). Entretanto, as reações com recuo de íons pesados podem ser significativas.

A perda de energia dos nêutrons em um moderador é devida principalmente ao processo de espalhamento elástico. O nêutron transfere no máximo uma fração $4 B_{r}\left(B_{r}+1\right)^{2}$ da sua energia aos núcleos de recuo, onde $B_{r}$ é a razão entre a massa do núcleo alvo e a massa do nêutron.

O espalhamento inelástico é importante como uma fonte de radiação gama no processo de moderação de nêutrons e causa grandes perdas de energia aos nêutrons em materiais com altos valores de $B_{r}$.[13].

Existem também nêutrons que possuem energia superior a $20 \mathrm{MeV}$ e são denominados nêutrons relativísticos [17]. 
A Tabela 1 apresenta um resumo das interações mais importantes de nêutrons com o tecido biológico para energias até aproximadamente $100 \mathrm{MeV}$ [18 e 19].

Tabela 1: Interações dos nêutrons com os elementos componentes do tecido biológico.

\begin{tabular}{|l|l|}
\hline Elemento & \multicolumn{1}{|c|}{ Interação } \\
\hline Hidrogênio & Espalhamento elástico e captura de nêutron \\
\hline Carbono & $\begin{array}{l}\text { Espalhamento elástico } \\
\text { Espalhamento inelástico } \\
\left.\left.\text { Reações (n, n` 3 } 3^{a}\right) \text { e (n, } \alpha\right)\end{array}$ \\
\hline Nitrogênio & $\begin{array}{l}\text { Espalhamento elástico } \\
\text { Espalhamento inelástico } \\
\text { Reações (n, p), (n, d), (n, t), } \\
(n, \alpha),(n, 2), \text { e (n,2n) }\end{array}$ \\
\hline Oxigênio & $\begin{array}{l}\text { Espalhamento elástico } \\
\text { Espalhamento inelástico } \\
\text { Reações (n, p), (n, } \alpha)\end{array}$ \\
\hline
\end{tabular}




\subsection{Dosimetria - definições básicas.}

Entende-se por dosimetria a medida da quantidade de radiação liberada em um local específico ou a quantidade de radiação absorvida neste local. Os efeitos biológicos das radiações dependem da quantidade de energia depositada nos tecidos. Esse padrão depende do tipo de tecido irradiado, bem como do tipo e intensidade das radiações. Isso torna necessário o uso de padrões quantitativos que nos possibilitem dosar uma irradiação. O fluxo de um feixe de radiação, que é a quantidade de energia que atravessa uma área num intervalo de tempo geralmente dada em n.cm ${ }^{-2} \cdot \mathrm{s}^{-1}$; a densidade do fluxo, que é a razão do fluxo pela área e a intensidade de radiação, que é dado pelo coeficiente fluxo de energia/superfície que atravessa representam padrões dessa dosimetria. É interessante ressaltar no momento que essa intensidade varia com o quadrado da distância entre a fonte e o alvo desde que não haja espalhamento dos raios no trajeto [19].

\subsubsection{Qualidade da radiação e a Dose Equivalente}

O risco devido à exposição à radiação depende tanto da própria exposição quanto da sua duração. As grandezas dosimétricas providenciam medições físicas do efeito da radiação em algum ponto no local de interesse. O efeito biológico devido à radiação resulta da deposição da energia, ionização do médio e da introdução de deslocamentos atômicos. As grandezas dosimétricas fundamentais são: a dose absorvida, os fatores de qualidade e a dose equivalente [19].

Existem duas grandes organizações internacionais para o desenvolvimento de convenções dosimétricas e avaliações de doses de radiação, sejam elas devidas à exposição à radiação externa ou por inalação ou por ingestão de algum composto de risco. Para experimentação e determinação de padrões são usados simuladores (phantom).

Estas duas organizações são a "International Commission on Radiation Units and Measurements" (ICRU) sediada em Bethesda, MD, USA, que estabelece assuntos relacionados com blindagens e dosimetria (publicando guias e recomendações) e a "International Commission on Radiological Protection" (ICRP), sediada em Estocolmo, Suécia, que publica também guias e recomendações internacionais sobre blindagens e práticas radiológicas. 
Outra organização que publica também assuntos radiológicos para os Estados Unidos é a "National Council on Radiation Protection and Measurements" (NCRP), sediada também em Bethesda, USA.

O objetivo principal da ICRU tem sido o de desenvolver recomendações aceitáveis pela comunidade internacional sobre as grandezas e unidades de radiação. A ICRU também determina as medições e aplicações destas grandezas nas áreas de diagnósticos radiológicos, radiocirurgia, radiobiologia e aplicações industriais [4]. A ICRP é reconhecida pela sua aplicação para a proteção do público das radiações.

Em sua utilização os nêutrons são moderados, espalhados e capturados dentro do corpo humano e todos estes processos possuem uma grande influência na dose de nêutrons e, consequentemente, na leitura do dosímetro utilizado, calibrado conforme as normas correspondentes [2].

\subsubsection{Dose Absorvida}

A dose absorvida é uma grandeza dosimétrica fundamental para a Proteção Radiológica. A Dose Absorvida $D$ é definida como a quantidade de energia (média) absorvida por unidade de massa. A unidade padrão é o Gray $(G y)$ sendo igual a energia transferida por 1 Joule per quilograma. A unidade tradicional da dose absorvida era o Rad, utilizado ainda por alguns autores como uma gentileza (para outros usuários) junto ao Gray, definido como 100 ergs por grama $(1 \mathrm{rad}=0,01 \mathrm{~Gy})$.

$$
D=\frac{d \bar{E}}{d m}
$$

\subsubsection{Fator de Qualidade (QF-Quality Factor) e Tranferência Linear de Energia} (LET - Linear Energy Transfer).

O Fator de Qualidade $(F Q)$ é um fator de ponderação que depende do tipo e da energia da radiação. O fator de qualidade para fótons e elétrons de qualquer energia é igual a 1. Para nêutrons o fator de qualidade depende da sua energia. $\mathrm{O}$ fator de qualidade para uma partícula carregada depende do seu Poder de Freamento (Stopping Power), que é também conhecido como a transferência linear de energia, o LET. O LET é descrito como a perda esperada de 
energia por unidade de distância do caminho percorrido pela partícula carregada. Valores típicos de Fatores de Qualidade são apresentados na Tabela 2 [19, 20 e 21].

Tabela 2: Fatores de Qualidade para diferentes radiações

\begin{tabular}{|c|c|}
\hline Radiação & Fator de qualidade (FQ) \\
\hline $\mathrm{X}, \boldsymbol{\gamma}, \boldsymbol{\beta} \pm$, (Todas as Energias) & 1 \\
\hline Nêutrons $<10 \mathrm{KeV}$ & 10 \\
\hline $10-100 \mathrm{KeV}$ & 20 \\
\hline $0.1-2 \mathrm{MeV}$ & 10 \\
\hline $2-20 \mathrm{MeV}$ & 5 \\
\hline$>20 \mathrm{MeV}$ & 5 \\
\hline Prótons $(>1 \mathrm{MeV})[20]$ & 2 \\
\hline Prótons $(>1 \mathrm{MeV})[21]$ & 20 \\
\hline Partículas Alfa & 5 \\
\hline
\end{tabular}

\subsubsection{Dose equivalente}

A dose equivalente $(H)$ é uma medida do risco de radiação, sendo igual ao produto da dose absorvida e o fator de qualidade $(F Q)$ em um ponto no tecido, ou seja:

$$
H=D(F Q)
$$

A unidade padrão para dose equivalente é o Sievert (Sv) e a unidade tradicional é o rem onde $1 \mathrm{rem}=0,01 \mathrm{~Sv}$.

\subsubsection{Conversão da Fluência em Equivalente de Dose}

O coeficiente de conversão da fluência em dose é usado para estabelecer uma relação entre as grandezas mensuráveis e as grandezas operacionais. Este coeficiente é conhecido com a função-resposta, que é a dose ou resposta por unidade de fluência de nêutrons. As grandezas operacionais são determinadas utilizando a equação seguinte:

$$
H=\int \Re(E) \phi(E) d(E)
$$


Onde $H$ neste caso é o equivalente de dose pessoal ou ambiental, $\mathfrak{R}(E)$ é o coeficiente de conversão dependente da energia correspondente e $\Phi(E)$ é a fluência de nêutrons em função da energia [22].

\subsection{Dosimetria de nêutrons.}

A dosimetria de nêutrons tem uma relevância prática em um amplo intervalo de energia, por exemplo, em BNCT (Terapia de Captura de Nêutrons térmicos pelo Boro) e em FNT (Terapia de Nêutrons Rápidos). Entretanto, as grandezas dosimétricas usadas em proteção radiológica não são diretamente mensuráveis. Isto é devido principalmente à variável qualidade da radiação de nêutrons, expressa em fatores de ponderação da radiação para a obtenção da dose equivalente em um órgão. Para a obtenção da dose efetiva é necessário multiplicar a dose equivalente dos órgãos irradiados pelos fatores de ponderação do tecido.

Os campos de nêutrons na natureza são devidos aos raios cósmicos de energia alta e são importantes somente no ar a grandes altitudes (acima de $10 \mathrm{~km}$ ) ou nas naves espaciais.

Campos de nêutrons desenvolvidos pelo homem são encontrados em áreas restritas tais como os reatores de fissão nuclear, ou seja, usinas nucleares e reatores de pesquisas, experimentos de fusão nuclear e reatores experimentais a fusão, e em aceleradores de partículas para aplicações médicas e industriais, assim como em pesquisa básica de partículas de energia alta e física da matéria condensada. Os campos de nêutrons são encontrados também em depósitos e cascos de transporte de elementos combustíveis usados e lixo radioativo, como resultado, por exemplo, das reações $(\alpha, n)$. Devido a sua grande penetrabilidade, os nêutrons, frequentemente, respondem por uma fração substancial da dose total no entorno das blindagens radiológicas [23].

Apesar do baixo número de pessoas expostas a este tipo de radiação, profundas análises devem ser desenvolvidas para propósitos de proteção radiológica.

As complicações começam desde a complexa interação nuclear com a matéria, que inclui a estrutura dependente da energia na região de multi ressonância e o fato que os nêutrons com energias baixas em torno de uns poucos meV são capturados produzindo radiação gama de energia alta até vários $\mathrm{MeV}$. As energias de nêutrons entre alguns meV (em reatores nucleares) e algumas centenas de $\mathrm{MeV}$ (no espaço, em aeronaves, e produzidos por 
aceleradores de alta energia) são portanto importantes e cobrem um intervalo de energia de ao menos dez ordens de magnitude, necessitando de apropriada instrumentação dosimétrica para sua avaliação. Outras complicações surgem devido aos fatores de qualidade dependentes da energia e fatores de ponderação da radiação que requerem uma informação espectral adicional que vai além de uma mera medição da dose absorvida.

Isto pode ser obtido experimentalmente usando espectrometria de nêutrons ou teoricamente por cálculo de transporte usando técnicas de simulação de Monte Carlo. Finalmente tem-se que, os campos de nêutrons são inevitavelmente campos mistos de nêutron-fotón e, portanto, requerem técnicas dosimétricas especiais [23].

\subsection{Conversores de nêutrons.}

Diversos materiais são utilizados na prática de detecção de nêutrons. A detecção de nêutrons é realizada em três passos: o primeiro acontece na camada conversora do material conversor onde a radiação incidente produz partículas carregadas (de recuo, ${ }^{1} \mathrm{H}$ e alfas) seja por espalhamento (in)elástico (dominado por nêutrons rápidos), exotérmicos (dominado por nêutrons térmicos) ou radiações endotérmicas. No passo seguinte alguma destas partículas deposita energia no diodo de silício. No terceiro passo a deposição de energia no volume ativo leva à formação de pares elétron-lacuna, obtendo-se finalmente um sinal (pulso eletrônico) proporcional à carga gerada.

As partículas neutras, nêutrons ou fótons, não conseguem produzir diretamente portadores de carga na matéria, tendo como conseqüência no caso do silício a baixa sensibilidade para este tipo de radiação, à diferença das partículas carregadas onde sua sensibilidade é práticamente $100 \%$. Os fótons interagem com a matéria principalmente por meio de efeitos fotoelétricos, espalhamento Compton e produção de pares. Em todos estes processos são gerados elétrons energéticos que penetram o detector produzindo partículas carregadas nele.

Os nêutrons podem produzir partículas carregadas através de reações nucleares e também por espalhamento (produção de partículas de recuo energéticas). O processo de reação nuclear (captura) é dominante para nêutrons lentos. Os nêutrons rápidos podem ter espalhamento (núcleos de recuo) e desta maneira produzir íons energéticos resultando em sinais no detector. Estes processos, para partículas neutras, não são suficientemente eficientes nos detectores de silício sendo necessário realçá-los. Neste tipo de sensor, portanto, é colocado um material conversor quase que em contato com a área sensível do componente. A energia das partículas secundárias geradas na camada ativa é então depositada no volume 
sensível do componente, parcialmente, como energia de ionização. Os portadores de carga gerados produzem pulsos de corrente que podem ser registrados pelo sistema eletrônico. A altura de cada pulso resultante é diretamente proporcional à energia das partículas carregadas.

A sensibilidade destes componentes depende de vários parâmetros:

a) A área ativa do conversor deve ser grande o suficiente para ser sensível à detecção de nêutrons. Isto é limitado devido ao aumento do ruído com o aumento das dimensões.

b) A geometria e orientação do conversor, que pode influenciar a probabilidade de detecção de nêutrons e a eficiência de detecção angular.

c) A característica nuclear e química do material do conversor: tipo e concentração de isótopos no material que produzem um número maior de partículas pesadas carregadas por nêutron incidente.

d) A espessura do conversor deve ser otimizada: a probabilidade da geração de sinal por nêutron incidente em um sensor (Figura 3), para uma dada energia de nêutrons, aumenta com a espessura do conversor, alcançando seu máximo e logo diminuindo devido à absorção de nêutrons no conversor. Portanto, a ótima espessura do conversor deve estar perto de, mas menor que, o alcance das partículas pesadas carregadas no conversor [24].

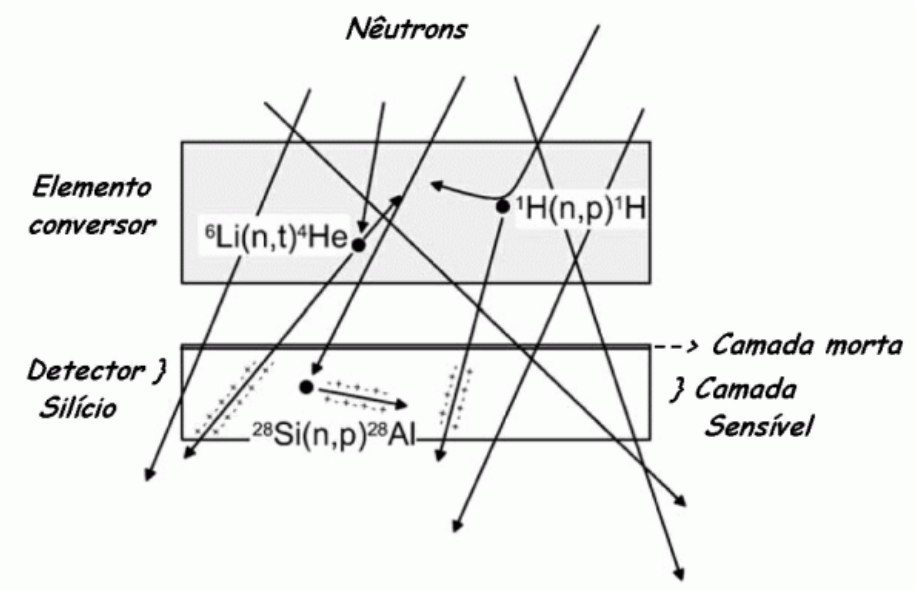

Figura 3: Esquema do princípio de operação de um sistema detector-conversor composto de um elemento conversor e de um detector de silício (camada sensível). 


\subsubsection{Tipos de conversores.}

\subsubsection{Conversor ${ }^{3} \mathrm{He}$}

$\mathrm{O}{ }^{3} \mathrm{He}$ é utilizado no desenvolvimento de detectores gasosos. Ele apresenta secção de choque de 5330 b (barns) para nêutrons térmicos. A conversão é feita por meio da reação:

$$
{ }_{2}^{3} \mathrm{He}+{ }_{0}^{1} n+{ }_{1}^{3} \mathrm{H}+{ }_{1}^{1} p+0,764 \mathrm{Mev}
$$

Nesta reação o próton emitido possui energia cinética de $\mathrm{E}_{\mathrm{p}}=0,573 \mathrm{MeV}$ enquanto o núcleo do trítio é emitido com a energia do ${ }^{3} \mathrm{H}$, igual a $0,191 \mathrm{MeV}$.

\subsubsection{Conversor ${ }^{6} \mathrm{Li}$}

$\mathrm{O}{ }^{6} \mathrm{Li}$ é um elemento usado como conversor para a detecção de nêutrons térmicos. Ele apresenta secção de choque de 940 barns para nêutrons térmicos. A reação de nêutrons térmicos com o ${ }^{6} \mathrm{Li}$ usado em detectores pode ser escrita como:

$$
{ }_{3}^{6} \mathrm{Li}+{ }_{0}^{1} n+{ }_{1}^{3} \mathrm{H}+{ }_{2}^{4} \alpha+4,78 \mathrm{MeV}
$$

Nesta reação o trítio emitido possui energia cinética do ${ }^{3} \mathrm{H}$ igual a 2,73 MeV enquanto a partícula $\alpha$ é emitida com energia igual a $2,05 \mathrm{MeV}$.

\subsubsection{Conversor ${ }^{10} \mathrm{~B}$}

$\mathrm{O}{ }^{10} \mathrm{~B}$ é usado em vários tipos de detectores de nêutrons principalmente nos detectores gasosos usando o gás ${ }^{10} \mathrm{BF}_{3}$ ou detectores revestidos com boro (boron-lined). Esse elemento apresenta secção de choque de 3840 barns para nêutrons térmicos.

No conversor de ${ }^{10} \mathrm{~B}$ um nêutron é absorvido com subseqüente transmutação para ${ }_{3}^{7} \mathrm{Li}$ e emissão de uma partícula $\alpha$. No ${ }^{10} \mathrm{~B}$ a reação de conversão $(n, \alpha)$ pode ser escrita como segue:

$$
{ }_{5}^{10} \mathrm{~B}+{ }_{0}^{1} \mathrm{n} \rightarrow\left\{\begin{aligned}
{ }_{3}^{7} \mathrm{Li}+{ }_{2}^{4} \alpha+2,792 \mathrm{MeV}(*) \\
\mathrm{Li}+{ }_{2}^{4} \alpha+2,310 \mathrm{MeV}(* *)
\end{aligned}\right.
$$

(*) Estado fundamental, sendo a freqüência dessa vertente de apenas $6 \%$ 
(**) Estado excitado, neste caso a freqüência dessa vertente e de 94\%. Nesta reação o Lítio emitido possui uma energia cinética de $0,840 \mathrm{MeV}$, sendo a partícula $\alpha$ emitida com uma energia de 1,47 MeV [25].

\subsubsection{Conversores hidrogenados (geradores ou radiadores de prótons de recuo).}

Estes elementos servem como fornecedores de prótons de recuo devido à reação (ou interação) de espalhamento elástico ser mais favorável nos núcleos leves. Dentre eles o hidrogênio é o mais utilizado, justificando a maneira de se referir a este componente.

No espalhamento elástico, a energia $(Q)$ liberada na reação de conversão é igual a zero devido ao princípio da conservação da energia, ou seja, a energia cinética total é conservada na reação.

O núcleo do átomo de hidrogênio possui apenas um próton e que ao ser espalhado é chamado de próton de recuo. Os detectores fundamentados nesse tipo de reação são chamados de detectores de próton de recuo.

Os detectores gasosos do tipo próton de recuo são usados na detecção de nêutrons de várias energias. Nesses detectores, para cada região de energia do nêutron incidente, o gás de preenchimento é aplicado a uma pressão apropriada a fim de otimizar o rendimento da detecção do fluxo de nêutrons.

Em detectores de estado sólido que utilizam materiais que tem em sua constituição hidrogênio, como, por exemplo, o polietileno, é usado um gerador de prótons de recuo. A água, a parafina e os plásticos como o polietileno são substâncias que mantém grandes proporções de hidrogênio em suas constituições. Dentre esses, o polietileno, cuja fórmula mínima é $\left(\mathrm{CH}_{2}\right)_{\mathrm{n}}$, possui $66 \%$ da constituição atômica do plástico. Além de ser um componente rico em hidrogênio possui excelentes qualidades físicas e mecânicas. $\mathrm{O}$ polietileno suporta temperaturas relativamente elevadas tendo ponto de amolecimento acima de $80^{\circ} \mathrm{C}$ e características mecânicas como a rigidez e a dureza que são desejáveis nos projetos dos detectores [25].

Salgir e Walker[26] descreveram um estudo relacionando a energia do nêutron incidente e o próton de recuo em material plástico. Os dados de Salgir e Walker mostram que 
numa fonte de Am-Be a quantidade de nêutrons emergentes em função da energia (entre $\sim 2,5$ e $\sim 12,25 \mathrm{MeV}$ ) apresenta um perfil complexo com um valor de pico ao redor de $5 \mathrm{MeV}$. Esses nêutrons ao incidirem em um filme de polietileno de espessura $0,8 \mathrm{mg} . \mathrm{cm}^{-2}$ produzem prótons de recuo num intervalo de aproximadamente 1,3 a $6 \mathrm{MeV}$ com um perfil de distribuição semelhante ao perfil gráfico da emissão dos nêutrons pela fonte de Am-Be.

\subsection{Detecção de nêutrons.}

As técnicas utilizadas para a detecção de nêutrons descritas em várias referências de dosimetria se baseiam na medição das partículas carregadas ou os fótons produzidos durante a interação dos nêutrons com a matéria [27, 28, 29, 30, 31 e 32]. As principais interações utilizadas são as de absorção $(n, \alpha),(n, p),(n, \gamma)$, (n,fissão) e as colisões elásticas com núcleos leves. Usualmente as diferentes técnicas de detecção são classificadas em função das partículas secundárias ao invés da energia do nêutron incidente. Entretanto, dar-se-á para cada uma delas, uma indicação do intervalo energético onde se utilizam e onde são mais eficazes, informação muito importante quando da seleção de alguma delas em concreto.

\subsubsection{Detecção por meio de prótons e partículas alfa.}

A Tabela 3 ilustra as reações de maior interesse utilizadas para a detecção dos nêutrons por meio dos prótons e partículas alfa, assim como a energia $\boldsymbol{Q}$ liberada e a seção de choque eficaz.

Tabela 3: Reações utilizadas para a detecção de nêutrons.

\begin{tabular}{|c|c|c|}
\hline Reação & Q (MeV) & $\begin{array}{c}\text { Seção choque eficaz térmica } \\
\text { (barns) }\end{array}$ \\
\hline${ }^{10} \mathrm{~B}(\mathrm{n}, \mathrm{a}){ }^{7} \mathrm{Li}$ & 2,79 & 3840 \\
\hline${ }^{6} \mathrm{Li}(\mathrm{n}, \mathrm{a})^{3} \mathrm{H}$ & 4,78 & 937 \\
\hline${ }^{3} \mathrm{He}(\mathrm{n}, \mathrm{p})^{3} \mathrm{H}$ & 0,764 & 5400 \\
\hline
\end{tabular}

Estas reações têm seções de choque eficazes elevadas no intervalo dos nêutrons térmicos e diminuem em função da velocidade e dos nêutrons segundo a lei de forma $1 . v^{-1} \mathrm{em}$ um amplo intervalo energético, sendo usadas essencialmente para a detecção de nêutrons térmicos. Os contadores proporcionais a ${ }^{3} \mathrm{He}$ ou a Trifluoreto de Boro, os cintiladores de Iodeto de Lítio ou a base de Sulfeto de Zinco revestidos em ${ }^{6} \mathrm{Li}$ ou em ${ }^{10} \mathrm{~B}$ e os dosímetros 
termoluminescentes $\left({ }^{6} \mathrm{Li}\right.$ e $\left.{ }^{7} \mathrm{Li}\right)$, são exemplos de detectores de nêutrons térmicos baseados nestas reações [33].

Alguns detectores de traços (dielétricos minerais ou orgânicos) estão baseados na detecção dos danos causados pelas partículas carregadas resultantes das reações $(n, \alpha)$ e $(n, p)$, os quais são previamente amplificados com procedimentos físico-químicos (revelado eletroquímico).

No caso de usar os contadores proporcionais a ${ }^{3} \mathrm{He}$ ou de trifluoreto de ${ }^{10} \mathrm{~B}$, a energia $Q$ liberada durante as reações $(n, p)$ e $(n, \alpha)$ é transferida em forma de energia cinética às duas partículas produzidas. Se o volume de detecção é grande, estas partículas depositam toda sua energia cinética no detector. Isto se traduz, no espectro de impulsos de saída, de um pico estrito no entorno da energia $\boldsymbol{Q}$. Devido a isto, é importante eleger reações que possuam $\boldsymbol{Q}$ elevados com o fim de garantir uma discriminação eficiente dos fótons parasitários e do ruído eletrônico.

Se as dimensões do detector são pequenas em comparação ao alcance das partículas produzidas, estas podem penetrar nas paredes do detector e, nesse caso, não depositam toda sua energia cinética no volume de detecção. Este efeito de parede se traduz no espectro de impulsos pela aparição de duas zonas planas correspondentes à deposição parcial de energia como ilustra a Figura 4 [33].

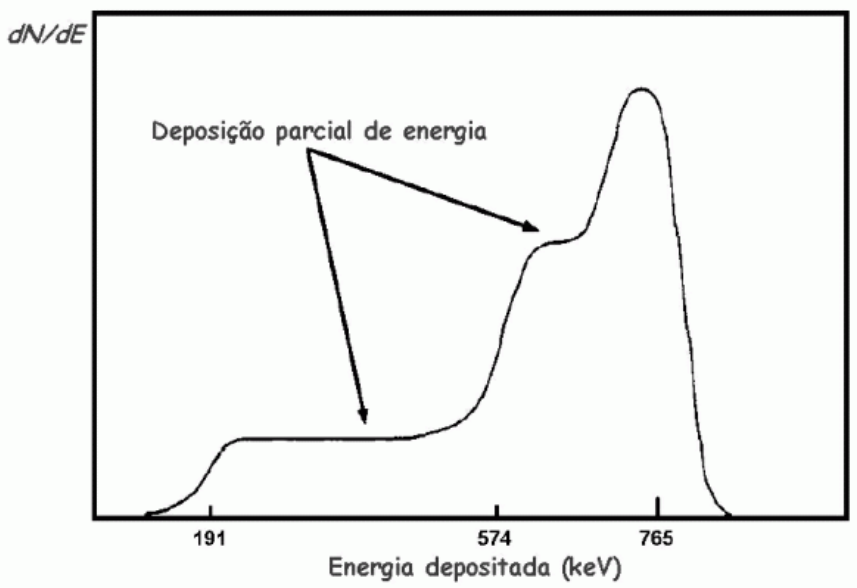

Figura 4: Espectro de impulsos de um contador proporcional ${ }^{3} \mathrm{He}$ com pronunciado efeito de parede. 
No caso em que não seja possível aumentar as dimensões do detector, a eliminação do efeito parede pode ser efetuada acrescentando ao gás detector uma pequena quantidade de um outro gás, com um alto poder de freamento tais como o Kriptônio ou o Xenônio com o fim de diminuir o alcance das partículas carregadas produzidas.

As reações ${ }^{6} \mathrm{Li}(\mathrm{n}, \alpha)^{3} \mathrm{H}$ e ${ }^{3} \mathrm{He}(\mathrm{n}, \mathrm{p})^{3} \mathrm{H}$ podem servir também para detectar nêutrons de energia alta. A energia dos nêutrons se determina calculando a diferença entre a soma das energias dos dois produtos da reação usada e a energia $\boldsymbol{Q}$ liberada por esta. Assim, entre os espectrômetros de nêutrons rápidos, usados para a medição dos nêutrons em um intervalo de energia compreendido entre aproximadamente $100 \mathrm{keV}$ e alguns $\mathrm{MeV}$, se encontram os contadores proporcionais, os detectores em "sandwich" utilizando o ${ }^{3} \mathrm{He}$ ou o ${ }^{6} \mathrm{Li}$ e certos cristais cintiladores revestidos com ${ }^{6} \mathrm{Li}$. A grande sensibilidade aos nêutrons térmicos, indesejáveis para esta aplicação, é suprimida cobrindo o detector com uma fôlha de material absorvente de nêutrons térmicos, o cádmio, por exemplo.

Alguns detectores usados na dosimetria de nêutrons são baseados nas difusões elásticas destes com os núcleos atômicos. Os alvos a eleger para este tipo de detectores são aqueles que possuem um alto conteúdo de material hidrogenado. O nêutron com uma massa comparável à do próton, pode entregar praticamente toda sua energia por meio de um choque elástico com um núcleo de hidrogênio.

A detecção dos núcleos de recuo (em particular os prótons de recuo) e a medição da sua energia permitem estabelecer o número e a distribuição energética dos nêutrons pelos quais foram gerados. A determinação do espectro energético dos nêutrons a partir do espectro dos prótons de recuo é realizada por meio de métodos de deconvolução apropriados. A sensibilidade da técnica dos prótons de recuo está limitada aos nêutrons que possuem uma energia suficientemente alta como para ionizar o meio detector [33].

Entre os detectores baseados em prótons de recuo, estão os seguintes [30]:

- componentes de emulsões fotográficas e alguns cintiladores orgânicos plásticos ou líquidos (Stilbeno, Cintilador líquido tipo NE-213, etc), usados no intervalo de energia de $500 \mathrm{keV}$ e $20 \mathrm{MeV}$. 
- Detector "Telescópio", usado no intervalo de $200 \mathrm{keV}$ e algumas dezenas de MeV. Este componente consiste em um cristal semicondutor situado a certa distância de um conversor de material hidrogenado e cujo interesse está centralizado nos prótons de recuo emitidos em um ângulo $\theta$ com referência à direção do feixe neutrônico incidente.

- Contadores proporcionais a hidrogênio chamados "a prótons de recuo" sensíveis a nêutrons de energias compreendidas entre $1 \mathrm{keV}$ e $15 \mathrm{MeV}$.

- Detectores de traços com conversores hidrogenados, como el "poly-allyldiglicol-carbone", mais conhecido como CR-39 ou o LR-115, utilizados com um conversor hidrogenado com implantação ou não de ${ }^{10} \mathrm{~B}$ e ${ }^{6} \mathrm{Li}$, são sensíveis aos nêutrons de energias compreendidas entre algumas dezenas de $\mathrm{keV}$ e $15 \mathrm{MeV}$.

- Detectores de borbulhas (Buble Drop Detector), em que pequenas gotas de um líquido aquecido se dispersam durante o processo de fabricação dentro de um polímero elástico, formando o detector. Quando um nêutron incide sobre o detector, o núcleo de recuo implicado na reação neutrônica provoca a evaporação das gotas individuais que se incham com o tempo. As borbulhas imobilizadas no polímero são visíveis aos olhos e uma vez contados fornecem uma indicação da dose neutrônica no campo de radiação.

- Contador Proporcional Equivalente ao Tecido (TEPC - Tissue Equivalent Proportional Counter), chamado também de contador de Rossi [34], caracterizado por uma parede e um gás de enchimento (a pressão) equivalentes ao tecido. Este contador, de forma cilíndrica, funciona de tal maneira que a amplitude do impulso elétrico produzido é proporcional à carga gerada pela partícula secundária, o que permite detectar a deposição energética individual da partícula primária no volume sensível. A pressão de enchimento se elege de maneira a simular um volume equivalente ao tecido de dimensões microscópicas. A contagem dos impulsos registrados permite a avaliação da dose absorvida e da dose equivalente. A distribuição dos impulsos se estende em um intervalo de energias compreendido entre $30 \mathrm{keV}$ para uma ionização simples até $\mathrm{MeV}$. O TEPC é sensível tanto aos nêutrons quanto aos fótons e a discriminação dos fótons é realizada eletronicamente explorando o fato de que o impulso gerado por um próton de recuo possui um tempo de subida (rise time) diferente do gerado por um elétron procedente de uma interação fotônica [30]. 
Qualquer fenômeno que varia de uma maneira previsível com a energia dos nêutrons pode ser utilizado como elemento primário de um sistema espectrométrico. Todos os espectrômetros se baseiam em quatro princípios:

- Medição das energias das partículas carregadas produzidas pela interação do nêutron.

- Medição do Tempo de Vôo sobre um alcance especifico.

- Medição da atenuação e moderação dos nêutrons em várias espessuras de um material hidrogenado.

- Medição das reações de ativação ou de fissão por meio de um conjunto de detectores com uma resposta energética variável. 


\subsection{Os semicondutores - generalidades}

\subsubsection{Estrutura cristalina}

A distribuição espacial dos átomos de um semicondutor é periódica formando uma rede (matriz) cristalina. Os átomos estão entrelaçados através de enlaces covalentes ocupando posições fixas ao redor das quais oscilam sem se afastar muito, constituindo este conjunto de pontos no espaço uma célula unitária que se repete periodicamente em três dimensões. Neste trabalho foram utilizados semicondutores de silício, os quais pertencem ao grupo IV da tabela periódica, tendo, portanto, quatro elétrons de valência que entrelaçam cada átomo com quatro átomos vizinhos situados nos cantos de um tetraedro. Este tipo de estrutura é conhecida como estrutura diamante, como ilustra a Figura 5. A distância entre os dois átomos mais próximos é de $2,35 \mathrm{~A}^{\mathrm{o}}$, a constante de rede $5,43 \mathrm{~A}^{\mathrm{o}}$ e a densidade $2,33 \mathrm{~g} \cdot \mathrm{cm}^{-3}$ [35-39].

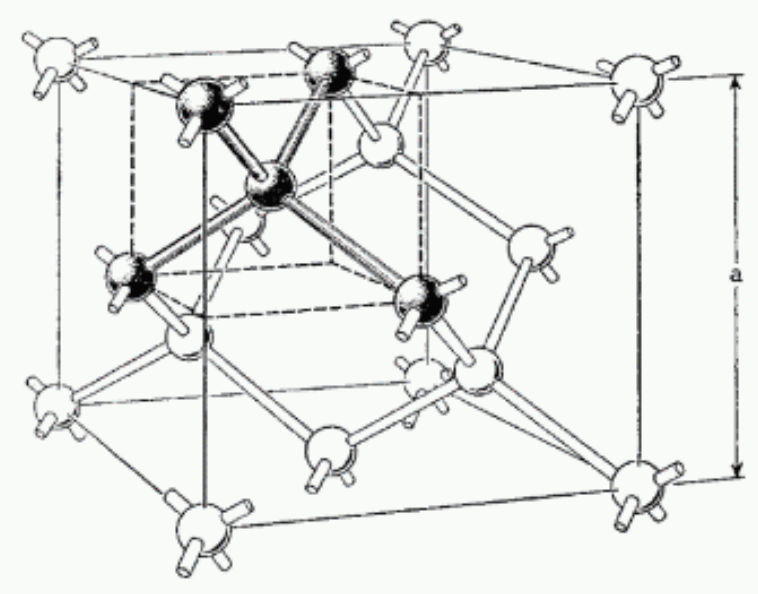

Figura 5: Estrutura cristalina tipo diamante ( $\mathrm{Si} \mathrm{e} \mathrm{Ge):} \mathrm{onde} \boldsymbol{a}$ é a constante de rede.

\subsubsection{Diodos semicondutores.}

Os diodos são semicondutores de silício usados em dosimetria nas instalações de radiocirurgia como uma câmara de ionização de estado sólido.

Estes diodos quando conectados a um eletrômetro apropriado, oferecem uma combinação única de alta sensibilidade, leitura imediata, simplicidade da operação, tamanho pequeno e robustez, além de apresentarem uma excelente resolução espacial, comparativamente às câmaras de ionização usuais. Diversos autores têm demonstrado sua utilização também no campo da microdosimetria [40 e 41]. 
Em cristais puros de silício o "gap" de energia entre a banda de valência e a de condução é de $1,1 \mathrm{eV}$ a temperatura ambiente, que resulta em um número consistente de elétrons na banda de condução $\left(1,5 \times 10^{10}\right.$ elétrons. $\left.\mathrm{cm}^{-3}\right)$. Com a finalidade de aumentar os portadores de carga livres, o silício pode ser dopado, substituindo-se alguns átomos de silício por átomos com um número diferente de elétrons de valência. O número de valência do silício é quatro, se átomos pentavalentes (como o fósforo ou o arsênico) são depositados na matriz de silício. Quatro elétrons de valência formam ligações covalentes com os átomos de silício e o ultimo elétron esta ligado debilmente [39].

Em particular, um elétron por átomo dopado ocupará um novo nível discreto de energia no "gap", bem próximo da banda de condução $(0,05 \mathrm{eV})$, tais elétrons serão facilmente excitados termicamente, aumentando a condutividade do semicondutor. Devido ao fato que as impurezas aumentam a quantidade de portadores de carga negativos, eles são chamados de átomos doadores, e um semicondutor dopado desta maneira é um semicondutor do tipo- $n$.

Também é possível dopar o silício com átomos trivalentes, como o gálio ou índio (chamados de receptores): isto gera níveis de energia próximos da banda de valência, estes estados podem ser alcançados facilmente por elétrons deixando lacunas na banda de valência que se comporta simplesmente como portadores de carga positiva. Estes materiais são chamados de tipo-p.

Ambos os portadores podem-se difundir no silício e através de técnicas de tratamento térmico e recombinações de um com o outro, podem voltar ao seu estado original (Annealing).

Quando se junta uma peça de silício tipo-n com uma do tipo-p (representando o modelo básico de um diodo), as lacunas começam a se difundir até a região-n através da junção, e similarmente os elétrons se dirigem até a região-p , como ilustrado na Figura 6 [39]. 


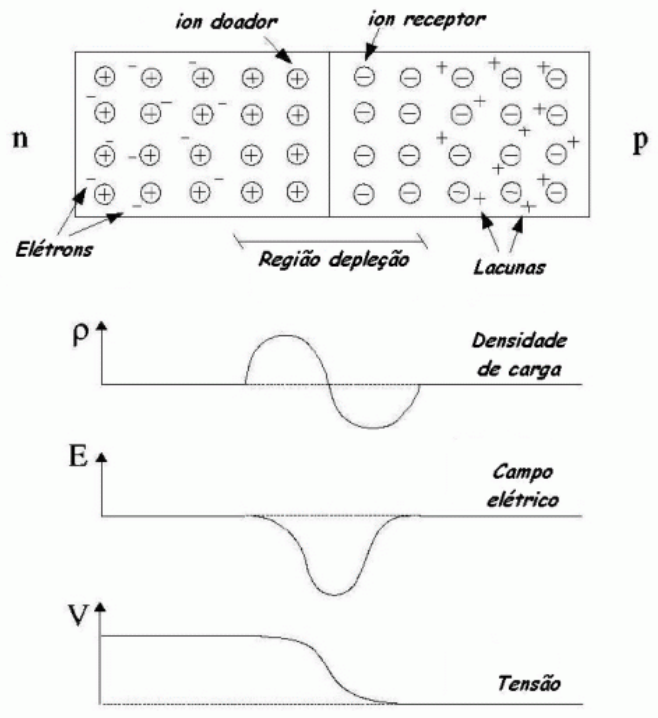

Figura 6: Representação esquemática de uma junção P-N.

Estes portadores se recombinam na região da junção causando um pico de carga com qualquer lado da própria junção. O silício tipo-p recebe elétrons extras, ficando carregado negativamente, e vice-versa no tipo-p.

Uma distribuição de carga diferente de zero é, portanto, produzida na junção com um gradiente de campo elétrico que interrompe o processo de difusão. Devido ao campo elétrico há uma diferença de potêncial conhecida como potêncial de contato. A região de campo elétrico diferente de zero é chamada de região de depleção; se uma carga livre é gerada nesta zona, ela é jogada até a região $n$ ou $p$ dependendo do sinal. Esta característica é útil na detecção da radiação; radiações ionizantes atravessando o silício geram pares elétron-lacuna que, se liberados na região de depleção, são arrastados até os dois lados do diodo. Se dois eletrodos são conectados ao dispositivo, uma corrente é detectável, sendo proporcional à ionização.

A região de depleção intrínseca, formada espontaneamente quando duas peças de silício dopadas diferentemente são juntadas, não é usualmente suficiente para uma boa sensibilidade. Com o fim de aumentar em tamanho a região ativa, uma tensão externa é aplicada ao diodo, de tal sorte que o potêncial de contato é amplificado: lacunas são atraídas na região $p$ afastada da junção, e vice-versa para os elétrons [39]. 
Este tipo de junção diz-se estar polarizada reversamente, e a tensão externa também melhora a eficiência da coleção de cargas. A Figura 7 mostra um circuito típico de diodo: uma fonte de alimentação fornece a polarização reversa, e a corrente produzida pela irradiação na região de depleção (proporcional à ionização e por conseqüência à dose absorvida) é medida instantaneamente por um amperímetro [39].

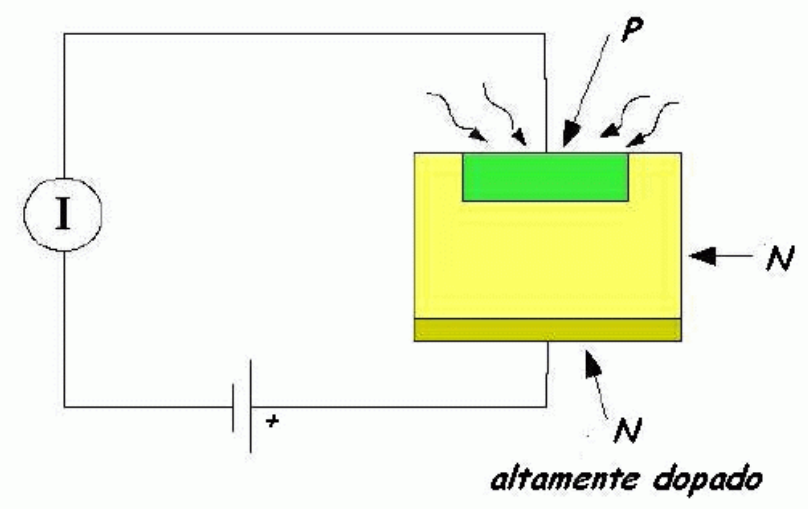

Figura 7: Esquema da polarização reversa do diodo.

Para a produção de um par elétron-lacuna não é utilizada toda a energia depositada pela radiação. Na temperatura ambiente a média de energia absorvida por par elétron-lacuna gerado é de 3,2 eV, onde dois terços se perdem por vibrações na matriz do componente. Esta quantidade é de qualquer maneira de uma ordem de magnitude menor que para ionização de um gás, por esta razão os diodos são mais sensíveis do que as câmaras de ionização gasosa de mesmo volume.

Devido ao fato que a resposta dos diodos é lida diretamente em um eletrômetro, esta é realizada em tempo real, mas seu fator de calibração é dependente da energia, e esta deve ser repetida periodicamente uma vez que a sensibilidade muda de acordo com o histórico de radiação recebida [42]. Eles estão disponíveis com volumes muito pequenos (na ordem de $1 \mathrm{~mm}^{3}$ ) resultando em uma boa resolução espacial, e por esta razão eles são muitos utilizados, como os TLDs, em simuladores (phantoms) e como dosímetros nas técnicas de tratamento In-Vivo [39]. 


\subsubsection{Dopagem de semicondutores.}

Os detectores semicondutores mostram uma queda de sensibilidade depois de uma pré-irradiação como resultado de danos de irradiação. A magnitude deste efeito depende da qualidade da radiação e do tipo de semicondutor, sendo maior para os de silício tipo- $n$. Um detector de alta dopagem tipo-p mostra um rápido decremento inicial na sua sensibilidade com a dose acumulada seguido de um efeito menos pronunciado. Em comparação, a sensibilidade diminui para um detector de baixa dopagem e permanecerá a uma taxa elevada, para maiores doses acumuladas [43].

Uma característica importante de qualquer dosímetro é a linearidade da resposta de dose por pulso. Rikner [44] demonstrou que a resposta de um diodo tipo-n é independente da dose por pulso. Posteriormente ele mostrou que o nível de dopagem e de resistividade afeta as propriedades do detector devido aos danos por radiação.

Por outro lado um detector tipo-p com baixa dopagem e resistividade de 10 ohms.cm foi comparado com um detector tipo-p de alta dopagem e de resistividade de 0,2 ohms.cm mostrando uma não-linearidade na taxa de dose com alta dose por pulso em feixes de alta energia. $\mathrm{O}$ detector tipo- $p$ com alta dopagem e baixa resistividade permaneceu linear mesmo com altos valores de dose por pulso.

\subsubsection{Dependência da resposta de semicondutores.}

Os diodos de silício podem exibir dependência com a temperatura e com o direcionamento. Grusell e Rikner mostraram que a variação da sensibilidade com a temperatura (SVWT) de um detector de silício tipo-p aumenta linearmente com o incremento de temperatura [45]. A magnitude deste aumento depende do nível de pré-irradiação do detector.

Esta variação aumenta com a dose acumulada até aproximadamente 6 kGy de elétrons de $20 \mathrm{MeV}$, entretanto permanece quase constante além deste ponto [45].

Devido à densidade, 1800 vezes maior que a do ar, a energia necessária para produzir um par elétron-lacuna em diodos de silício é de 3,5 eV, comparada aos $34 \mathrm{eV}$ necessários para produzir um par de íons análogos no ar. Portanto, os diodos podem ter volumes sensíveis muito pequenos. Tipicamente, um detector deste tipo tem dimensões de 2,5x2,5x0,4 $\mathrm{mm}^{3}$ de volume [3 e 46]. 


\subsubsection{Vantagens e desvantagens dos detectores de silício}

Os componentes semicondutores de silício apresentam varias vantagens que os tornam atrativos para a detecção de partículas, sendo elas as seguintes [25]:

1) devido à alta densidade do silício, a partícula ionizante perde toda sua energia em curto trajeto. Partículas $\beta$ e prótons de energia alta chegam a percorrer um metro de ar sem serem barradas. Em contrapartida, são totalmente freadas em um centímetro de silício. Consequentemente, é conseguida uma considerável eficiência de detecção por unidade de volume efetivo do detector. $\mathrm{O}$ alcance das partículas alfa no silício varia de $10 \mu \mathrm{m}$ a $1000 \mu \mathrm{m}$ para energias de 3,0 MeV a $50 \mathrm{MeV}$ ". As partículas alfa, produzidas na reação dos nêutrons com o ${ }^{10} \mathrm{~B}$, têm um alcance que depende da energia inicial da partícula. O silício possui boa sensibilidade para detecção de prótons. Os prótons, núcleos dos átomos de hidrogênio, ao sofrerem choque com nêutrons são liberados dentro de um intervalo de energia que depende da energia do nêutron incidente e do ângulo de incidência. $\mathrm{O}$ alcance do próton no silício varia de aproximadamente $90 \mu \mathrm{m}$ a $1000 \mu \mathrm{m}$ para partículas com $3 \mathrm{MeV}$ a aproximadamente $12 \mathrm{MeV}$,

2) sua capacidade para produzir um par elétron-lacuna. No silício, para produzir um par elétron-lacuna, são necessários somente $3,6 \mathrm{eV}$ de energia e esse valor independe do tipo de radiação e da sua energia inicial. Já no germânio, para produzir um par elétronlacuna, a energia necessária é de somente 2,8 eV. Essas energias são aproximadamente oito vezes menores do que a necessária para ionizar o gás Argônio e ao redor de 200 vezes menor do que a necessária para liberar um fotoelétron no cátodo de uma fotomultiplicadora usada com os detectores cintiladores. Para uma mesma energia da partícula incidente é liberado um número consideravelmente maior de cargas elementares em um cristal de silício ou germânio comparativamente a uma câmara de ionização ou em um detector de cintilação. Assim, as flutuações estatísticas são notavelmente menores e, portanto, levam a um maior poder de resolução da partícula detectada,

3) a elevada mobilidade de elétrons e lacunas. Esta característica, unida às pequenas dimensões do detector, resulta em um tempo de aquisição muito curto e, portanto, uma elevada resolução em tempo que pode chegar a ser da ordem de nanosegundos, 
4) a facilidade de construir detectores constituídos de lâminas muito finas, de modo a absorver uma pequena parte da energia da partícula incidente, obtendo-se com isso uma medida da ionização especifica $d E / d$. O silício é mais usado do que o germânio na fabricação de detectores porque pode ser operado em temperaturas do ambiente dos laboratórios. O germânio, ao contrário, devido a maior facilidade de produção espontânea de par elétron-lacuna necessita ser operado em temperaturas baixas e geralmente é refrigerado com nitrogênio líquido.

O uso de fotodiodos também apresenta desvantagens [31, 35, 44 e 47], que eventualmente podem ser limitantes para a aplicação desejada. Estas desvantagens são descritas a seguir:

1) devido ao fato que o diodo é polarizado reversamente, uma pequena quantidade de corrente consegue fluir mesmo que o componente esteja coberto por inteiro sem deixar passar a luz. Esta corrente, chamada de corrente de fuga, é uma das causas de ruído e pode limitar, em algumas aplicações, a energia mínima a ser detectada e a resolução do conjunto detector;

2) como em todo semicondutor, a uma temperatura diferente do zero absoluto, são produzidas vibrações na rede gerando portadores de cargas livres os quais são responsáveis também na formação do ruído;

3) a capacitância existente em uma junção é uma característica inerente, que pode ser reduzida com polarização reversa, mas não eliminada. Esta capacitância será responsável pelo aumento do ruído no estagio pré-amplificador;

4) as doses de radiação recebidas pelo detector produzem danos (defeitos) no material semicondutor, resultando em uma perda de sensibilidade que depende da energia da radiação incidente. Quanto maior a energia incidente maior o dano causado ao detector. Porém, a variação desta sensibilidade diminui com o aumento da dose acumulada. Esta degradação da sensibilidade tornar-se-á mais lenta através do tempo conforme a utilização do detector. 
No desenvolvimento do projeto foram utilizados fotodiodos PIN e diodos de Barreira de Superfície (SSBD - Silicon Surface Barrier Detector). A sigla PIN tem origem no substrato de silício intrínseco (I), ou seja, com um baixo índice de contaminantes e alta resistividade, no qual se inicia a construção do fotodiodo. A parte superior deste substrato recebe eletrodos de alumínio, em uma disposição com formato de rede, que formarão a região tipo-p $(\mathrm{P})$ do fotodiodo. A extremidade oposta, por difusão ou contato com um material pentavalente, dará origem a região tipo- $n(\mathrm{~N})[47]$. 


\subsection{Semicondutores em dosimetria e detecção de partículas - Histórico}

A utilização de diodos semicondutores para a detecção de nêutrons começou, na prática, com Birk et al. (1963) usando a técnica de conversor na face frontal de um diodo em campos de nêutrons rápidos, conseguindo bons resultados na espectroscopia de nêutrons. Utilizando polietileno como conversor de nêutrons para prótons de recuo, conseguiram a detecção de prótons espalhados em pequenos ângulos, obtendo uma resolução de $270 \mathrm{keV}$ para nêutrons de $6 \mathrm{MeV}$, demonstrando a conveniência de utilizar a vantagem das reações internas $(n, p)$ e $(n, \alpha)$ no silício para espectroscopia de nêutrons rápidos [48].

Kovacevic et al. (1978) apresentaram um componente desenvolvido por eles no Instituto Ruder Boskovic em Zagreb, Yugoslavia (na época) e discutiram sobre os aspectos físicos do componente e do conversor hidrogenado usado como um gerador de prótons de recuo, colocado em frente do fotodiodo de silício do tipo planar. A comparação dos resultados analíticos e experimentais incluindo a eficiência do sensor mostrou que esse sistema de detecção era capaz de medir a dose de radiação de nêutrons de $5 \operatorname{Rad}(0,05$ Gy) com uma precisão de $\sim 5 \%$ [49].

Anos depois Eisen et al. (1983) apresentaram um trabalho analítico e experimental para o desenvolvimento de um sistema dosimétrico em tempo real para o intervalo de energia de $1 \mathrm{eV}$ até $14 \mathrm{MeV}$, sendo adequado para medições de dose equivalente de nêutrons desde 3 mRem $(30 \mu \mathrm{Sv})$ até $100 \mathrm{Rem}(1 \mathrm{~Sv})$ e taxas de doses de $300 \mathrm{mRem} \cdot \mathrm{h}^{-1}\left(3 \mathrm{mSv} \cdot \mathrm{h}^{-1}\right)$ até 50 Rem.h $\mathrm{h}^{-1}\left(0,5 \mathrm{~Sv} \cdot \mathrm{h}^{-1}\right)$. Este sistema dosimétrico consistia de quatro detectores de Barreira de Superfície (SSBD - Silicon Surface Barrier Detector). Para a detecção três deles utilizavam conversor de ${ }^{10} \mathrm{~B}$ cobrindo suas faces e um quarto coberto por uma fôlha de polietileno. Este sistema dosimétrico podia estimar o espectro de nêutrons através da separação da dose equivalente total em intervalos de $1 \mathrm{eV}$ até $30 \mathrm{keV}, 30 \mathrm{keV}$ até $1 \mathrm{MeV}$ e de 1 até $14 \mathrm{MeV}$ [50].

Matsumoto e Aizawa (1988), do Instituto de Tecnologia Musashi, Japão, desenvolveram um sistema dosimétrico a ser aplicado em BNCT (BNCT - Boron Nêutron Capture Therapy), terapia de captura de nêutrons pelo boro, aplicada em tumores no cérebro. Eles mostraram a viabilidade de se medir simultaneamente o fluxo de nêutrons térmicos e a taxa de dose de radiação gama incidente no paciente, durante o tratamento, utilizando um 
diodo semicondutor de silício de junção PN, desenvolvido na instituição, junto com um conversor do tipo ${ }^{6} \mathrm{LiF}[51]$.

Para medições comparativas foi utilizado também um sistema cintilador BGO acoplado a uma fibra ótica. Shiraishi et al. (Universidade de Nagasaka, Japão, 1988), desenvolveram pesquisas com o fim de caracterizar um tipo de dosímetro pessoal usando semicondutores, para fins de proteção radiológica. Para isto, desenvolveram a fabricação de dois detectores Barreira de Superfície em um único "wafer". Este componente $d E$ e $E$ trabalha com duas partes, a primeira parte corresponde ao fino contador $d E$ que detecta e identifica as partículas alfa, os tritons e prótons de recuo, ao mesmo tempo em que discrimina a radiação gama de BG. A outra parte do sistema, o contador $E$ é usado na identificação de prótons de energia alta. Esta parte do contador é de uma espessura maior que o contador $d E$. Isto é necessário para distinguir os prótons de energia alta da radiação gama de BG. Após o estudo e análise computacional dos resultados mostraram a viabilidade de se usar este tipo de sistema em espectroscopia, mas para dosimetria, a eficiência de detecção mostrou que o componente não era muito adequado [52].

Nakamura et al. (Universidade de Tohoku, Japão, 1989), desenvolveram um dosímetro pessoal de ampla faixa de energia utilizando dois detectores de silício. Este desenvolvimento, fabricado sob encomenda pela Fuji Electric Co, consiste de dois tipos de detectores de junção PN. O primeiro é um detector de silício dopado com boro altamente enriquecido em ${ }^{10} \mathrm{~B}(96 \%)$ usando o polietileno como moderador e conversor. O segundo detector utiliza apenas o conversor de polietileno. Os resultados mostraram que este tipo de dosímetro pode ser promissor como contador de equivalente de dose, devido ao fato que e insensível a radiação gama de equivalente de dose ambiente até $0,2 \mathrm{~Sv} \cdot \mathrm{h}^{-1}\left(20 \mathrm{R} \cdot \mathrm{h}^{-1}\right)$ e possui uma dependência angular baixa entre 0 e 45 graus [53].

Barelaud et Al. (LEPOFI - Faculdade das Ciências, França, 1991) desenvolveram diodos detectores (fabricados na própria instituição) para a dosimetria de nêutrons, visando seu uso em conjunto de um sistema eletrônico (baseado em microprocessador) para a dosimetria de nêutrons (pessoal). As conclusões foram satisfatórias para definir uma metodologia diferencial de medição com dois diodos detectores, mostrando a viabilidade de se medir uma taxa de equivalente de dose mínima de uma centena de $\mu S v \cdot h^{-1}$ [54]. 
O mesmo grupo de pesquisas (Barelaud et al. (França, 1993) fez uma atualização do projeto de detecção anterior (1991), utilizando simulações em código Monte Carlo (EGS4) para fótons e desenvolvendo um novo programa (software - PNEDIOD) para nêutrons. Graças à apropriada estrutura para otimizar os parâmetros, a discriminação da radiação gama foi aprimorada mais uma vez. Sob estas condições, o patamar de energia do detector para nêutrons alcançou até $200 \mathrm{keV}$. Concluíram que o sistema possui um nível de discriminação de fótons perto dos $300 \mathrm{keV}$ e sua sensibilidade para radiação gama é de 320 impulsos. $\mathrm{cm}^{-2} \cdot \mu \mathrm{Sv}^{-1}$ com um nível energético de captura em $130 \mathrm{keV}$ e uma energia máxima no espectro de $552 \mathrm{keV}$. Para nêutrons, os resultados apresentaram uma sensibilidade para os feixes monoenergéticos (de $570 \mathrm{keV}$ até $14 \mathrm{MeV}$ ) igual a $0,85 \pm 0,25$ impulsos. $\mathrm{cm}^{-2} . \mu \mathrm{Sv}^{-1}$ com um nível de captura energética de $125 \mathrm{keV}$. Para os campos polienergéticos a sensibilidade resultou em $0,77 \pm 0,11$ impulsos $\mathrm{cm}^{-2} \mu \mathrm{sV}^{-1}$ com um nível compreendido entre 350 e $550 \mathrm{keV}$ [55].

Hosono et al. (Universidade de Tokyo, Japão, 1995) utilizaram um conversor de polietileno $(45 \mu \mathrm{m})$ acoplado a um fotodiodo da Hamamatsu, junto com um preamplificador sensível a carga (desenvolvido por eles) para experiências de detecção de nêutrons, conseguindo uma eficiência de $7,810^{-5}$ para nêutrons rápidos e uma sensibilidade de energia maior que $1,2 \mathrm{MeV}[56]$.

Rosenfeld et al. (grupo de pesquisas, do Departamento de Física da Universidade de Wollongong, Austrália, 1996), desenvolveram experiências em Macro e Micro dosimetria utilizando transistores de efeito de campo (FET - Field Effect Transistor) pareados. Foram feitas comparações com um diodo coberto por um conversor de ${ }^{10} \mathrm{~B}$ e uma câmara de ionização equivalente tecido na medição da distribuição de dose media do Boro e o espectro microdosimétrico devido as partículas alfa e íons de ${ }^{7} \mathrm{Li}$ de um simulador de Perspex exposto ao feixe epitérmico no reator de Brookhaven (Estados Unidos). Os resultados mostraram a importância do tamanho (pequeno) do detector para medições dosimétricas, uma vez que fornecem uma perturbação mínima do campo no ponto de medição.

Para a Terapia de Nêutrons Rápidos (FNT - Fast Neutron Therapy) o detector mostrou sua utilidade em medições do perfil de dose de nêutrons e a medição simultânea do espectro de prótons de recuo [57]. 
Bordy et al. (Instituto de Proteção e Segurança Nuclear, Franca, 1997), desenvolveram pesquisas para a utilização de um diodo único, como elemento primário de um dosímetro pessoal, usando a técnica de discriminação por análise da forma dos pulsos. Foi utilizado um diodo de junção PN coberto com um conversor hidrogenado com um dos seus lados revestido de uma camada de ${ }^{10} \mathrm{~B}$, permitindo que a sensibilidade aumente de um fator de dois para uma energia de nêutrons de $250 \mathrm{keV}$.

A utilização desta técnica permite uma redução radical na resposta do componente à radiação por fótons. Usando a análise da forma do pulso, o diodo pode alcançar os requisitos para dosimetria individual de nêutrons. Finalmente, os autores recomendam a utilização de códigos de simulação (Monte Carlo) para uma análise de interações dos nêutrons com o moderador [58].

Posteriormente em 1999, Rosenfeld et al. desenvolveram uma pesquisa de aplicação de componentes semicondutores (diodos PIN e MOSFETs) para dosimetria de campos de radiação nêutron-gama. Demonstraram mais uma vez a melhor vantagem dos componentes utilizados, o seu pequeno tamanho, que evita distorções do campo de radiação no ponto de medição. Eles podem ser usados para o planejamento de dose em terapia de nêutrons e RaiosX de Megavoltagem. Em aceleradores clínicos (LINAC), os MOSFETs, com um invólucro especial, forneceram dados sobre a distribuição de dose na região de "Build-up" melhor que quaisquer dosímetros usados correntemente (na época, 1999).

Em modalidades de tratamento que utilizam campos mistos, os dois componentes podem determinar os diferentes componentes de dose e ainda medir a qualidade radiológica de um dado feixe quando usado no modo de microdosimetria [59].

Nakamura et al. (Universidade de Tohoku, Japão, 1999) caracterizaram um dosímetro pessoal em tempo real usando dois detectores de silício. O dosímetro contém um sensor para nêutrons rápidos e outro sensor para nêutrons térmicos. Estes dois sensores são semicondutores do tipo-p cobertos com dois tipos de conversores de polietileno e ${ }^{10} \mathrm{~B}$. A eficiência de detecção foi medida em um campo de nêutrons térmicos, e outro campo de nêutrons monoenergéticos de $8 \mathrm{keV}$ até $22 \mathrm{MeV}$. Para testes de desempenho os dois detectores foram irradiados em diferentes instalações (reatores nucleares, aceleradores, e instalações de produção de radioisótopos e combustível nuclear. Este dosímetro pessoal pode 
detectar nêutrons com energias de nêutrons térmicos até umas dezenas de MeV. Ele pode determinar o equivalente de dose de nêutrons dentro de um fator de 2 (margem de precisão), sendo insensível à radiação gama até uma taxa de dose de $1 \mathrm{~Sv} \cdot \mathrm{h}^{-1}$ [60].

Madi Filho et al. (Instituto de Pesquisas Energéticas e Nucleares, IPEN, Brasil, 2001), apresentaram os resultados do desenvolvimento de um diodo semicondutor do tipo Barreira de Superfície (SSBD - Silicon Surface Barrier Detector) junto com um fino material conversor (polietileno), capaz de produzir partículas carregadas (prótons), que foi utilizado para detectar nêutrons em um reator nuclear de baixa potência (Potência Zero). Foram utilizados dois tipos de conversores; um deles constituído por uma lâmina de alumínio (1 mm de espessura) revestido de uma camada de ${ }^{10} \mathrm{~B}$ (enriquecido a 90,1\%), gerando partículas alfa pela reação $(\mathrm{n}, \alpha)$ para nêutrons térmicos e um outro, sendo uma fôlha de polietileno $\left(\mathrm{CH}_{2}\right)_{\mathrm{n}}$, gerando prótons através da reação (n,p). A espessura ótima dos conversores foi otimizada analítica e experimentalmente e foi mostrado por meio da experimentação que o conversor de polietileno tem melhor desempenho que o conversor de ${ }^{10} \mathrm{~B}[61]$.

Agosteo et al (Departamento de Engenharia Nuclear, Politécnico de Milano, Itália, 1999), desenvolveram experiências em espectrometria de evento único. Estes experimentos foram focalizados nos danos de irradiação em componentes eletrônicos. Foram utilizados fotodiodos da Hamamatsu em campos térmicos e nêutrons rápidos monoenergéticos. Junto destes componentes foi testado também um preamplificador sensível a carga (H4083). O conjunto foi irradiado com nêutrons térmicos usando como fonte um acelerador Van de Graaff para estudos em BNCT do LNL (Laboratório Nacional de Legnaro). Estes nêutrons são gerados por meio da reação ${ }^{9} \mathrm{~B}(\mathrm{~d}, \mathrm{n}){ }^{10} \mathrm{~B}$ e moderados com água pesada e a grade de grafite do reator. Os resultados forneceram um guia de procedimentos para caracterizar componentes do tipo ASIC (application of specific integrated circuit) para monitoração em espectrometria de evento único. Assim, também foi demonstrada a viabilidade de um espectrômetro de prótons de recuo usando fotodiodos PIN [62].

Posteriormente, Mesquita et al. (Instituto de Pesquisas Energéticas e Nucleares, IPEN, Brasil, 2003) avaliaram um diodo semicondutor tipo PIN para detecção de nêutrons usando o polietileno como conversor. Foi utilizado um modelo matemático para o cálculo da melhor espessura do polietileno. Como fontes de nêutrons foram utilizadas uma de $\mathrm{AmBe}$ e as instalações do reator IPEN/MB-01. Os resultados mostraram a eficácia do detector, usando 
fotodiodo PIN, para nêutrons rápidos, e a possibilidade de se utilizar este componente como um dispositivo de referência nas calibrações de potência do reator [63].

Jae Lee et al. (Instituto Avançado de Ciência e Tecnologia, KAIST, Coréia, 2003) desenvolveram um dosímetro pessoal usando semicondutores PIN e desenvolvendo um algoritmo de conversão para dosimetria. Para testes de desempenho o instrumento foi irradiado com energias no intervalo de $50 \mathrm{keV}$ e $1,25 \mathrm{MeV}$ e taxas de dose de $3 \mathrm{mR} \cdot \mathrm{h}^{-1}$ $\left(30 \mathrm{~Sv} \cdot \mathrm{h}^{-1}\right)$ e $25 \mathrm{R} \cdot \mathrm{h}^{-1}\left(0,25 \mathrm{~Sv} \cdot \mathrm{h}^{-1}\right)$ [64].

Agosteo et al. (2003), grupo de pesquisas do Instituto Politécnico de Milano apresentou um estudo sobre o desempenho de um fotodiodo usado em espectrometria de prótons de recuo. A função resposta do detector foi avaliada com feixes de nêutrons monoenergéticos. Esta resposta foi também determinada analiticamente e usando o código de Monte Carlo (código FLUKA). O grupo investigou os efeitos das partículas secundárias produzidas pelas interações dos nêutrons térmicos e rápidos no diodo de silício [65].

Voytchev et al. (2003) obtiveram sucesso na implementação do uso de detectores PIN para a detecção de nêutrons térmicos. Eles utilizaram conversores de Fluoreto de Lítio $\left({ }^{6} \mathrm{LiF}\right)$ de 2 e $0,6 \mu \mathrm{m}$, estes conseguidos através da deposição atômica, o ${ }^{6} \mathrm{LiF}$ foi evaporado em um suporte de alumínio de $1 \mathrm{~mm}$ de espessura e superfície de $1,4 \times 1,4 \mathrm{~cm}^{2}$, e selado com uma camada de prata de $10 \mathrm{~nm}$ de espessura. A fonte de nêutrons usada foi de AmBe dentro de uma instalação especial para se trabalhar com nêutrons. Foram realizadas simulações (Monte Carlo) para estudo das interações dos nêutrons incidentes e a detecção de trítions e partículas alfa (MCNP4c) e um programa (software ALPHASIM), desenvolvido pelo grupo de pesquisa para o transporte de íons. Foram também realizadas medições com detectores termoluminescentes (TLD600 e TLD700) para determinação das taxa de doses. Os resultados foram satisfatórios [66].

Agosteo et al. (2004), desenvolveram experiências para um espectrômetro de prótons de recuo, usando diodos PIN, mas implementando uma discriminação de fótons por forma de pulsos (Pulse-Shape Discrimination).

Para as experiências foram usados um fotodiodo da Hamamatsu e um preamplificador sensível à carga (H4083). Como conversor, foi usado uma lâmina de polietileno de $1 \mathrm{~mm}$ de 
espessura. A discriminação por forma de pulsos permitiu trabalhar com o detector na configuração de máxima depleção e a máxima energia de nêutrons detectável foi de $6 \mathrm{MeV}$, para uma depleção de $300 \mu \mathrm{m}$, mantendo, entretanto, o limite inferior em $900 \mathrm{keV}$ [67].

Adamiec et al. (Universidade de Valladolid, Espanha, 2004) mostraram as propriedades de um sistema de detecção de nêutrons constituído por um fotodiodo de silício da Hamamatsu em conjunto com um analisador multicanal. Para o desenvolvimento das experiências foi utilizada a instalação de irradiação do Departamento de Engenharia Nuclear da Universidade. A resposta do detector foi comparada com outro instrumento rastreado e os resultados foram satisfatórios. Concluíram que este tipo de detector pode ser usado como medidor do equivalente de dose ambiente para uma fonte de $\mathrm{AmBe}$ (com conversores de ${ }^{6} \mathrm{LiF}$ ou polietileno inseridos na esfera de parafina) [68].

McGregor et al. (Universidade de Kansas, Estados Unidos, 2008), desenvolveram um detector de nêutrons compacto a ser utilizado como um dosímetro pessoal em tempo real. O detector consiste de diodos PIN produzidos com silício de alta pureza. Cada detector possui milhares de (micro) perfurações circulares nas quais foi depositado ${ }^{6} \mathrm{LiF}$ (como elemento conversor) para que os diodos sejam sensíveis a nêutrons térmicos. A maior eficiência obtida foi de $12 \%$ para nêutrons térmicos. Dispositivos moderados com polietileno de alta densidade podem ser usados para medições de nêutrons rápidos. O detector foi usado para medições de fluxo no reator de pesquisas nucleares TRIGA MARK (Universidade Estadual de Kansas, Estados Unidos) [69]. 


\subsection{Microdosimetria.}

A microdosimetria é a área que trabalha com eventos e sua distribuição de deposição de energia a nível microscópico e sua relação com efeitos da radiação em alvos biológicos [70]. Ela é formalmente definida por Rossi e Zaider [71] como o "estudo sistemático e quantificação da distribuição espacial e temporal da energia absorvida na matéria irradiada".

A escala de medição da microdosimetria é tipicamente ao nível de microns. Nestas pequenas dimensões, a ferramenta básica da microdosimetria experimental tem sido o contador proporcional a baixa pressão conhecido como o TEPC (Contador Proporcional Tecido Equivalente) [72].

Quando os primeiros trabalhos sobre microdosimetria foram publicados nas décadas de 50-60 por Rossi e outros pesquisadores [73-75] a relevância desta abordagem ficou imediatamente aparente: em radiobiologia fundamental, para um melhor entendimento dos mecanismos primários da ação da radiação e em proteção radiológica, onde se trabalha com doses baixas, um pequeno número de eventos e com diferentes tipos de radiação. Em radiocirurgia onde as doses são relativamente altas, a relevância da microdosimetria pareceu, no início, um pouco limitada. Entretanto, com o desenvolvimento da terapia por nêutrons (e terapia de alto LET), a possibilidade de aplicação da microdosimetria se tornou mais evidente [76].

A microdosimetria tem mostrado uma evolução e um aumento, nas últimas décadas, da sua possibilidade de aplicação em campos como a Proteção Radiológica e a Física Médica [77].

Um microdosímetro "ideal" deve ter as seguintes características: (a) ser equivalente tecido, (b) possuir vários microns de espessura ativa, (c) ter um nível de ruído que permita a detecção de sinais baixos na ordem de $100 \mathrm{eV} \cdot \mu \mathrm{m}^{-1}$, e (d) ser capaz de detectar (com boa resolução de energia) traços de partículas de forma individual [78].

\subsubsection{Equivalência ao tecido}

A microdosimetria usando silício requer um conversor equivalente tecido cobrindo a área sensível do detector. Idealmente, as interações detectadas aparecem exclusivamente de eventos originados no meio que circunda o detector. Portanto, o dispositivo deve ter uma 
camada com espessura pequena e o volume sensível deve ser tão pequeno quanto possível para realçar as partículas "cruzadoras" (crossers) e reduzir as interações nucleares diretas com o silício. Um estudo comparativo entre interações no tecido e no silício em FNT (Fast Nêutron Therapy) foi descrita por Bradley e colaboradores [3]. Para energia de nêutrons menores que $5 \mathrm{MeV}$, as medições microdosimétricas em volumes de silício com dimensões na ordem de $1 \mu \mathrm{m}$ não são significativamente afetadas por eventos originados dentro do silício.

Para energias de nêutrons maiores, o espectro de energias lineais altas podem ser afetadas por reações elásticas e inelásticas do silício [78]

\subsubsection{Semicondutores em Microdosimetria - Histórico}

A primeira comparação de medições microdosimétricas entre contadores proporcionais esféricos e detectores de estado sólido foi realizada por Dicello et al em 1980. Eles demonstraram que os detectores de silício eram capazes de medições sob plena intensidade de feixes terapêuticos enquanto que os contadores proporcionais precisavam de uma redução na intensidade do feixe [79].

Orlic et al. em 1989 trabalharam em aplicações de proteção radiológica. Usaram um fotodiodo sem nenhuma polarização para obter uma espessura sensível de $5 \mu \mathrm{m}$ e um conversor de polietileno montado sobre o detector [80].

Kadachi et al. (1994) estenderam o trabalho de Orlic comparando a resposta de um fotodiodo de silício (PIN) com uma espessura sensível de $8 \mu \mathrm{m}$ a uma tensão de zero Volt e $13 \mathrm{~mm}^{2}$ de área, com um contador proporcional (TEPC) com diâmetro simulado de $1 \mu \mathrm{m}$ [81].

O conceito de macro e micro dosimetria foi introduzido por Rosenfeld et al em 1996. Os métodos microdosimétricos são especialmente úteis para terapia com radiações de altoLET (Transferência Linear de Energia) devido aos requisitos de uma especificação quantitativa da qualidade da radiação [82].

Um microdosímetro pessoal para microdosimetria foi desenvolvido por Schroder et al. (Centro de Pesquisas de Julich, Alémanha, 1995). Foram desenvolvidas experiências utilizando um circuito integrado de memória estática (64kbit) SRAM para a detecção, um 
circuito integrado de memória dinâmica (1 Mbit) e um diodo de Arsenato de Gálio sob campos de nêutrons e fótons. Os resultados serviram para estabelecer procedimentos para se conseguir uma melhor sensibilidade, a correlação dos espectros com a geometria plana do detector e a comparação com um contador equivalente tecido (TEPC) para se conseguir otimizar a caracterização de um detector de silício [83].

Comparações adicionais, com o primeiro trabalho (1994) foram realizadas mais tarde por Kadachi et al. (1996) usando fotodiodos (p-n, PIN e PNN) e tamanhos de depleção no dispositivo de silício de 1, 3, 5 e 8 micra [84].

Rosenfeld et al. (Universidade de Wollongong, Austrália, 2000) apresentaram um semicondutor (fabricado pela Fuji Electric Co, Japão) com tecnologia SOI (Silicon on Insulator) para ser utilizado como microdosímetro em terapia de prótons. O sistema consiste de um arranjo matricial de 120x40=4800 diodos e cada diodo com uma junção de $10 \times 10 \mu \mathrm{m}$, com um tamanho total de $0,044 \mathrm{~cm}^{2}$ de área (diodos conectados em paralelo). Toda esta estrutura está em um dispositivo de cerâmica DIL (Dual in Line) de 28 pinos. Foram desenvolvidas experiências nas instalações para terapia por prótons de Tsukuba, Japão e em Boston, Estados Unidos. Os resultados foram promissores e mostraram o sucesso de uma nova abordagem para se trabalhar em microdosimetria usando detectores semicondutores [85].

Agosteo et al. (2005) desenvolveram um estudo para um microdosímetro de estado sólido, baseado na tecnologia de "Telescópio de Silício" (monolithic silicon telescope). Foram realizadas diversas simulações com código de Monte Carlo (FLUKA) para definir o detector (fabricado, sob encomenda, pela ST Electronic, Alémanha). Eles conseguiram uma resposta de energia no nível de $40 \mathrm{keV}$ [86].

Carolan et al. (Universidade de Wollongong, Austrália, 2006) mostraram um método para medir o equivalente-tecido de dose usando um diodo PIN e fôlhas de ativação em feixes de nêutrons epitérmicos com $\mathrm{E}_{\mathrm{n}}<100 \mathrm{keV}$. Esta abordagem consiste em observar a mudança na tensão direta de polarização do diodo causada pelos danos de deslocamento induzidos por nêutrons na junção do diodo. Todo este estudo foi baseado na simulação do sistema e componente usando o código de Monte Carlo. O estudo simulado mostrou que para o espectro de nêutrons com energias máximas de $500 \mathrm{eV}$ um simples fator escalar é adequado para a 
conversão do kerma* (Kinetic Energy Released per Unit Mass - energia cinética liberada por unidade de massa) por danos em kerma no tecido. Para espectros com energias até $30 \mathrm{keV} \mathrm{a}$ suplementação de medições com fôlhas de ativação possibilita a estimativa da dose no tecido dentro de um $5 \%$. Para nêutrons com energias até $100 \mathrm{keV}$, esta técnica ainda pode ser usada com certa redução da exatidão. Concluíram que este método é mais apropriado para nêutrons de energia baixa quando a fonte é um reator (feixes epitérmicos), mas pode ser útil para nêutrons epitérmicos originados em aceleradores clínicos, operando com fluxo de nêutrons a energias $>100 \mathrm{keV}$ [87].

(*) O kerma é uma das grandezas utilizadas para avaliar o efeito das radiações ionizantes ao interagirem com a matéria. 


\subsection{Simulação usando o código de Monte Carlo.}

O código de Monte Carlo é uma solução numérica para um problema que modela objetos interagindo com outros objetos ou seus meio ambientes baseado em relações simples de objeto-objeto ou objeto-meio ambiente. Representa um intento de modelar a natureza através de simulação direta da dinâmica essencial do sistema em questão. Nesse sentido, o método de Monte Carlo é essencialmente simples na sua abordagem. Procura por uma solução para um sistema macroscópico através da simulação de suas interações microscópicas.

Uma solução é determinada por meio de amostragens aleatórias das relações, ou das interações microscópicas, até os resultados. Assim, o mecanismo para executar o processo para uma solução envolve ações repetitivas ou cálculos.

Os produtos das ciências básicas e aplicadas são dependentes de medições, teoria e de simulações de Monte Carlo. O Monte Carlo é freqüentemente chamado de concorrente de outros métodos de cálculos macroscópicos, chamados de métodos analíticos ou determinísticos. A prática da ciência é quem decide quando o uso de um método resulta melhor que o outro [88].

No contexto de transporte de radiação, as técnicas de Monte Carlo são aquelas as quais simulam as trajetórias de partículas individuais e os processos de interação da radiação com a matéria pela geração de números pseudo-aleatórios, a partir da distribuição probabilística que governa os processos físicos envolvidos. Pela simulação de um grande número de histórias, obtêm-se informações sobre o valor médio de quantidades macroscópicas.

O programa de Monte Carlo MCNP é um código computacional amplamente utilizado na área de transporte de radiação envolvendo nêutrons, fótons e elétrons. A capacidade de tratamento de geometrias complexas em três dimensões e a variedade de opções de dados de entrada faz deste código uma ferramenta muito conveniente e poderosa no campo da proteção radiológica, modelagem de instalações nucleares, detectores e blindagem de radiação [89-91]. 


\section{4.- MATERIAIS E MÉTODOS}

\subsection{Materiais}

4.1.1 Diodos semicondutores de Barreira de Superfície (SSBD - Silicon Surface Barrier Detector).

Foram avaliados três tipos de semicondutores: Detectores de Barreira de Superfície ORTEC, Detector TMF-1 de Barreira de Superfície (IPEN) e Fotodiodos PIN HAMAMATSU.

\subsubsection{Detectores Barreira de Superfície da ORTEC.}

Dois detectores do tipo BA-040-200-300, fabricados pela ORTEC, foram avaliados, um deles está revestido com uma fina camada de ouro e o outro revestido de alumínio, ambos os detectores apresentam (conforme o fabricante) uma resolução ou largura a meia altura, do inglês "Full Width at Half Maximum” (FWHM), de $40 \mathrm{keV}$ e uma espessura ativa, quando totalmente expandida, de $300 \mu \mathrm{m}$. Os detectores possuem área ativa de $200 \mathrm{~mm}^{2}$, resistividade total de $8700 \Omega$.cm e especificação de polarização reversa máxima de $50 \mathrm{~V}$.

\subsubsection{Detector de silício TMF-1 de Barreira de superfície.}

Este detector de Barreira de Superfície foi fabricado no IPEN utilizando "wafers" (Topsil), com resistividade de $50 \mathrm{k} \Omega . \mathrm{cm}$, diâmetro de $2,54 \mathrm{~cm}$ e área total de $5 \mathrm{~cm}^{2} \mathrm{com} 1 \mathrm{~mm}$ de espessura, de acordo com a técnica desenvolvida por TAKAMI et al [93].

Aproximadamente $3,14 \mathrm{~cm}^{2}$ da superfície sensível foi coberta com $80 \mu \mathrm{g} . \mathrm{cm}^{2}$ de ouro e a outra face com $40 \mu \mathrm{g} . \mathrm{cm}^{2}$ de alumínio para formar um eletrodo ôhmico por meio da técnica de deposição a vácuo. Este tipo de arranjo do TMF-1 apresenta uma camada de depleção de $420 \mu \mathrm{m}$ a $40 \mathrm{~V}$ de polarização reversa e capacidade especifica de $70 \mathrm{pF}$ [25].

\subsubsection{Fotodiodos PIN da HAMAMATSU.}

O outro sensor utilizado foi o fotodiodo PIN S3590-04 fabricado pela HAMAMATSU, é um fotodiodo do tipo "sem janela" (windowless), com área sensível de 10x10 mm, apresenta uma camada de depleção máxima para tensões reversas acima de $35 \mathrm{~V}$. A capacitância deste detector é de aproximadamente 70 pf e sua corrente de penumbra é menor que 1,5 nA para uma polarização de $40 \mathrm{~V}$ [94]. 
Também foram utilizados nas experiências os componentes semicondutores (Fotodiodos PIN) S1223-01 e o S1336-18BU (ambos fabricados pela HAMAMATSU) para comparação com o S3590-04. A Figura 8 mostra os três tipos de detectores de barreira de superfície e a Figura 9 o detector TMF-1 junto com o fotodiodo S3590-04 e a fonte de ${ }^{241}$ Am.

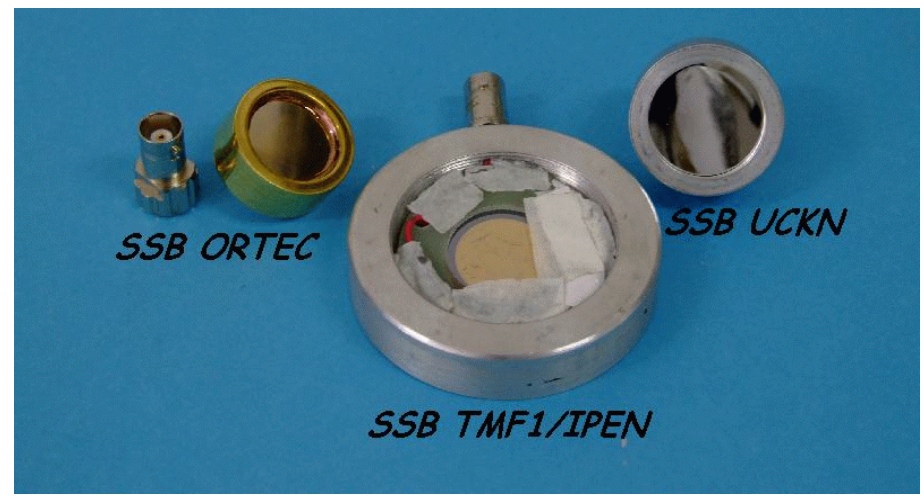

Figura 8: Detectores de Barreira de Superfície produzidos pela ORTEC e IPEN.

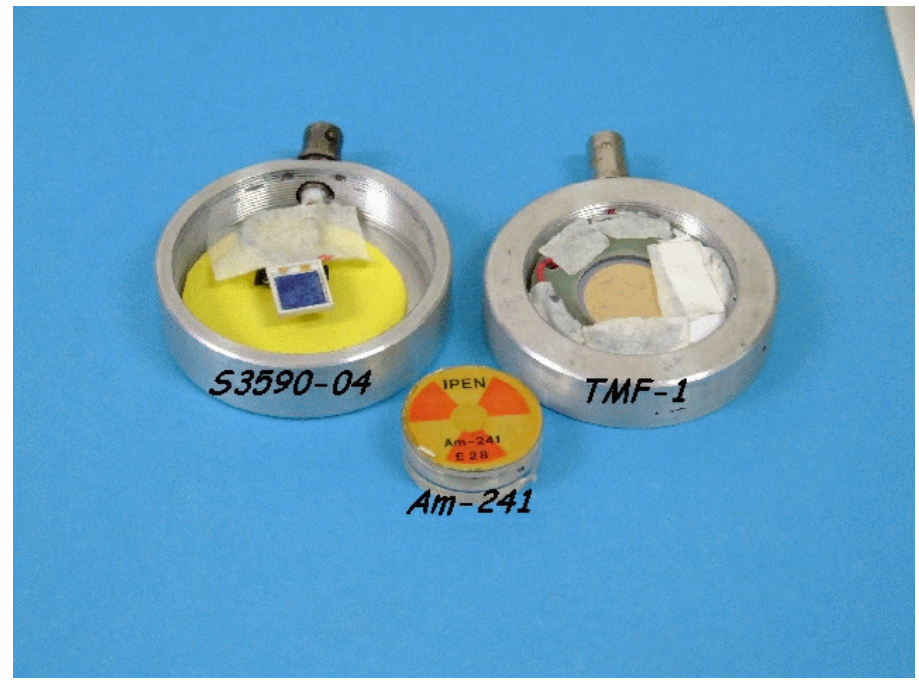

Figura 9: Fotodiodo HAMAMATSU S3590-04(A), detector IPEN TMF-1 e a fonte $\mathrm{de}^{241} \mathrm{Am}$.

Todos os componentes (SSB e Fotodiodos) foram testados com tensão de 0, 5, 15, 24, 40, 50 e $60 \mathrm{~V}$, conforme a especificação do fabricante. O melhor desempenho foi alcançado com o detector S3590-04 com polarização reversa de $15 \mathrm{~V}$ para o caso da fonte de AmBe. 
Na Tabela 4 é apresentado um resumo das principais características dos diodos usados.

Tabela 4: Características básicas dos detectores e fotodiodos utilizados nas experiências.

\begin{tabular}{|c|c|c|c|c|}
\hline Detector & $\begin{array}{c}\text { Voltagem (Bias) } \\
(\text { Volts })\end{array}$ & $\begin{array}{c}\text { Depleção } \\
(\mathbf{m m})\end{array}$ & $\begin{array}{c}\text { Área sensível } \\
\mathbf{( c m}^{\mathbf{2}}\end{array}$ & $\begin{array}{c}\text { FWHM } \\
(\mathbf{k e V})\end{array}$ \\
\hline TMF-1 & 60 & 0,450 & 3,14 & n.a. \\
\hline S3590-04 & 100 & 0,300 & 0,85 & $8,0(\mathrm{FM})^{*}$ \\
\hline S1223-01 & 30 & $0,008(\mathrm{a} 0,0 \mathrm{~V})$ & 0,13 & $8,0(\mathrm{FM})^{*}$ \\
\hline S1336-18BR & 5 & 0,200 & 0,012 & $8,0(\mathrm{FM})^{*}$ \\
\hline ORTEC (D) & 100 & 0,300 & 5,50 & $40($ ORTEC) \\
\hline ORTEC (Pr) & 100 & 0,300 & 5,50 & 40 (ORTEC) \\
\hline
\end{tabular}

* $\mathrm{FM}=$ fonte mista, $\mathrm{D}=$ Dourado, $\mathrm{Pr}=$ Prateado

\subsubsection{Componentes moderadores}

O processo de redução de energia de um nêutron para a região térmica é conhecido como termalização ou moderação.

Existe um número de possíveis reações nucleares que podem ocorrer quando um nêutron colide com um núcleo. $\mathrm{O}$ espalhamento e a captura radioativa são as duas classes possíveis de reação, sendo o espalhamento a mais importante.

Moderadores são materiais que reduzem a velocidade dos nêutrons em um pequeno número de colisões e possuem uma baixa probabilidade de absorção. Um material moderador ideal deve possuir [95]:

- Grande seção de choque de espalhamento

- Pequena seção de choque de absorção

- Grande perda de energia por colisão

\subsubsection{Componentes conversores}

Neste projeto foram utilizados três tipos de conversores de nêutrons: conversores de boro, de polietileno e polietileno borado. 


\subsubsection{Conversor de Boro.}

Este conversor foi usado para detecção de nêutrons térmicos, é composto de uma lâmina de alumínio coberta por uma camada de Boro (densidade de $1,54 \mathrm{mg} \cdot \mathrm{cm}^{-3}$ ). $\mathrm{O}{ }^{10} \mathrm{~B}$ apresenta uma seção de choque para nêutrons térmicos maior que para os nêutrons rápidos. Para determinar a espessura mais eficiente do ${ }^{10} \mathrm{~B}(90,1 \%$ de enriquecimento e $91 \%$ de pureza), como conversor (n, $\alpha$ ), foram utilizadas diferentes lâminas (alumínio de 0,5 mm) revestidas com Boro na face sensível do detector, com valores de 0,5 até $2 \mu \mathrm{g} . \mathrm{cm}^{-2}$ [61].

\subsubsection{Conversor de Polietileno.}

Este conversor foi usado para a detecção de nêutrons rápidos, é composto de um filme de polietileno (densidade de 1,08 g. $\mathrm{cm}^{3}$ ) com espessuras de 0,12 até $2 \mathrm{~mm}$. Ele foi utilizado como um gerador de prótons de recuo quando da incidência direta dos nêutrons da fonte de AmBe sem qualquer moderação preliminar [63].

\subsubsection{Conversor de Polietileno-Borado.}

Este tipo de conversor foi usado para a detecção de nêutrons térmicos e rápidos, é composto de uma tela confeccionada a base de boro natural fabricada pela Kodak-Pathé (França). Na sua fabricação, uma quantidade de boro $(65 \mu \mathrm{m})$ em pó (pureza 99,9\%) é misturada a um aglutinante orgânico (gel ou cola) e ambos são depositados em uma base plástica $(105 \mu \mathrm{m})$. Este conjunto passa por um processo de prensagem a quente, resultando em uma superfície homogênea de coloração marrom. Nesta condição, o ${ }^{10} \mathrm{~B}\left(0,9\right.$ g.cm $\left.{ }^{-3}\right)$ permanece aderido a esta superfície [96].

\subsubsection{Emissores alfa utilizados para calibração em energia.}

\subsubsection{Fontes de calibração.}

As fontes de calibração são necessárias para a calibração em energia do Canal de Aquisição de Dados (módulo preamplificador, amplificador, processador, placa de aquisição, inserida no computador (PC) e software Maestro). Neste trabalho foram utilizadas as fontes de ${ }^{241} \mathrm{Am}$ e mista de três nuclídeos $\left({ }^{239} \mathrm{Pu}+{ }^{241} \mathrm{Am}+{ }^{244} \mathrm{Cm}\right)$.

\subsection{Fonte de ${ }^{241} \mathrm{Am}$.}

É uma fonte de baixa atividade (fabricada no IPEN) utilizada normalmente para verificação e calibração do pico de energia do ${ }^{241} \mathrm{Am}$ em $5.486 \mathrm{keV}$ do sistema de 
espectroscopia alfa. Para esse projeto de avaliação sua atividade é suficiente devido à sensibilidade própria dos componentes semicondutores utilizados.

4.1.4.1.2 Fonte de nuclídeos mista de Plutônio, Amerício e Curium $\left({ }^{239} \mathrm{Pu}+{ }^{241} \mathrm{Am}+{ }^{244} \mathrm{Cm}\right)$.

É uma fonte produzida pela AMERSHAM, de ${ }^{239} \mathrm{Pu},{ }^{241} \mathrm{Am} \mathrm{e}{ }^{244} \mathrm{Cm}$ usada para a calibração em energia utilizando três isótopos com energias conhecidas para obter a curva de energia versus contagens. Esta fonte possui uma atividade de $5,5 \mathrm{kBq}(150 \mathrm{nCi})$.

\subsubsection{Módulos preamplificadores sensíveis à carga (PSC).}

Foram utilizados dois tipos de preamplificadores sensíveis à carga: o modelo 9101 produzido pela SOSHIN e o preamplificador ORTEC 142AH.

\subsubsection{Módulo preamplificador Sensível à Carga da SOSHIN INC., (PSC-9101).}

Este módulo é constituído de duas partes:

a) um circuito eletrônico CS9101, montado com tecnologia SMD (Surface Mounting Device) com um revestimento de cerâmica e

b) Resistor de $100 \mathrm{M} \Omega$ com o objetivo de limitar a corrente de polarização reversa do detector, conectado na entrada do preamplificador SOSHIN 9101, com uma tensão variável de 0 até $40 \mathrm{~V}$ (Figura 10).

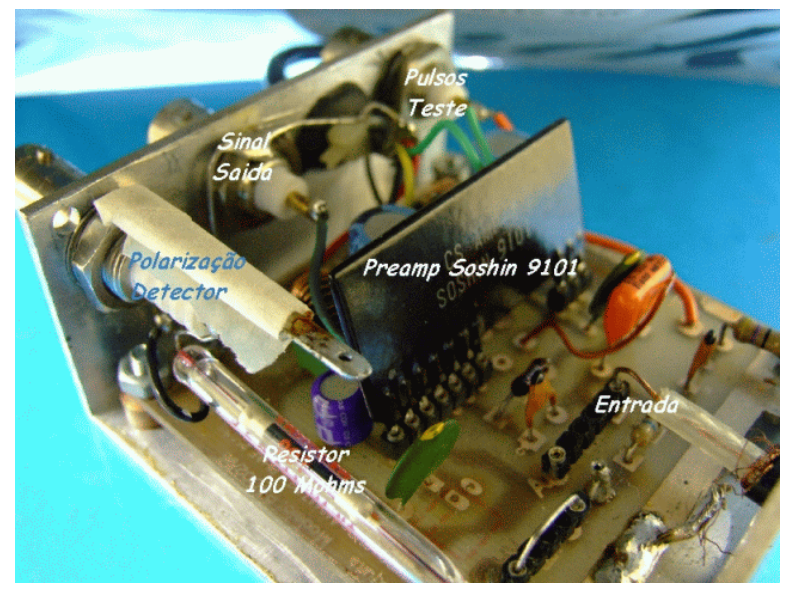

Figura 10: Preamplificador sensível à carga SOSHIN 9101.

\subsubsection{Módulo preamplificador sensível à carga ORTEC 142AH.}

É um preamplificador padrão para desenvolvimento de experiências em espectroscopia alfa e campos mistos nêutrons-gama, é constituído de: 
a) circuito amplificador sensível à carga com tecnologia discreta (transistores e CI’s) e

b) resistor de $300 \mathrm{M} \Omega$ para limitar a corrente de polarização reversa do detector, ligado ao conector correspondente (HV) do módulo (Figura 11).

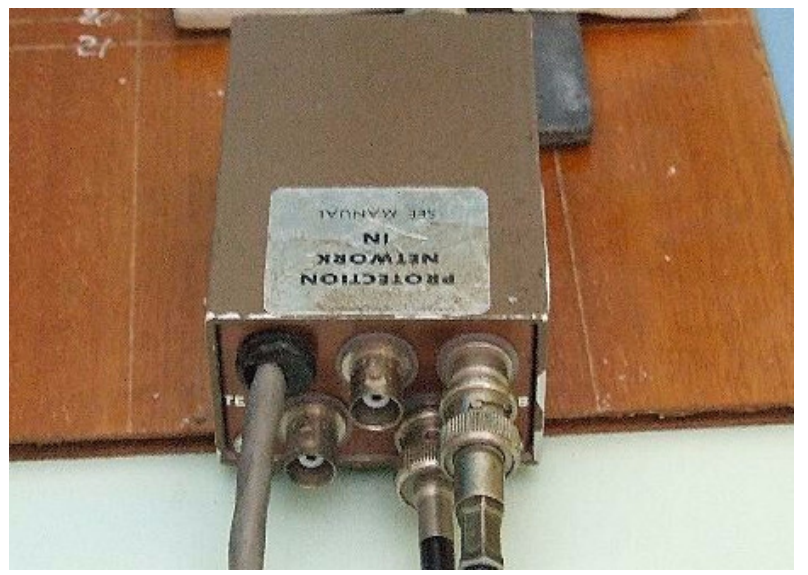

Figura 11: Preamplificador ORTEC 142AH e conectores utilizados.

4.1.6 Eletrônica associada e sistema de aquisição de dados utilizados na avaliação dos semicondutores (Arranjo experimental).

Com o propósito de desenvolver os experimentos foi implementada uma configuração de instrumentos (Figura 12). Esta configuração foi utilizada para a detecção de:

a) nêutrons rápidos e térmicos (nêutrons rápidos termalizados) vindos da fonte de $\mathrm{AmBe}$ e do reator IPEN/MB-01 (núcleo - na ponte) e

b) nêutrons térmicos/epitérmicos da instalação para Neutrongrafia do reator IEA-R1 (BH8).

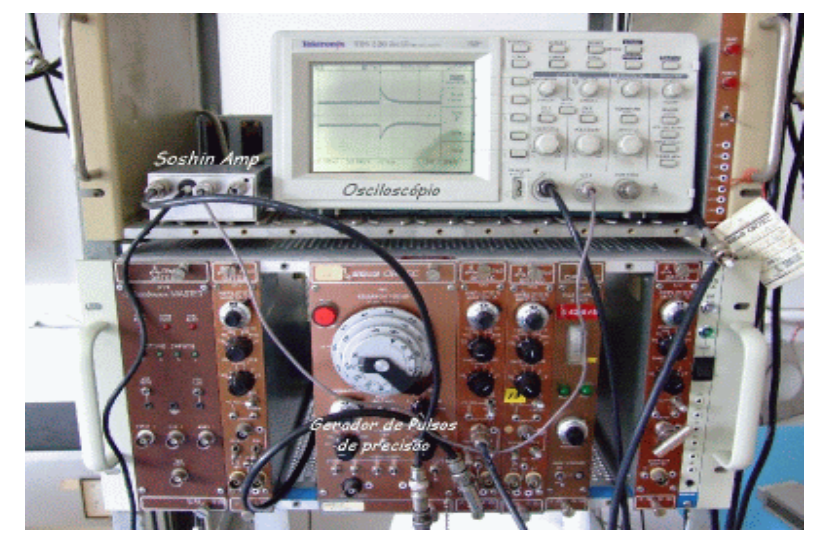

Figura 12: Configuração da instrumentação usada para os testes e medições. 
A instrumentação para a calibração e aquisição de dados foi definida implementando a configuração seguinte:

a) cada detector foi acoplado a um preamplificador sensível à carga (SOSHIN ou ORTEC),

b) fonte de tensão regulável HEWLETT PACKARD (HP6206B) para tensões de 0, 4, 15, 24, 40 e $60 \mathrm{~V}$,

c) a saída do preamplificador foi ligada, por meio de um cabo coaxial RG59B (75 $\Omega$ ), a um amplificador de espectroscopia ORTEC modelo 672 (ou o modelo 572),

d) a saída deste módulo foi conectada a um módulo Spectrum Master 919 da ORTEC para processamento digital do sinal analógico e este acoplado a um módulo DAC (conversor analógico-digital) interno a um PC, rodando um software Maestro Signal Analyzer (em ambiente Windows 3.11),

e) Osciloscópio TEKTRONIX modelo TDA220 para visualização do sinal de pulsos (amplitude, freqüência e período),

f) para a verificação do canal de aquisição (tensão versus energia) foi utilizado o módulo gerador de pulsos (Pulse Research 448) fabricado pela ORTEC.

Não foi utilizado qualquer tipo de câmara de vácuo para as experiências.

\subsubsection{Fontes de nêutrons.}

Neste trabalho foram utilizadas três tipos diferentes de fontes de nêutrons: fonte de AmBe, a instalação de neutrongrafia do reator IEA-R1 e a instalação do reator IPEN/MB-01.

\subsubsection{Fonte de AmBe-Bancada Experimental no Laboratório CENF.}

A fonte de nêutrons AmBe utilizada neste trabalho é do tipo polienergética de reação $(\alpha, n)$, com uma atividade nominal de 37 GBq (1 Ci) em Agosto de 1970 e taxa de emissão de $2,4.10^{6} \mathrm{n} \cdot \mathrm{s}^{-1}$ [25]. Para fins de corrigir a perda pelo decaimento radioativo a atividade foi calculada para a data das verificações finais das experiências (Junho de 2009) obtendo-se uma 
taxa de emissão de 2,07. $10^{6} \mathrm{n} \cdot \mathrm{s}^{-1}$. A Figura 13 ilustra o espectro típico de energia dos nêutrons emitidos, pesquisados por vários autores, de uma fonte de AmBe [97-99].

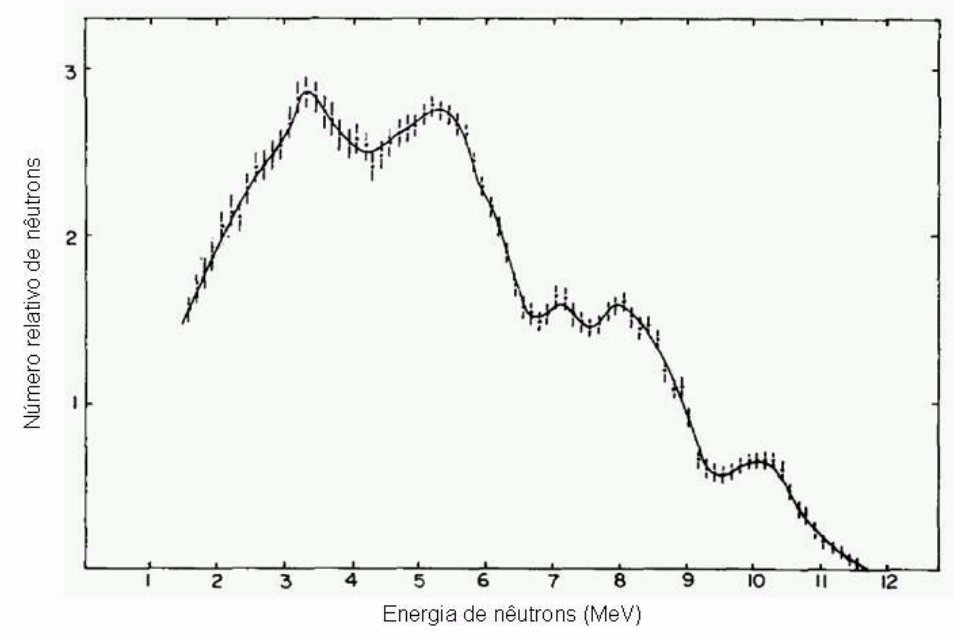

Figura 13: Exemplo do espectro da energia dos nêutrons emitidos por uma fonte de AmBe (adaptada de Thompson e Taylor) [97].

\subsubsection{Reatores nucleares de pesquisas.}

Os reatores nucleares são as fontes mais intensas de nêutrons. Sua operação baseia-se na reação de fissão nuclear que acontece em certos nuclídeos de alto número de massa atômica tais como o ${ }^{233} \mathrm{U},{ }^{235} \mathrm{U}$ ou ${ }^{239} \mathrm{Pu}$. Quando um núcleo fissionável absorve um nêutron, ele se parte em dois núcleos mais leves, emitindo de 2 a 3 nêutrons. Os nêutrons resultantes ficam disponíveis para continuar a reação se chocando como outros núcleos e assim por diante produzindo outras e outras reações de fissão, a conhecida reação em cadeia. Os reatores de pesquisas podem fornecer um fluxo de nêutrons de até $10^{14} \mathrm{n} \cdot \mathrm{cm}^{-2} \cdot \mathrm{s}^{-1}$. Além do seu grande campo de nêutrons, muitos reatores têm a vantagem de fornecer feixes utilizáveis de nêutrons térmicos com intensidades de $10^{6}$ até $10^{8} \mathrm{n} . \mathrm{cm}^{-2} \cdot \mathrm{s}^{-1}$, sendo isto muito útil para propósitos de moderação de nêutrons [95].

\subsection{Reator nuclear IEA-RI}

O reator IEA-R1 é um reator do tipo piscina projetado para uma potência térmica de 2 MW e modificado para operar a potência de até $5 \mathrm{MW}$ térmicos usando circulação forçada para resfriamento, podendo operar até 200 KW com circulação natural. Sua primeira 
criticalidade aconteceu em 16 de Setembro de 1957. O reator opera durante 64 horas ( $2^{\mathrm{a}}$ a $4^{\mathrm{a}}$ feira) contínuas por semana e 2 dias $\left(5^{\mathrm{a}}\right.$ e $6^{\mathrm{a}}$ feira $)$ dedicados à manutenção geral [100].

$\mathrm{O}$ reator possui 13 tubos de experimentação (BH-Beam Holes), sendo alguns deles mostrados na Figura 14, com a indicação de uso experimental: BH3 - Experimentos em técnicas de BNCT (Boron Nêutron Capture Therapy), BH8 - Experimentos em técnicas de Neutrongrafia e BH13 - Experimentos Reações Fotoelétricas.

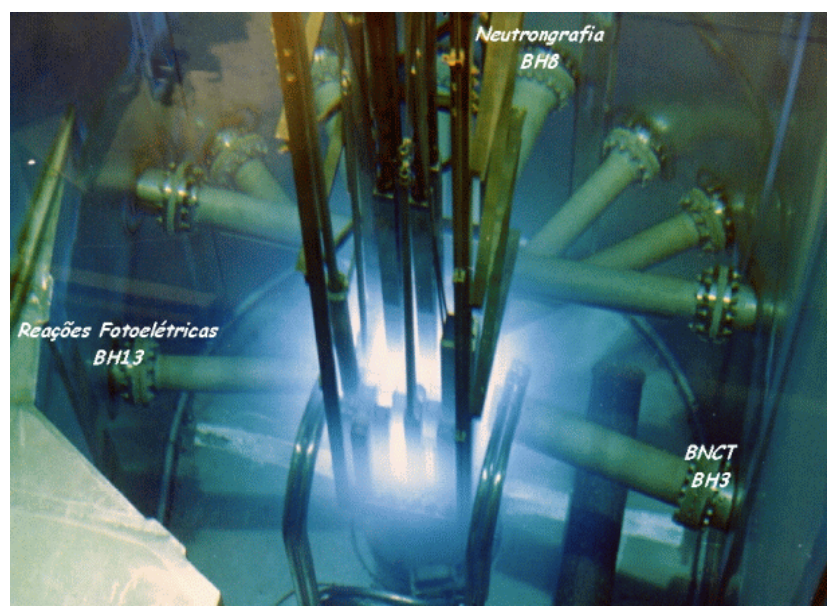

Figura 14: Núcleo do reator IEA-R1 com a indicação dos Tubos de Experimentação (BHs) para desenvolvimento de pesquisas em BNCT, Neutrongrafia e Gama.

\subsection{Instalação de Neutrongrafia, nêutrons térmicos e epitérmicos.}

O reator IEA-R1 é uma fonte de nêutrons, sendo seu fluxo de $3,5 \cdot 10^{13} \mathrm{n} . \mathrm{cm}^{-2} \cdot \mathrm{s}^{-1}$, aproximadamente, operando a uma potência de $2 \mathrm{MW}$. Este fluxo é muito alto para ser aplicado diretamente aos componentes semicondutores, pois causaria imediatamente danos por irradiação irreversíveis nos componentes.

Para medições de nêutrons térmicos/epitérmicos foi utilizada a instalação experimental de Neutrongrafia localizada no saguão de experimentação do reator. Esta instalação utiliza o tubo de experimentação (Beam Hole) BH8 (Figura 14) com o propósito de ser utilizada para experimentos de técnicas radiográficas com nêutrons [101]. A instalação possui um sistema de moderadores, filtros, colimadores e blindagens para se obter um espectro de nêutrons térmicos, epitérmicos e até frios a partir do fluxo no núcleo do reator [102].

O fator total de redução para o fluxo de nêutrons, devido à utilização dos filtros e colimadores, é de $2,5 \cdot 10^{-8}$, resultando em um fluxo aproximado de $2,1 \cdot 10^{6} \mathrm{n} \cdot \mathrm{cm}^{-2} \cdot \mathrm{s}^{-1}$ no lugar 
de irradiação, com uma taxa de dose equivalente de $24 \mathrm{mSv} \cdot \mathrm{h}^{-1}$ e $84 \mathrm{mSv} \cdot \mathrm{h}^{-1}$ para radiação gama e nêutrons respectivamente, para uma potência de operação de 3,5 MW. Existe também nesta instalação, na área de irradiação ao redor do BH, uma blindagem externa para requisitos de proteção radiológica [103]. A Figura 15 mostra a instalação de Neutrongrafia do reator IEA-R1.

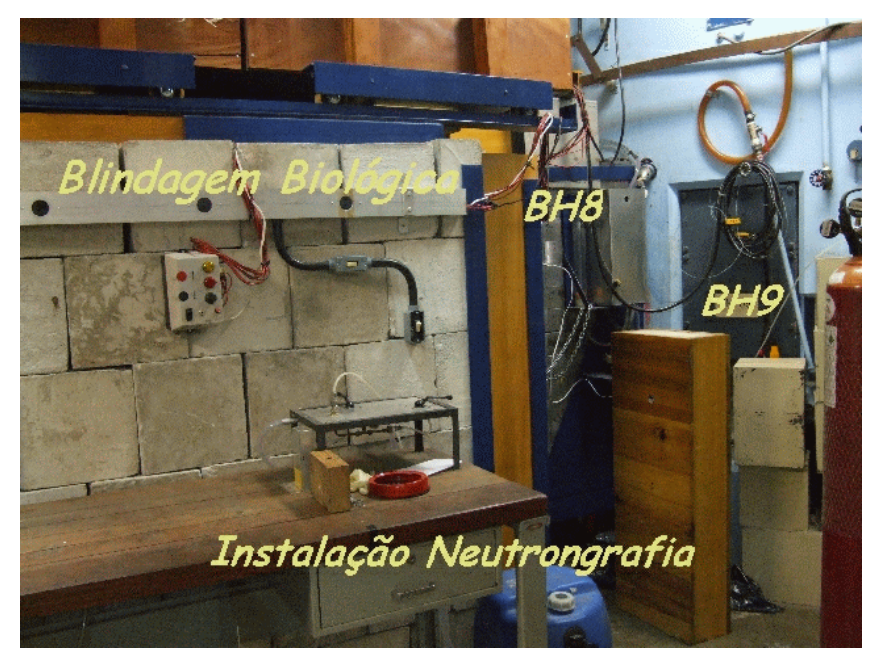

Figura 15: Instalação para Neutrongrafia (reator IEA-R1).

\subsection{Reator IPEN/MB-01 (Unidade Crítica)}

O reator IPEN/MB-01 é um reator nuclear de pesquisa projetado e construído por pesquisadores e engenheiros da instituição e outras firmas de engenharia nacionais com suporte financeiro da Marinha do Brasil. Sua primeira criticalidade aconteceu em 5 de Novembro de 1988.

Esta Unidade Critica (UCRI) é uma instalação que permite a simulação de todos os parâmetros nucleares de um reator nuclear de potência em escala sem a necessidade de construir complexos sistemas para a remoção de calor (por exemplo).

Este tipo de reator é conhecido como Reator de Potência Zero ou Unidade Crítica, sendo neste caso projetado para operar com uma potência máxima de 100 Watts térmicos [104]. A Figura 16 mostra o núcleo do reator e o arranjo de detectores nucleares para sua operação. 


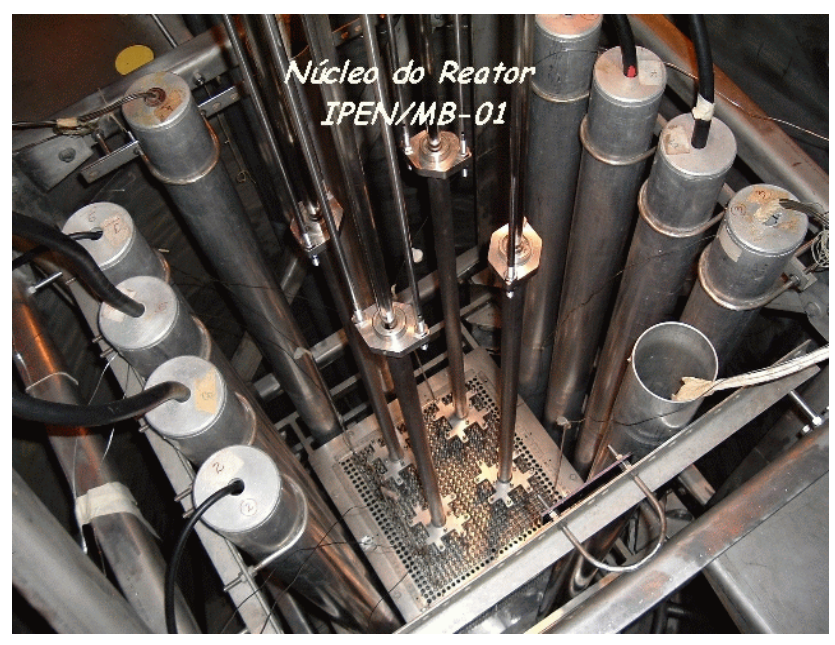

Figura 16: Núcleo do reator IPEN/MB-01 e os detectores nucleares para sua operação.

\subsection{Métodos}

Diversos tipos de semicondutores foram inicialmente testados, tais como transistores FETs, fototransistores, diodos de barreira de superfície e fotodiodos. No transcurso da parte experimental foi decidido desenvolvê-la apenas com diodos barreira de superfície e fotodiodos. Foram testados dois tipos de Preamplificadores de Carga e na finalização do projeto as medições se concentraram no componente (fotodiodo) S3590-04 HAMAMATSU e o preamplificador 142AH ORTEC.

\subsubsection{Método para testes preliminares de componentes (Laboratório CENF).}

Três métodos foram utilizados para estes testes preliminares: teste de "Rise Time", testes dos preamplificadores para pulsos de entrada e testes comparativos dos detectores de barreira de superfície.

\subsubsection{Teste de "Rise Time” dos preamplificadores SOSHIN 9101 e ORTEC 142AH.}

Foram comparados os tempos de "Rise Time" para cada preamplificador. Este parâmetro "Rise Time" expressa o tempo de formação do sinal. Para isto. o detector TMF-1 foi conectado a cada preamplificador utilizando uma polarização reversa de $40 \mathrm{~V}$ e foi utilizada uma fonte de ${ }^{241} \mathrm{Am}$ para irradiar o detector. 


\subsubsection{Testes de preamplificadores sensíveis à carga (PSC)}

Foram realizados testes para medir a resposta de dois tipos de PSC para pulsos de entrada utilizando um gerador de pulsos de precisão (ORTEC - Pulse Research 448).

A Figura 17 mostra a bancada experimental utilizada para os testes preliminares.

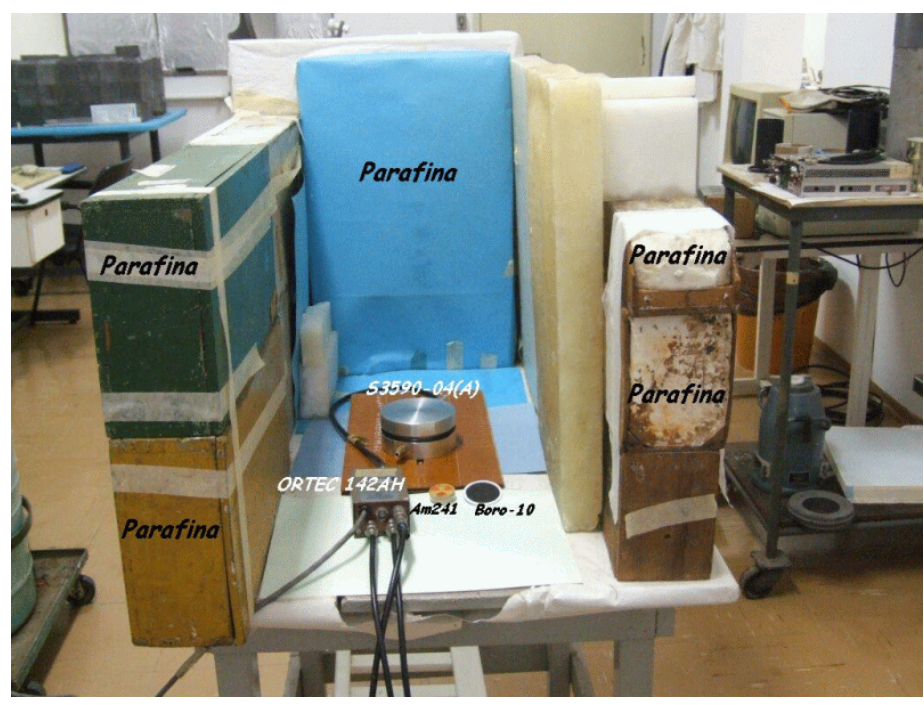

Figura 17: Bancada experimental e arranjo de proteção radiológica.

\subsection{Módulo Preamplificador SOSHIN 9101.}

Neste módulo aplicaram-se pulsos (sinal) na entrada de teste (Test Pulse) deste preamplificador, conforme indicado na Figura 10. Conforme o nível de tensão do pulso de entrada (no Multicanal) de 1 a 10 volts verificou-se a resposta (Contagens vs. Canal) no analisador multicanal AMC.

\subsection{Módulo Preamplificador ORTEC 142AH.}

No caso deste preamplificador, de forma idêntica ao SOSHIN 9101, foram aplicados pulsos na sua entrada. Para os dois casos a largura dos pulsos (shape-time) foi variada entre 1 e $10 \mu \mathrm{s}$. 


\subsection{Testes comparativos dos detectores tipo barreira de superfície (SSB-Silicon Surface}

Barrier).

Foram testados três tipos de detectores SSB: dois deles ORTEC, um com película de Au (modelo 040-200-300) e outro com uma película de prata-alumínio e um detector construído no IPEN modelo TMF-1. A resposta de cada um deles foi verificada para uma fonte de ${ }^{241} \mathrm{Am}$ colocada a uma distância de 0,5 $\mathrm{mm}$ aproximadamente da face sensível de cada detector.

\subsubsection{Método de calibração do sistema para detecção e processamento.}

\subsubsection{Calibração utilizando fonte de ${ }^{241} \mathrm{Am}$.}

Utilizando uma fonte de ${ }^{241} \mathrm{Am}$ (fabricada no IPEN), os detectores foram testados com diversos valores de ganho e de forma de pulso (shape time), variando de 0,5 até $10 \mu$ s para se encontrar a melhor resposta e resolução (FWHM - Full Width Half Maximum) para os detectores. Optou-se por utilizar os valores de 2 e $6 \mu$ s, conforme o tipo de detector sendo utilizado [105].

Com o módulo gerador de pulsos (ORTEC 448 Pulser), é adicionado ao espectro obtido um sinal de pulsos com uma amplitude que coincida com o pico da maior contagem obtida no espectro, é marcado este canal como sendo o canal correspondente à energia principal da fonte de ${ }^{241} \mathrm{Am}$ e o módulo de aquisição (AMC), é calibrado por meio do software do AMC (Calibration) para a energia de $5486 \mathrm{keV}$.

Com o mesmo instrumento gerador de Pulsos (ORTEC 448), é feita uma varredura do AMC com pulsos de uma mesma contagem (freqüência), mas com nível de sinal de 0,5 até 10 V. Com este espectro de pulsos é obtida a reta de resposta para os canais versus a energia correspondente [106].

Utilizando este fator de conversão e assumindo os valores de energia correspondente a cada Canal de aquisição a curva de Canal versus Contagens é transformada para o espectro em energia versus contagens.

Esta calibração foi necessária, pois nas experiências preliminares somente procuravase visualizar a resposta dos componentes semicondutores sob radiação de partículas carregadas, alfa e prótons. 


\subsubsection{Calibração utilizando fonte mista $\left({ }^{239} \mathrm{Pu},{ }^{241} \mathrm{Am} e^{244} \mathrm{Cm}\right)$.}

Este tipo de fonte é o padrão utilizado normalmente para calibração em energia de sistemas de espectrometria para partículas carregadas. É uma fonte com atividade de $5,55 \mathrm{KBq}(150 \mathrm{nCi})$ fabricada pela HAMERSHAM colocada junto ao detector a uma distância de 0,5 mm, logo acima da área real dos detectores [107]. Não foi utilizado qualquer tipo de colimação. Uma vez verificado e estabelecido o padrão de calibração foram repetidas as medições para nêutrons rápidos e térmicos no Laboratório CENF utilizando a fonte de AmBe especificada anteriormente para obter os espectros de nêutrons (térmicos e rápidos).

\subsection{Método de detecção de nêutrons térmicos}

Para a detecção de nêutrons térmicos foi utilizado o conversor de ${ }^{10} \mathrm{~B}$ descrito anteriormente em 4.1.3.1. Este conversor foi colocado na face frontal do detector TMF-1 e do fotodiodo S3590-04 logo acima da área sensível do detector a uma distância de 0,5 mm aproximadamente. Para a aquisição dos dados foram utilizados os instrumentos definidos em 4.1.6 e o detector polarizado com tensão reversa de 0 a $40 \mathrm{~V}$.

No caso da fonte de AmBe, esta foi colocada a uma distância de $30 \mathrm{~mm}$ do conversor

de ${ }^{10} \mathrm{~B}$. Na instalação de Neutrongrafia cada elemento detector, junto com o respectivo conversor, foi colocado a uma distância de $500 \mathrm{~mm}$ do ponto de saída do feixe térmicoepitérmico.

\subsection{Método de detecção de nêutrons rápidos}

Para a detecção de nêutrons rápidos foi utilizado um conversor de polietileno, descrito anteriormente em 4.1.3.2 desempenhando-se como um gerador de prótons, sendo colocado da mesma forma da seção anterior. Para as medições com fonte AmBe e na instalação de Neutrongrafia seguiu-se o método da seção anterior. Para o caso da UCRI os elementos detectores e seus respectivos conversores foram colocados a uma distância de $360 \mathrm{~mm}$ do centro do núcleo. A aquisição dos dados e a polarização reversa foram realizadas como na seção anterior. 
4.5 Método de simulação por Monte Carlo para definir o fluxo de nêutrons emergentes do moderador a parafina.

Utilizando o método de Monte Carlo foi simulado o esquema da fonte de nêutrons AmBe, sendo utilizado $70 \mathrm{~mm}$ de parafina, para obter o fluxo de nêutrons térmicos por segundo na posição do detector (dentro do invólucro). Não foi considerada a lâmina conversora de Boro. Na Tabela 5 são apresentados os resultados para os nêutrons térmicos e a Tabela 6 mostra os resultados para o fluxo incidente (nêutrons rápidos sem moderação) a uma distância fonte-detector de $30 \mathrm{~mm}$ [108].

Tabela 5: Resumo do cálculo da energia e fluxo incidentes na superfície ativa do detector.

\begin{tabular}{|c|c|c|}
\hline Nêutrons & Energia $(\mathbf{M e V})$ & Fluxo $\left(\mathbf{n . c m}^{-2} \cdot \mathbf{s}^{-1}\right)$ \\
\hline Térmicos & $\mathrm{E}<6,2510^{-7}$ & $4,2210^{2}$ \\
\hline Epitérmicos & $6,2510^{-7}<\mathrm{E}<1,0$ & $9,9410^{2}$ \\
\hline Rápidos & $1,0<\mathrm{E}<15,0$ & $1,3810^{3}$ \\
\hline Total & & $2,79610^{3}$ \\
\hline
\end{tabular}

Tabela 6: Resumo do cálculo da energia e fluxo incidentes na superfície ativa do detector sem qualquer moderação a uma distância fonte-detector de $30 \mathrm{~mm}$.

\begin{tabular}{|c|c|c|}
\hline Nêutrons & Energia $(\mathbf{M e V})$ & Fluxo $\left(\mathbf{n} \cdot \mathbf{c m}^{-\mathbf{2}} \cdot \mathbf{s}^{\mathbf{- 1}}\right)$ \\
\hline Epitérmicos & $\mathrm{E}<1,0$ & $2,3110^{3}$ \\
\hline Rápidos & $1,0<\mathrm{E}<15,0$ & $1,0510^{4}$ \\
\hline Total & & $1,2810^{4}$ \\
\hline
\end{tabular}

O ponto máximo de $70 \mathrm{~mm}$ foi considerado como a espessura ótima, obtido experimentalmente também conforme trabalho desenvolvido em similares circunstâncias [25].

No APÊNDICE A (página 106) é mostrado o esquema de modelação utilizado para o uso do código Monte Carlo (MCNP). 
4.6 Método para a determinação da espessura otimizada da película (ou lâmina) de polietileno.

A espessura ideal da fôlha de polietileno (densidade de $1,08 \mathrm{~g} . \mathrm{cm}^{-3}$ ) foi implementada em trabalho anterior por meio do desenvolvimento do modelo matemático seguinte:

$$
R(c p s)=\varepsilon_{p} \cdot N_{0} \cdot\left(1-e^{-\Sigma . X}\right) \cdot e^{\mu_{.} X}+\varepsilon_{n} \cdot N_{0} \cdot e^{\Sigma . X}
$$

Onde $R$ (cps) é a resposta (contagens por segundos), $X$ a espessura da folha de polietileno, $\varepsilon_{p}$ é a eficiência de detecção de prótons, $N_{0}$ é taxa de emissão de nêutrons da fonte $\mathrm{AmBe}$, determinada pelo método de ativação de folhas ou por simulação usando o código de Monte Carlo, $\Sigma$ é a seção de choque macroscópica média aos nêutrons incidentes no conversor e $\mu$ é o coeficiente de absorção de prótons no polietileno [25]. 


\section{5. - MEDIÇÕES EXPERIMENTAIS}

5.1 Médições de nêutrons térmicos utilizando conversor de ${ }^{10} B$.

As experiências foram realizadas no Laboratório CENF utilizando uma fonte de AmBe instalada em uma bancada experimental. Requisitos de radioproteção foram atendidos e implementados para trabalhar com este tipo de fonte por meio de uma blindagem biológica, composta de uma estrutura de blocos de $10 \mathrm{~cm}$ de parafina (formato em $\mathrm{U}$ ). Medições dosimétricas para esta fonte resultaram em uma taxa de dose equivalente de $850 \mu \mathrm{Sv}_{\mathrm{h}} \mathrm{h}^{-1}$ e 20 $\mu S v \cdot h^{-1}$ para nêutrons e para radiação gama respectivamente a uma distância de $50 \mathrm{~mm}$. Para uma distância de $1000 \mathrm{~mm}$ os valores foram de $50 \mu \mathrm{Sv} \cdot \mathrm{h}^{-1}$ e $4 \mu \mathrm{Sv}^{\mathrm{h}} \mathrm{h}^{-1}$ para nêutrons e radiação gama respectivamente. As medições foram realizadas com um "Survey Meter" fabricado pela LUDLUM MEASUREMENTS Modelo 2363.

O fluxo de nêutrons desta fonte foi moderado (termalizado) por meio de um bloco de parafina de $70 \mathrm{~mm}$ de espessura e área de $100 \mathrm{~cm}^{2}$. O fluxo resultante foi aplicado a um conversor de ${ }^{10} \mathrm{~B}$ e as partículas carregadas resultantes, junto com a radiação gama, foram detectadas pelos semicondutores utilizados. A Figura 18 mostra o esquema de medição usado.

Além dos nêutrons térmicos quando da moderação (parafina), existe também uma geração de radiação gama, produto das interações dos nêutrons com o material hidrogenado da parafina. Para discriminar este sinal é necessário blindar o detector contra a radiação dos nêutrons térmicos permitindo somente a passagem da radiação gama. Assim, a resposta do detector para o nível de radiação gama foi obtida cobrindo o detector por inteiro com uma lâmina de cádmio com uma espessura suficiente $(1 \mathrm{~mm})$ para bloquear os nêutrons térmicos.

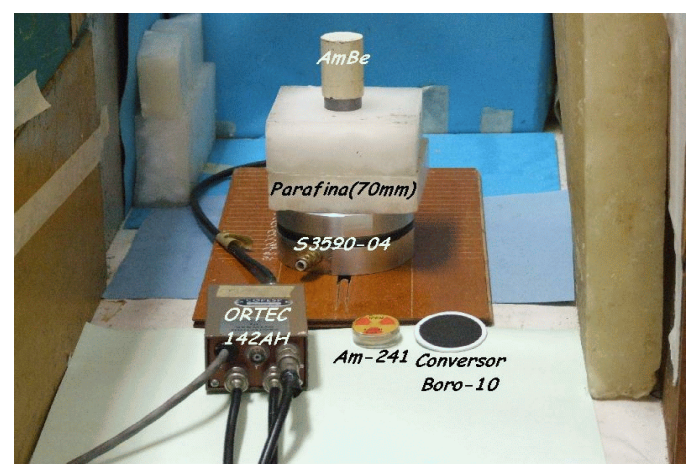

Figura 18: Arranjo experimental para a detecção de nêutrons térmicos. 


\subsection{Medição de nêutrons térmicos utilizando conversor de polietileno borado.}

Para as medições utilizando um conversor de polietileno borado produzido pela Kodak foi usada a mesma configuração e metodologia anterior.

\subsection{Medição de nêutrons rápidos usando polietileno.}

Neste caso não se utilizou qualquer tipo de moderação para a fonte de AmBe. A fonte foi posicionada diretamente sobre a tampa (centro) do invólucro do detector. A distância fonte-detector foi de $30 \mathrm{~mm}$ aproximadamente e este polarizado com $15 \mathrm{ou} 40 \mathrm{~V}$.

Para detectar estes nêutrons rápidos, a área (face) do semicondutor foi coberta por um filme de polietileno com espessuras que variaram de 0,12 a $1 \mathrm{~mm}$, sendo o detector polarizado da mesma forma anterior. A Figura 19 mostra a configuração para este tipo de detecção.

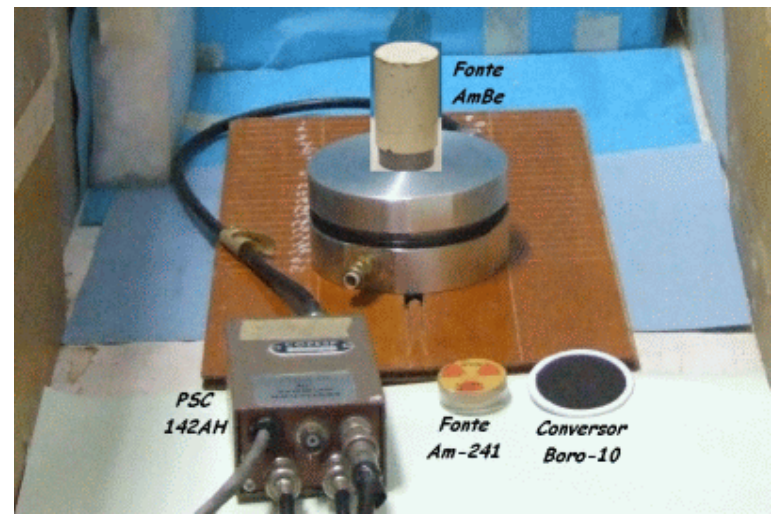

Figura 19: Arranjo experimental (configuração) para medições de nêutrons rápidos.

5.4 Medições na instalação de Neutrongrafia - Detecção de nêutrons térmicos e epitérmicos.

As experiências foram realizadas com o reator operando em 2 MW (teste preliminar com o TMF-1 e o S3590-04(A) e conversor de polietileno de 0,12 $\mathrm{mm}$ de espessura) e com o reator em 3,5 MW (com o S3590-04(B) utilizando conversor de ${ }^{10} \mathrm{~B}$ e polietileno de $1 \mathrm{~mm}$ de espessura).

A resposta do fotodiodo S3590-04(B) foi obtida seguindo a metodologia em 4.3 e 4.4 (página 57). No APÊNDICE B (página 108) são mostrados os valores de fluxo térmico e epitérmico obtido por meio do método de ativação de fôlhas. 
A Figura 20 mostra a configuração física deste experimento.

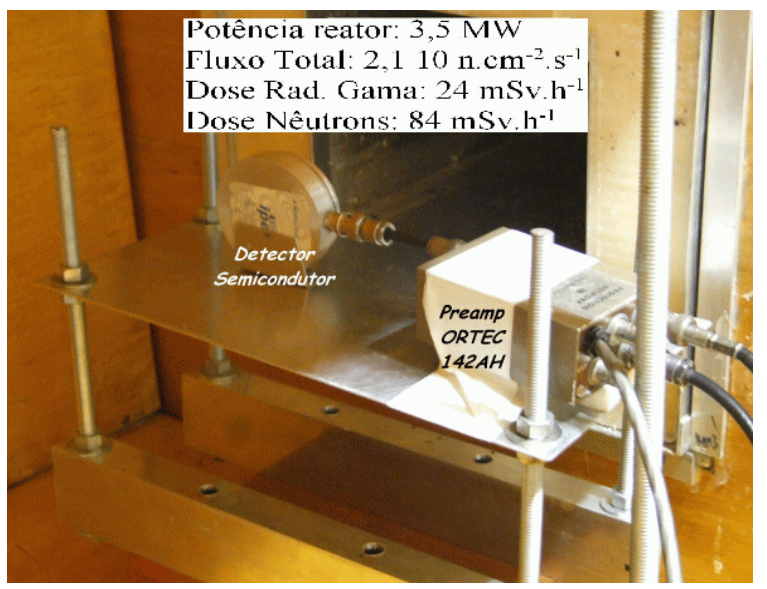

Figura 20: Configuração física do detector TMF-01 e preamplificador ORTEC 142AH para medições de nêutrons térmicos e epitérmicos.

5.5 Medições no núcleo do reator IPEN/MB-01 (UCRI) - Detecção de nêutrons rápidos.

As medições para estas experiências foram realizadas com o reator operando em potências de 1, 2, 4, 5 e 10 Watts e os detectores foram instalados a uma distância radial de $360 \mathrm{~mm}$ e a meia altura do núcleo do reator. A metodologia usada foi a mesma do item 4.1.3.2 usando como conversor uma fôlha de polietileno de $0,12 \mathrm{~mm}$ de espessura. A Figura 21 mostra o núcleo do reator e o arranjo do detector para as medições de nêutrons rápidos.

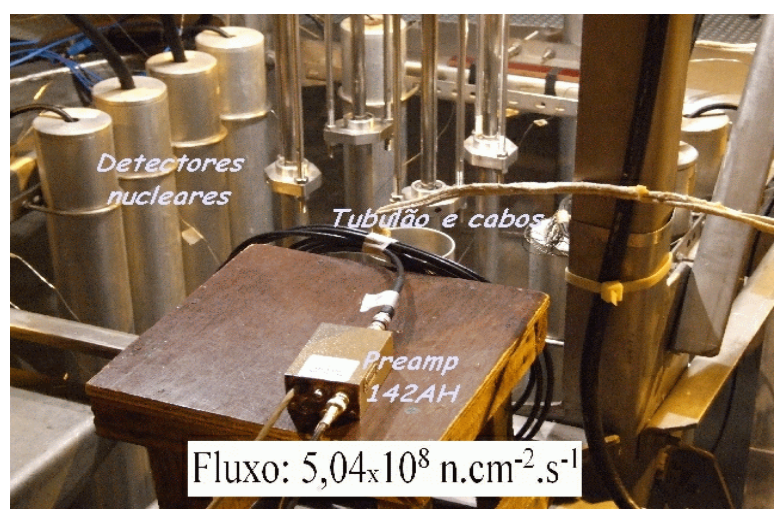

Figura 21: Núcleo do reator IPEN/MB-01 e o arranjo do detector para as medições. 
O fluxo de nêutrons incidentes foi estimado previamente utilizando a técnica de fôlhas de ativação, resultando em um fluxo de nêutrons térmicos (médio) de $5,04 \cdot 10^{8} \mathrm{n} \cdot \mathrm{cm}^{-2} \cdot \mathrm{s}^{-1}$ [104]. 


\section{6. - RESULTADOS E DISCUSSÕES}

\subsection{Teste de "Rise Time” dos preamplificadores SOSHIN 9101 e ORTEC 142.}

Para o estudo de fenômenos rápidos tais como os sinais devidos a radiações ionizantes é recomendável que os circuitos eletrônicos envolvidos na aquisição destes sinais possuam uma resposta rápida para a formação dos pulsos correspondentes. O parâmetro "Rise Time" caracteriza o intervalo de tempo que o sinal de pulso leva para ir de 10 a $90 \%$ da rampa de subida (sinais + ) ou descida (sinais - ).

Na Figura 22 é apresentada a resposta do preamplificador SOSHIN 9101 visualizada em osciloscópio (TEKTRONIX 220). O pulso de saída (CH1) deste preamplificador é de aproximadamente $65 \mathrm{mV}$ de altura (sinal flutuante) com largura de $75 \mu \mathrm{s}$.

O canal CH1 representa o sinal de saída do preamplificador SOSHIN 9101 e o canal CH2 é o sinal de saída do Amplificador 572 ORTEC.

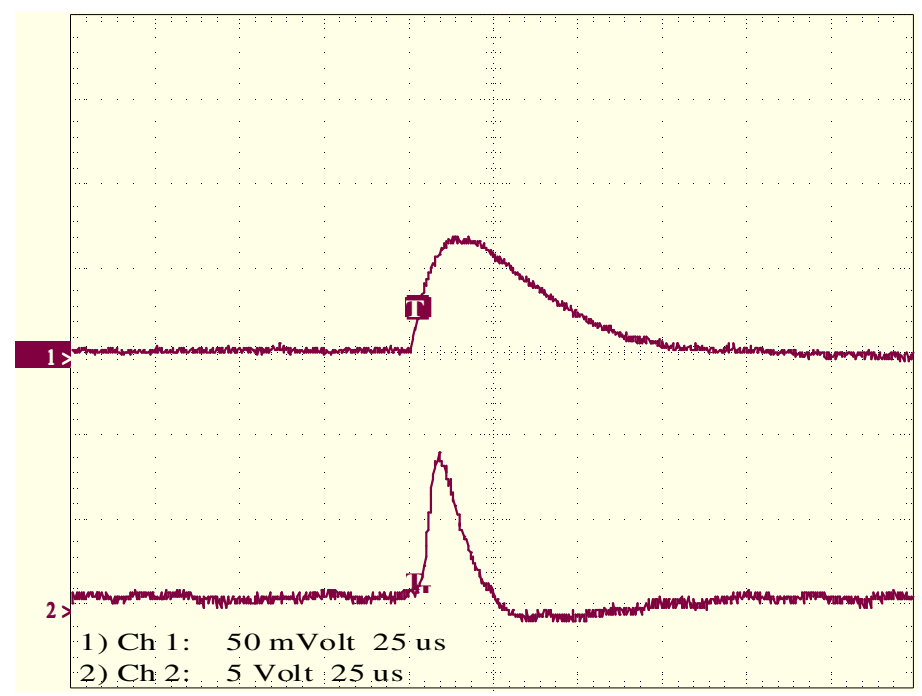

Figura 22: Resposta do preamplificador SOSHIN para tempos de "Rise Time" utilizando o detector TMF-1 a partículas alfa (fonte ${ }^{241} \mathrm{Am}$ ).

A Figura 23 mostra o sinal de saída do amplificador de espectroscopia ORTEC 572 (CH2), para o preamplificador ORTEC 142AH e o detector TMF-1. Este sinal corresponde a um pulso com 7,5 V aproximadamente e $25 \mu$ s de duração com "Rise Time" de $10 \mu$ s. 


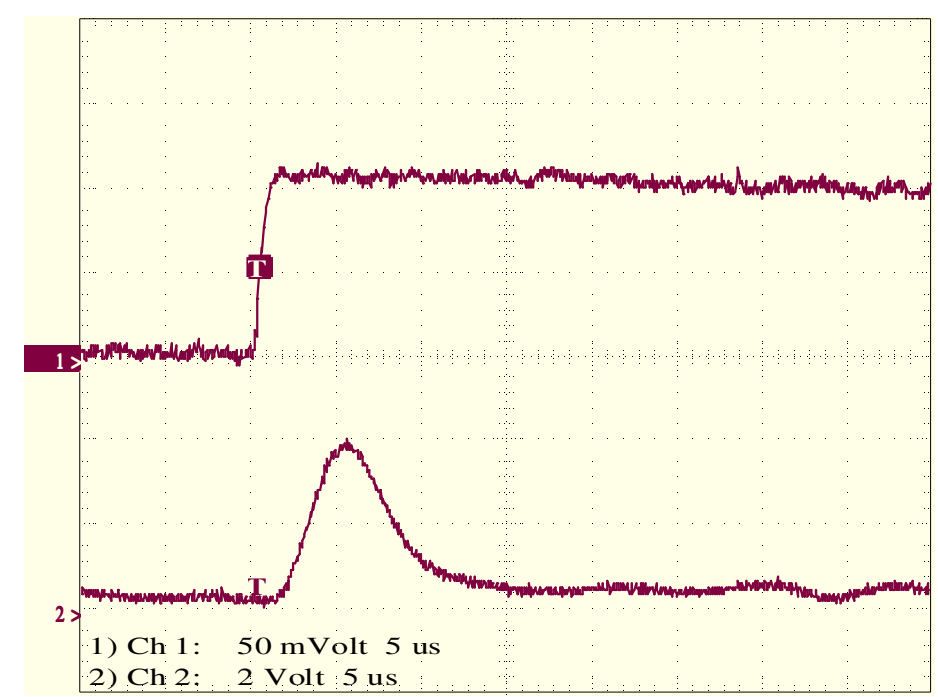

Figura 23: Resposta do preamplificador ORTEC 142AH para tempos de "Rise Time" utilizando o detector TMF-1 a partículas alfa (fonte ${ }^{241} \mathrm{Am}$ ).

O pulso de saída (CH1) do preamplificador ORTEC 142 é de uma largura de $500 \mu \mathrm{s}$ (embora não seja possível visualizar a largura devido a incompatibilidade da base tempo, comum para os dois canais do osciloscópio, para mostrar os dois sinais) e altura de $65 \mathrm{mV}$.

A saída do amplificador de espectroscopia ORTEC $572(\mathrm{CH} 2)$ mostra um pulso com 4 Volts aproximadamente e $20 \mu$ s de duração (Rise Time de $5 \mu$ s).

O canal CH1 (Figura 23) representa o sinal de saída do PSC ORTEC 142AH e o canal CH2 é o sinal de entrada para o analisador multicanal MCA (saída do amplificador 572 ORTEC). Na figura pode-se notar que o sinal de saída do PSC possui uma largura de pulso bem maior que a do sinal de entrada ao MCA sendo esta de $500 \mu$ s. Em ambos preamplificadores foi aplicada uma tensão de alimentação (reversa) de $24 \mathrm{~V}$ para o detector TMF1.

Para determinar a razão sinal-ruído e o "Rise Time” não foi considerada a influência do cabo coaxial de conexão entre o detector e o preamplificador o qual tem uma influência importante devido a que as impedâncias de entrada dos preamplificadores não são iguais introduzindo um erro no sinal entregue pelo detector. Como o intuito do trabalho é uma 
avaliação de componentes, não foi considerada uma análise mais especifica deste problema o qual deverá ser considerado em uma situação em que seja necessário caracterizar completamente um detector.

6.2 Detectores SSB TMF-1 e ORTEC com os preamplificadores 142AH e SOSHIN 9101.

Foi utilizada uma fonte de ${ }^{241} \mathrm{Am}$ para obter a resposta dos três sensores a partículas alfa. Cada um destes sensores foi ligado ao preamplificador ORTEC modelo 142AH, sendo eles colocados em cubículos que os isolam da luz, mas não foram usados em vácuo. Da mesma forma foram realizados os testes utilizando o preamplificador sensível à carga SOSHIN 9101.

A Figura 24 mostra a resposta do detector TMF-1 conectado ao preamplificador da ORTEC e a Figura 25 conectado ao preamplificador SOSHIN.

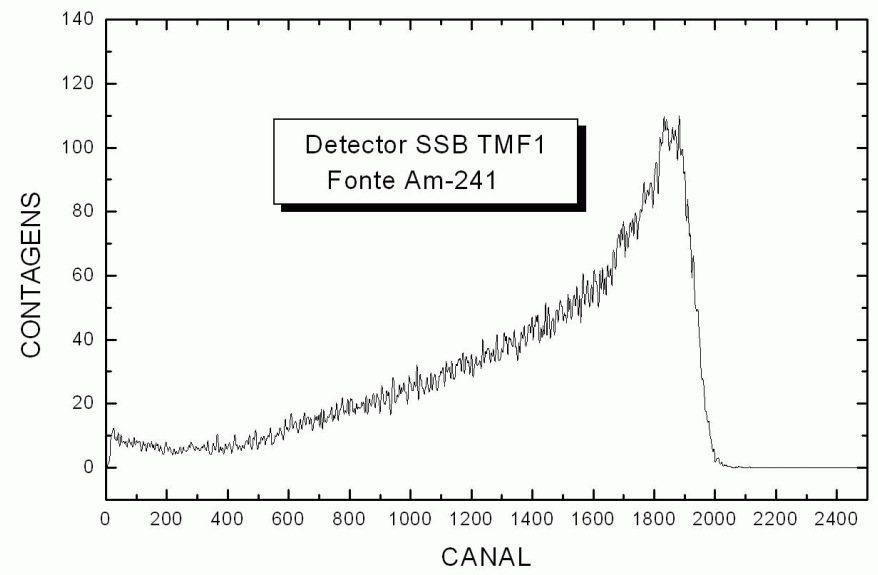

Figura 24: Resposta do detector TMF-1 conectado ao preamplificador ORTEC 142AH (fonte de ${ }^{241} \mathrm{Am}$ ). 


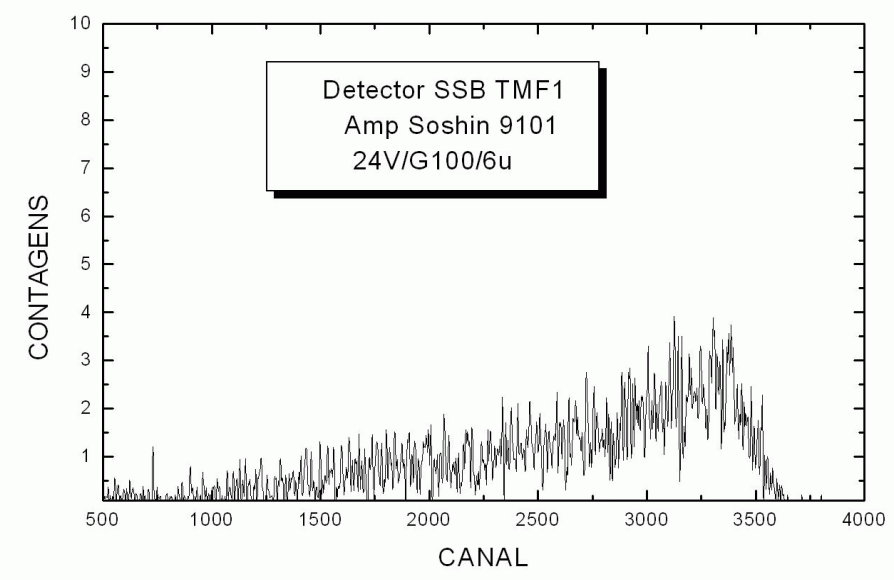

Figura 25: Resposta do detector TMF-1 conectado ao preamplificador SOSHIN 9101 (fonte de ${ }^{241} \mathrm{Am}$ ).

As Figuras 26 e 27 mostram a resposta dos detectores SSB da ORTEC com banho de ouro $(\mathrm{Au})$ e com banho de prata $(\mathrm{Ag})$ respectivamente, para uma fonte de ${ }^{241} \mathrm{Am}$ utilizando um preamplificador ORTEC 142 como condicionador do sinal vindo de cada detector.

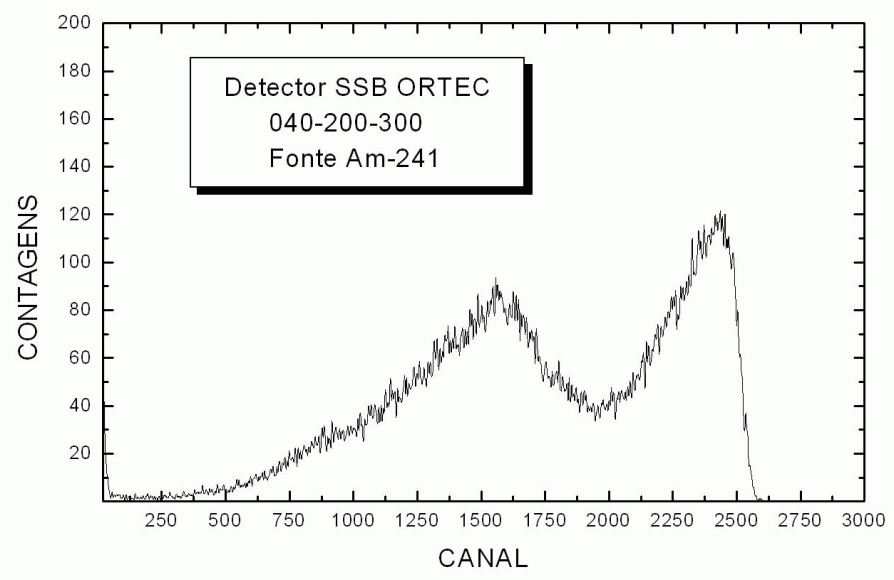

Figura 26: Resposta do detector SSB ORTEC (Au) conectado ao preamplificador ORTEC 142AH (fonte de $\left.{ }^{241} \mathrm{Am}\right)$. 


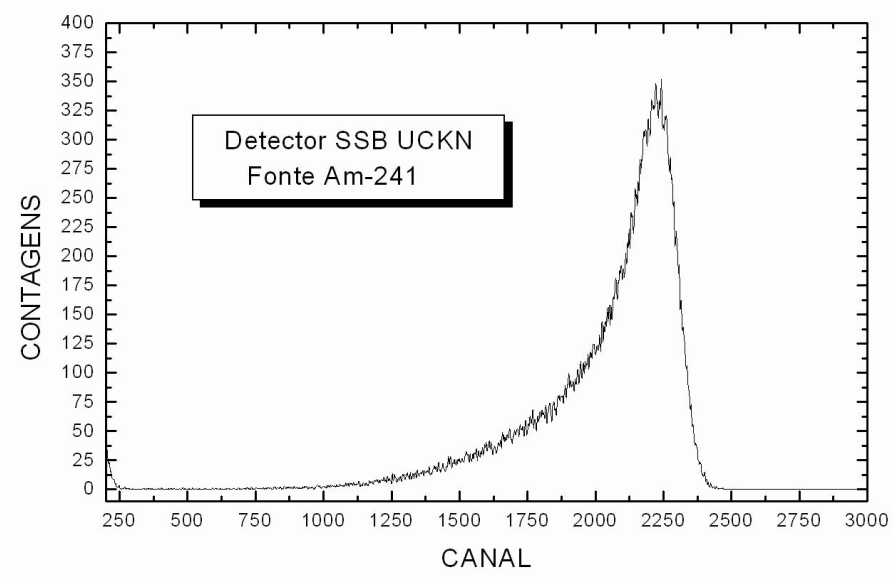

Figura 27: Resposta do detector SSB ORTEC (Ag) conectado ao preamplificador ORTEC 142AH (fonte de ${ }^{241} \mathrm{Am}$ ).

\subsection{Teste dos detectores SSB ORTEC com preamplificador SOSHIN 9101.}

Da mesma forma foram realizados os testes aos detectores SSB utilizando o preamplificador sensível à carga SOSHIN 9101. As Figuras 28 e 29 mostram a resposta de cada um dos sensores $(\mathrm{Au})$ e (Ag) utilizando amplificador SOSHIN.

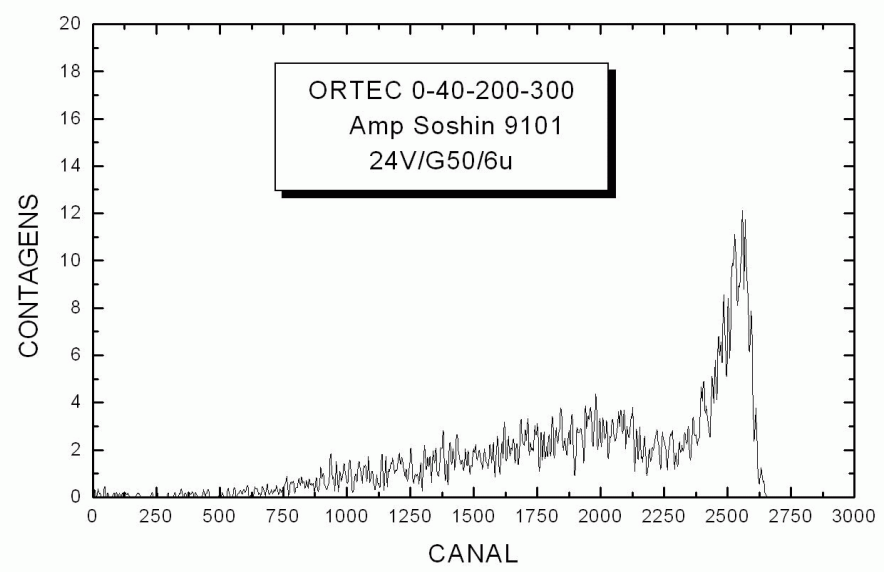

Figura 28: Resposta do detector ORTEC $(\mathrm{Au})$ conectado ao preamplificador SOSHIN 9101 (fonte de ${ }^{241} \mathrm{Am}$ ). 


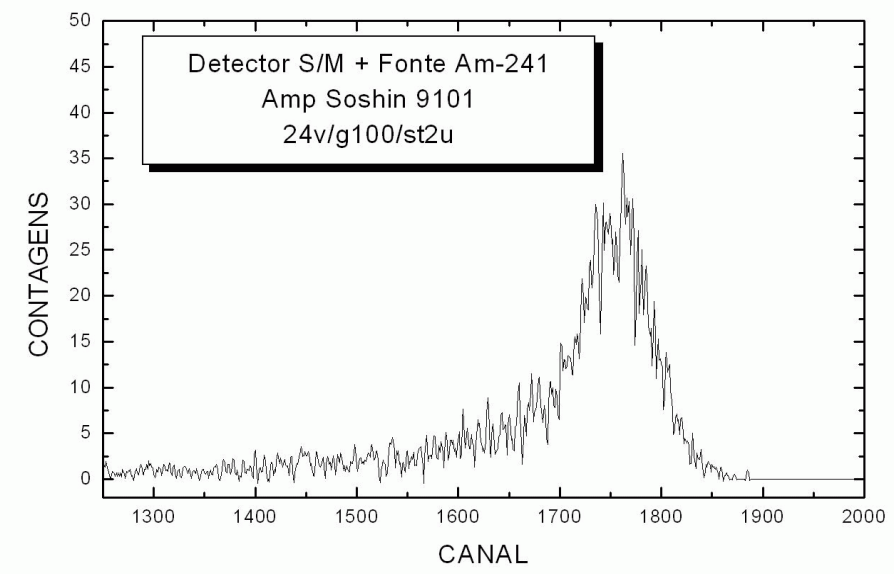

Figura 29: Resposta do detector ORTEC (Au) conectado ao preamplificador SOSHIN 9101 (fonte de ${ }^{241} \mathrm{Am}$ ).

Os gráficos das Figuras 24 a 29 mostram as respostas obtidas tanto para o teste de pulsos (preamplificadores) e a resposta dos três detectores de barreira de superfície. Nestas respostas pode-se notar o ruído excessivo envolvendo os sinais dos preamplificadores com destaque para o preamplificador SOSHIN.

De uma forma geral, o preamplificador SOSHIN mostrou um nível de ruído muito maior que o preamplificador da ORTEC, isto é devido à montagem dos componentes adicionais para alimentar o circuito eletrônico $( \pm 12 \mathrm{~V})$, ao resistor de $100 \mathrm{M} \Omega$ em serie com a tensão de alimentação reversa e à blindagem do circuito impresso implementado para se trabalhar com este componente. Por outro lado, o preamplificador da ORTEC mostrou uma melhor sensibilidade e estabilidade através do tempo de aquisição de dados ( 2 a 10 horas).

\subsection{Calibração utilizando fonte de ${ }^{241} \mathrm{Am}$.}

Para a calibração usando este tipo de fonte foi obtida a resposta para o detector S3590-04(A) utilizando um preamplificador ORTEC 142AH como condicionador do sinal. A distância da fonte até o detector foi de $0,5 \mathrm{~mm}$ aproximadamente. A Figura 30 apresenta a resposta para este fotodiodo e preamplificador. 
Através dos módulos de processamento, aquisição de dados e do programa (software) Maestro foram obtidos os valores de resolução em FWHM para o fotodiodo sendo este de 14 canais no caso do fotodiodo HAMAMATSU S3590-04(A).

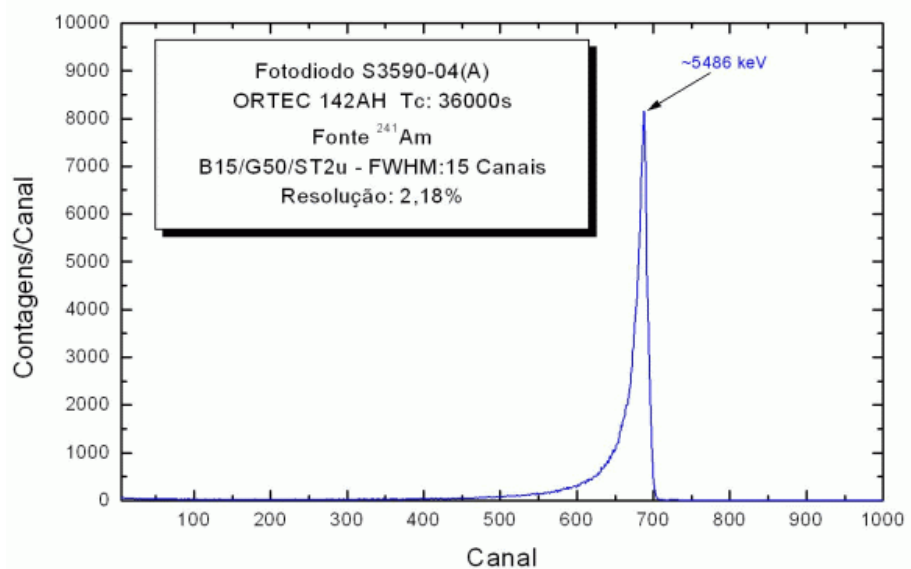

Figura 30: Resposta do fotodiodo S3590-04(A) a uma fonte de ${ }^{241} \mathrm{Am}$.

\subsection{Calibração - Testes de linearidade do canal de aquisição.}

\subsubsection{Preamplificador SOSHIN 9101}

A resposta para este módulo está ilustrada na Figura 31. Pode-se observar uma pequena queda na linearidade para pulsos de 4,7 e $9 \mathrm{~V}$, isto é devido a pequenas flutuações de sinal sobretudo no processamento analógico do preamplificador sensível à carga.

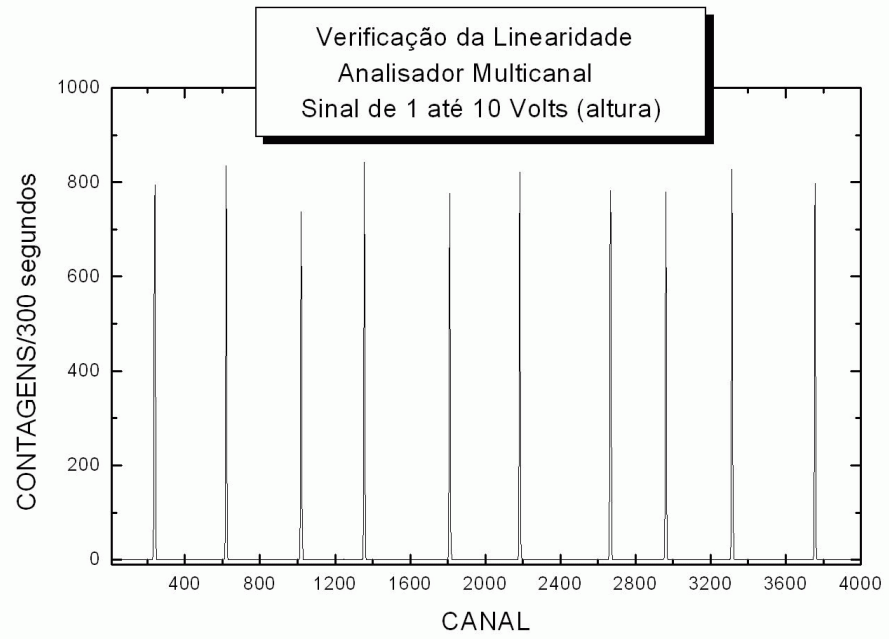

Figura 31: Distribuição para o preamplificador SOSHIN 9101 (pulsos 1 a 10 Volts). 
A Figura 32 apresenta a resposta do canal de aquisição para uma varredura de pulsos com amplitudes variando de 0,5 a 10 volts

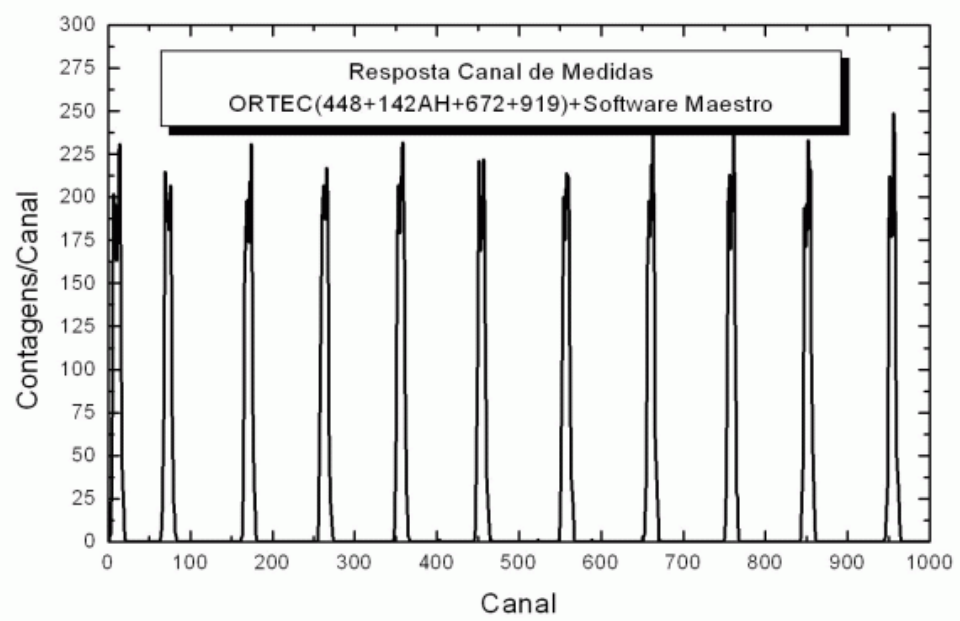

Figura 32: Resposta do sistema a uma varredura de pulsos com amplitude de 0 a 10 Volts.

Com este espectro de pulsos obteve-se a reta de resposta (mostrada na Figura 33) para a relação de Canal versus Energia correspondente, sendo esta relação a seguinte (com desvio padrão de 0,42638$)$, sendo o $\mathrm{N}^{\circ}$ de Canal diferente de 0 :

Energia $=-0,2927+8,02071 * N^{o}$ Canal.

Utilizando este fator de conversão e assumindo os valores de energia correspondente a cada Canal de aquisição, transforma-se a curva de Canal versus Contagens para o espectro em Energia versus Contagens como indicado no exemplo da Figura 34. 


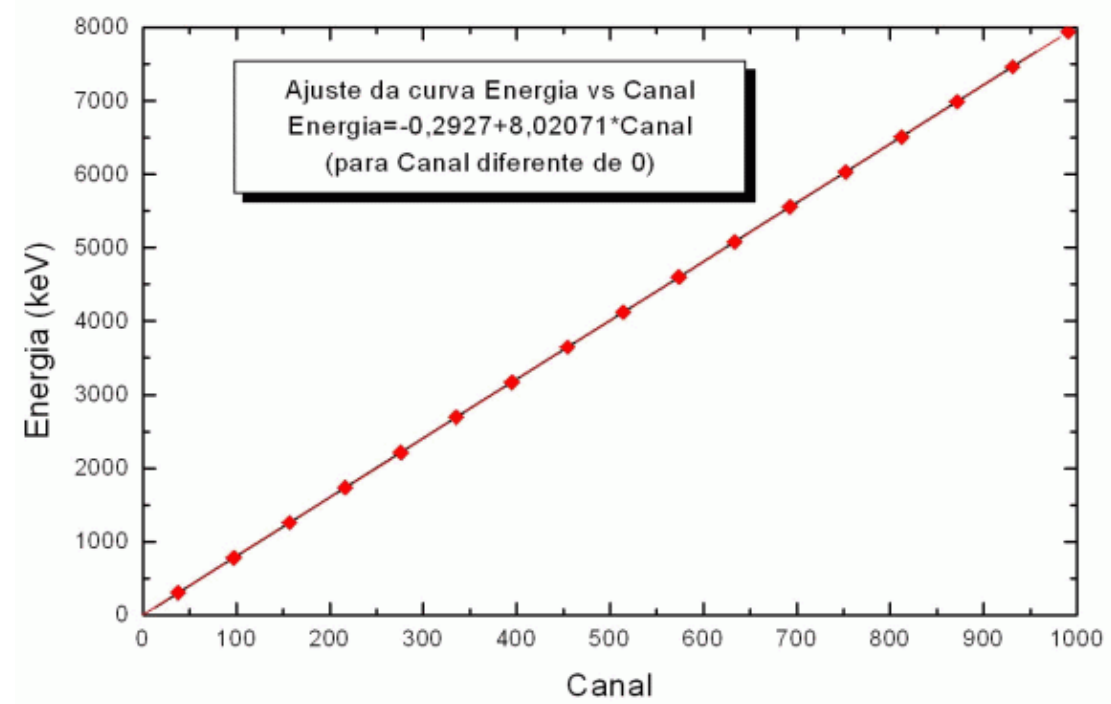

Figura 33: Ajuste da curva de Energia vs. Canal.

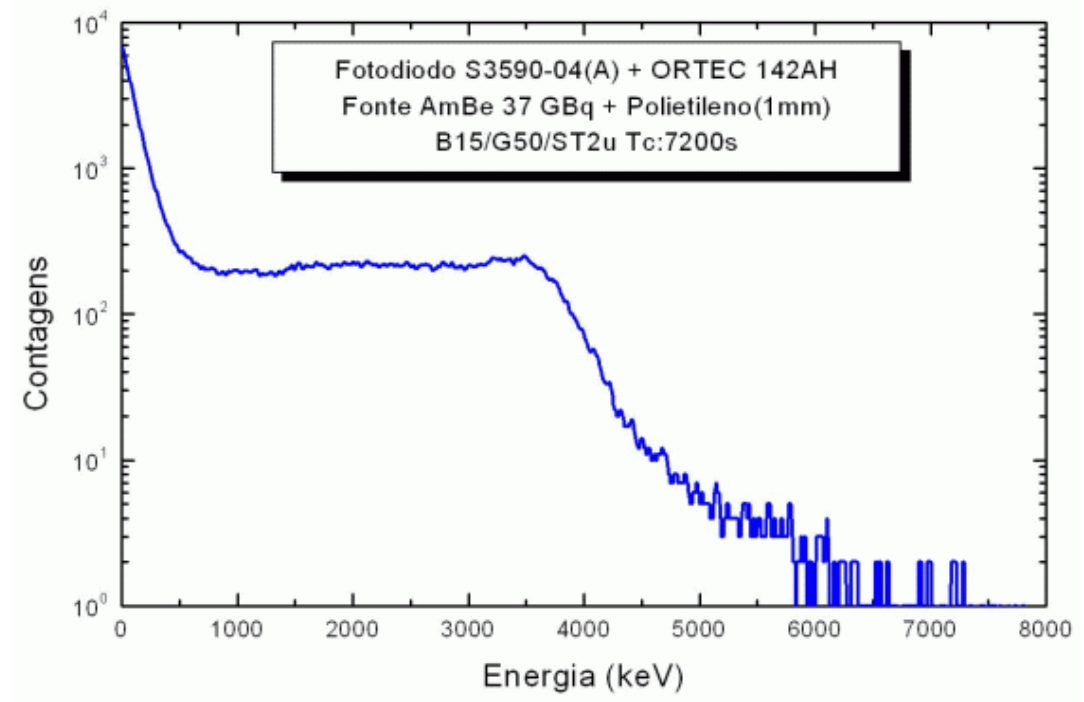

Figura 34: Exemplo do espectro de Energia vs Contagens para o fotodiodo S3590-05(A). 
6.6 Resposta dos fotodiodos PIN, S3590-04(A) e S1223-01, para a calibração com fonte de ${ }^{241} \mathrm{Am}$.

As respostas de dois tipos de fotodiodos PIN, o S3590-04 e o S1223-01 são mostradas nas Figuras 35 e 36 respectivamente.

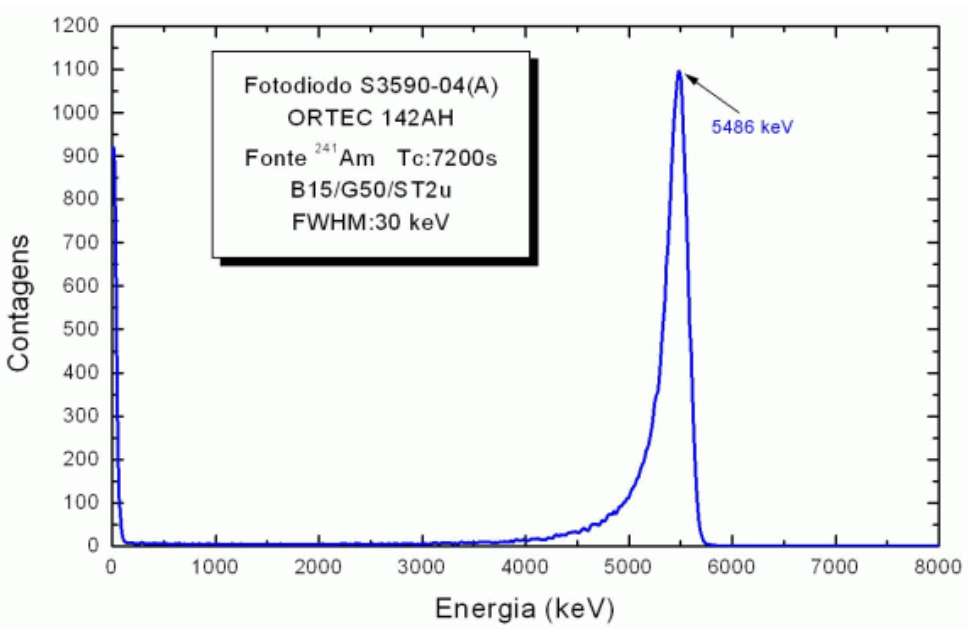

Figura 35: Resposta do fotodiodo S3590-04 a uma fonte de ${ }^{241} \mathrm{Am}$.

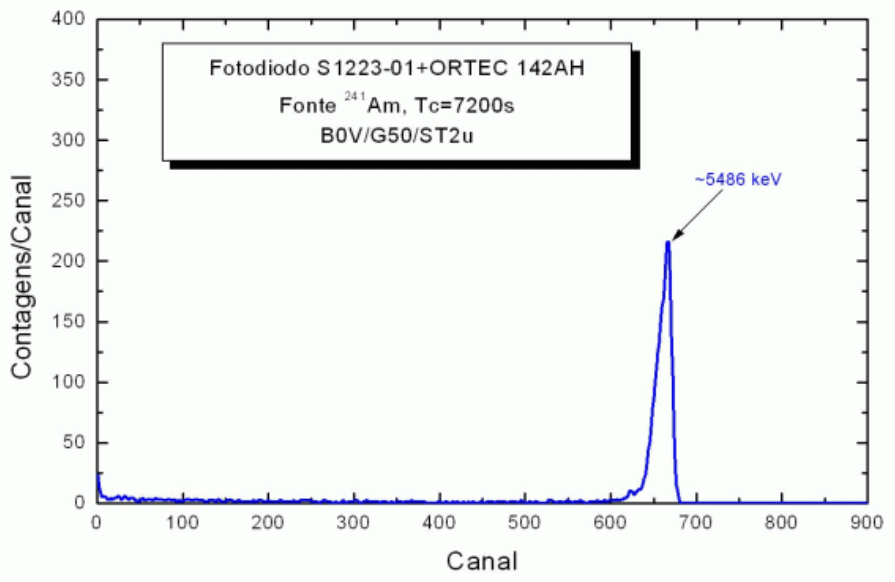

Figura 36: Resposta do fotodiodo S1223-01 a uma fonte de ${ }^{241} \mathrm{Am}$. 
6.7 Calibração utilizando fonte mista $\left({ }^{239} \mathrm{Pu},{ }^{241} \mathrm{Am} e^{244} \mathrm{Cm}\right)$.

A Figura 37 apresenta os espectros para os três tipos de Fotodiodos utilizados e a Figura 38 a resposta em particular do fotodiodo PIN HAMAMATSU S1336-18BR, a resolução de cada um dos detectores foi calculada resultando ao redor de $8 \%$ [44].

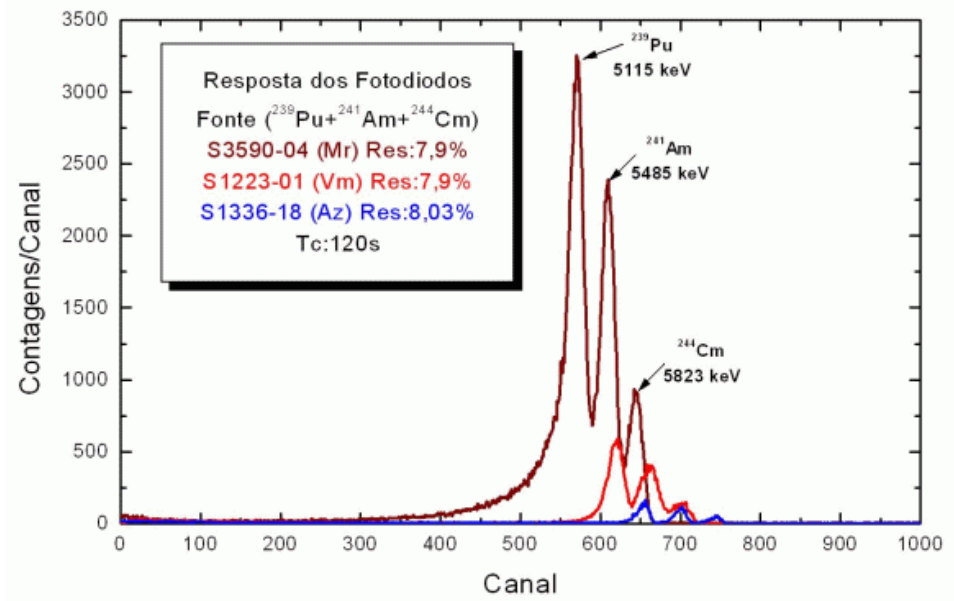

Figura 37: Resposta dos fotodiodos S3590-04, S1223-01 e S1336-18BU utilizados para a fonte mista $\left({ }^{239} \mathrm{Pu}+{ }^{241} \mathrm{Am}+{ }^{244} \mathrm{Cm}\right)$.

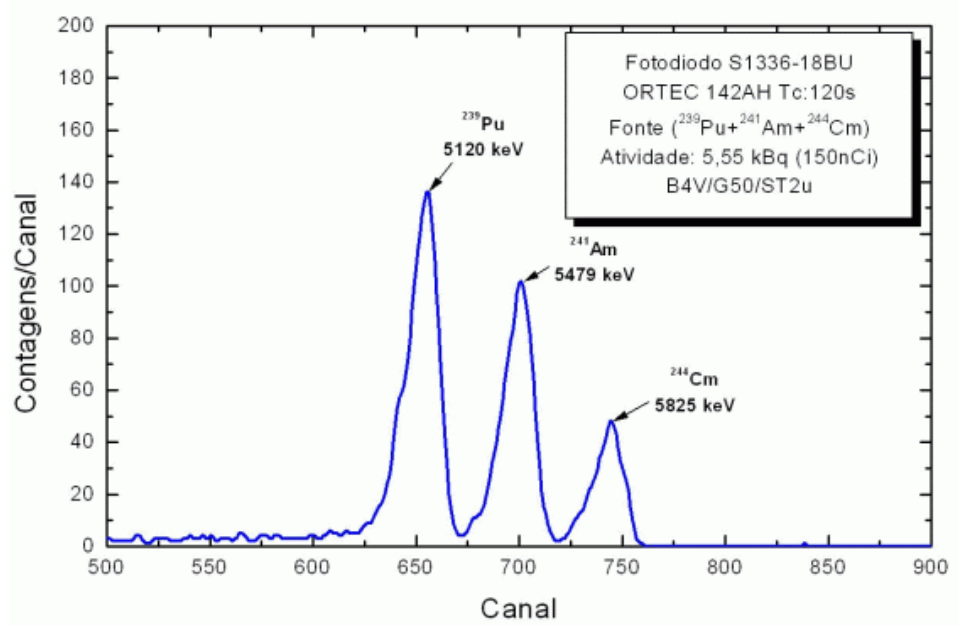

Figura 38: Resposta do fotodiodo S1336-18BU utilizado para a fonte mista

$$
\left({ }^{239} \mathrm{Pu}+{ }^{241} \mathrm{Am}+{ }^{244} \mathrm{Cm}\right) \text {. }
$$


A Figura 39 mostra a influência da tensão de polarização na camada de depleção através da resposta nas contagens.

Para 0 e $60 \mathrm{~V}$ obtém-se respostas de 2,5 e $6 \mathrm{MeV}$ respectivamente, para o mesmo tipo de conversor de polietileno de $1 \mathrm{~mm}$.

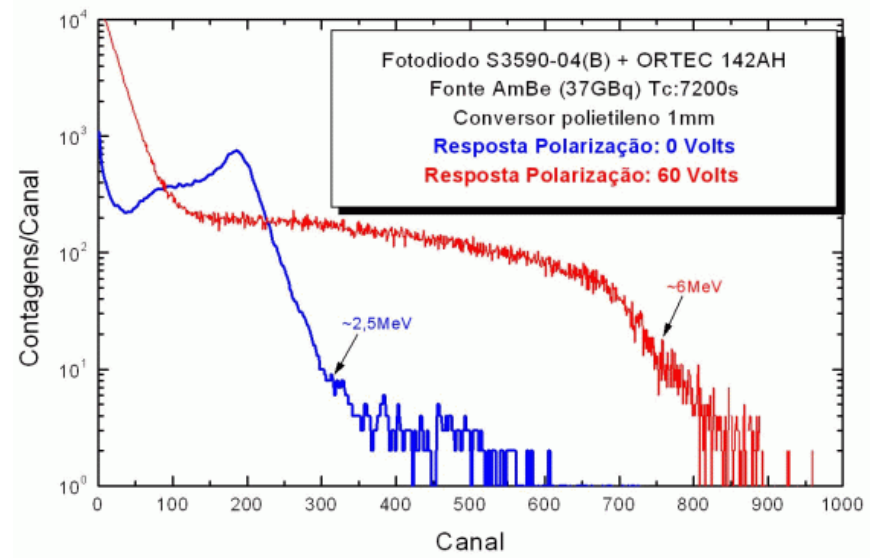

Figura 39: Resposta do fotodiodo S3590-04(A) para uma polarização de 0 e 60 V e conversor de polietileno de $1 \mathrm{~mm}$.

A Figura 40 apresenta a resposta do fotodiodo S3590-04(A) à radiação gama para tensões de polarização de $0,15,24,40$ e $60 \mathrm{~V}$.

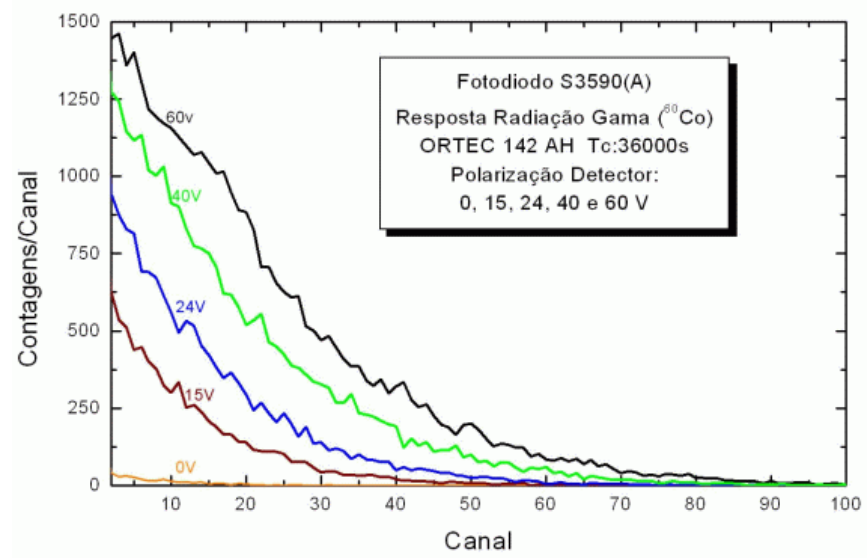

Figura 40: Resposta do fotodiodo $\mathrm{S} 3590-04(\mathrm{~A})$ à radiação gama $\left({ }^{60} \mathrm{Co}\right)$ para uma polarização de $0,15,24,40$ e $60 \mathrm{~V}$. 
Os três componentes da HAMAMATSU foram irradiados com uma fonte de ${ }^{241} \mathrm{Am} \mathrm{e}$ com uma fonte de nuclídeos mista $\left({ }^{239} \mathrm{Pu},{ }^{241} \mathrm{Am}\right.$ e $\left.{ }^{244} \mathrm{Cm}\right)$, com atividades suficientes para a avaliação destes componentes na detecção de partículas alfa.

A calibração do sistema obedeceu a um procedimento padrão, obtendo-se a resolução em energia dos detectores TMF-1 e S3590-04(A), sendo de 54 e de 14 canais respectivamente, usando uma fonte de ${ }^{241} \mathrm{Am}$ de intensidade suficiente para obter uma contagem maior que 1000 impulsos em 2 horas.

Para se obter uma reta de calibração em energia do canal de aquisição foi usada a fonte mista com três nuclídeos. Dos resultados para este tipo de fonte, foram determinadas uma resolução de 8\% para os fotodiodos PIN usados (S3590-04, S1223-01 e S1336-18BR), e uma reta de ajuste (conversão) de canais para energia, no espectro fornecido pelo software Maestro, obtida através da técnica dos mínimos quadrados usando o programa ORIGIN. Este resultado é satisfatório para o objetivo de detectar prótons de recuo e partículas alfa da conversão $(\mathrm{n}, \alpha)$ da reação nuclear do ${ }^{10} \mathrm{~B}$. Utilizando uma câmara de vácuo, a resolução intrínseca pode ser determinada mais apropriadamente, devido à ausência do ar (existente) entre o detector e a fonte [109]. No entanto, o uso de uma câmara de baixa pressão seria despropositado para as finalidades de avaliação de um detector de monitoração de nêutrons como foi o objetivo deste trabalho.

A Figura 39 mostra a influência da polarização reversa na resposta do fotodiodo S3590-04(B). Foi demonstrado experimentalmente, em uma configuração para nêutrons rápidos usando a fonte de $\mathrm{AmBe}(37 \mathrm{GBq})$ e um conversor de polietileno de $1 \mathrm{~mm}$ de espessura, que à medida que se aumenta a polarização reversa aumenta o intervalo de energia na resposta do detector. Isto é devido ao fato de que a camada de depleção aumenta até seu valor máximo, dependendo da polarização usada. Este valor de polarização reversa foi obtido experimentalmente, resultando em um valor de tensão a partir dos $35 \mathrm{~V}$. Por outro lado, aumentando a espessura aumenta o volume de detecção do fotodiodo, resultando em uma maior sensibilidade para radiação gama e ruído de fundo (BG), devido à variação da capacitância de entrada do circuito preamplificador [47]. A resposta do fotodiodo à radiação gama em função da tensão de polarização é apresentada na Figura 40. 
Nesta Figura 40 nota-se que para $60 \mathrm{~V}$ de polarização o sinal correspondente à radiação gama é muito grande em comparação à polarização de $0 \mathrm{~V}$, mas para este valor de 0 volts perde-se informação para energias maiores de 2,5 MeV. Por esta razão optou-se por centralizar as experiências para uma polarização de $15 \mathrm{~V}$ para a qual o fotodiodo teve o melhor desempenho.

\subsection{Detecção de nêutrons térmicos (fonte AmBe)}

Para a detecção de nêutrons térmicos a partir de uma fonte de AmBe é necessário que o feixe de nêutrons seja moderado (termalizado). Isto foi conseguido utilizando a parafina como moderador. A Figura 41 apresenta um esquema do processo de detecção de nêutrons térmicos usando o conversor baseado em ${ }^{10} \mathrm{~B}$. A energia destes nêutrons térmicos permite a produção de partículas alfa na reação $(\mathrm{n}, \alpha)$ com o ${ }^{10} \mathrm{~B}$, transmutando-o para ${ }^{11} \mathrm{~B}$ em estado energético instável decaindo após $10^{-12} \mathrm{~s}$ aproximadamente, emitindo uma partícula alfa e transmutando para o ${ }^{7} \mathrm{Li}[25]$.

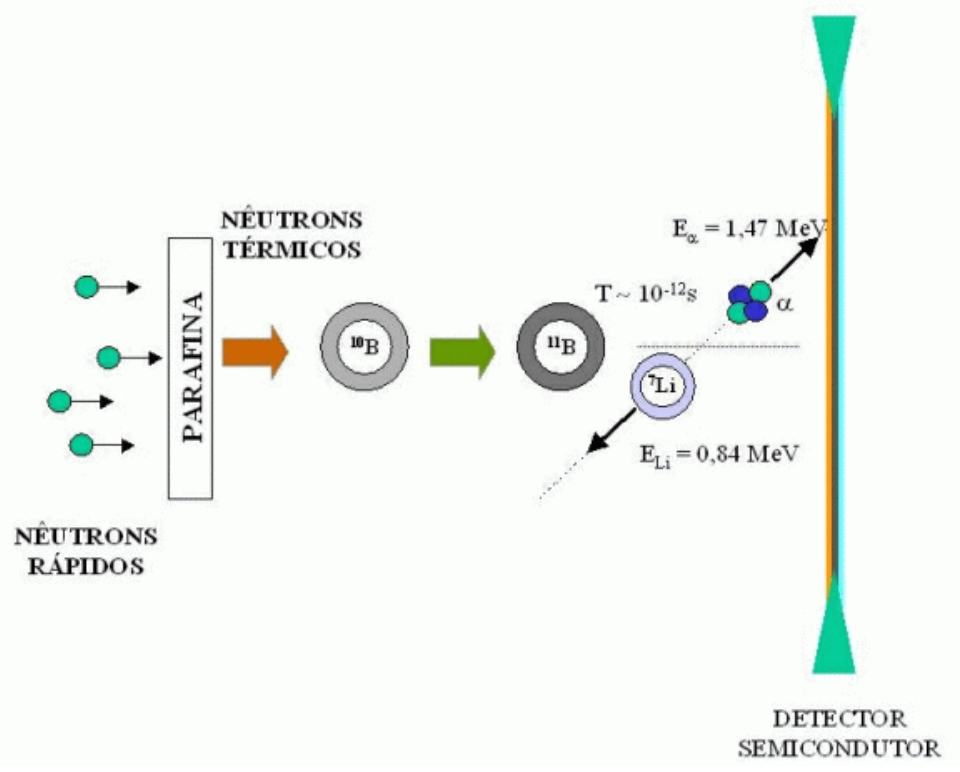

Figura 41 Esquema de detecção de nêutrons térmicos utilizando conversor de ${ }^{10} \mathrm{~B}$ [25]. 


\subsubsection{Resposta do fotodiodo S3590-04(A) para nêutrons térmicos (Laboratório CENF).}

A resposta do fotodiodo S3590-04(A) polarizado com tensão reversa de 15 Volts usando conversor de ${ }^{10} \mathrm{~B}$ é mostrada na Figura 42.

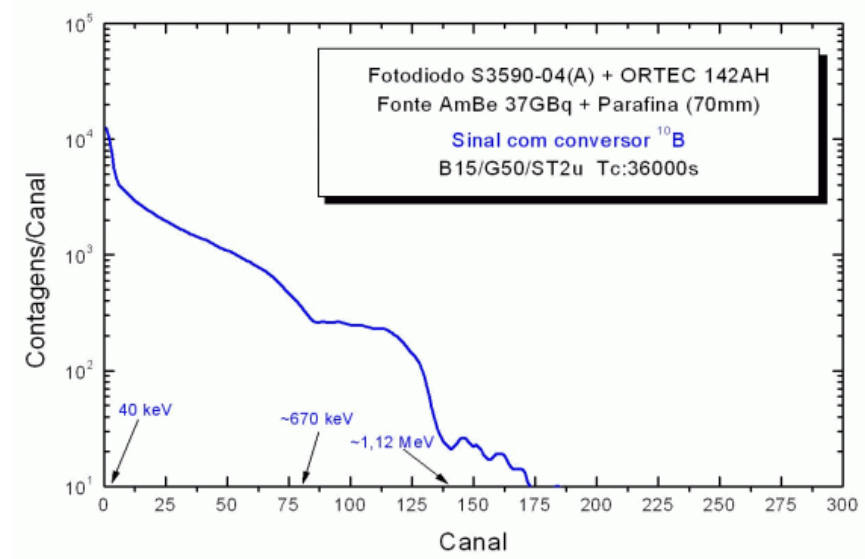

Figura 42. Resposta do fotodiodo S3590-04(A) para medições com nêutrons térmicos utilizando conversor de ${ }^{10} \mathrm{~B}$ e polarizado com 15 Volts.

Na Figura 43 são apresentadas as respostas do fotodiodo S3590-04(A) a nêutrons térmicos com conversor de ${ }^{10} \mathrm{~B}$, o sinal correspondente à radiação gama (fotodiodo sem conversor, mas coberto por uma lâmina de cádmio) e a diferença destes sinais.

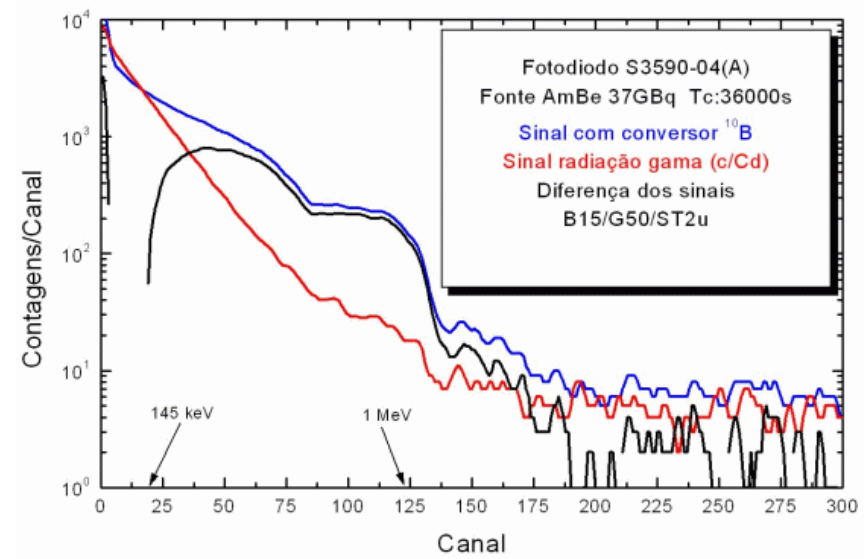

Figura 43: Resposta do fotodiodo para nêutrons térmicos (polarização reversa de $15 \mathrm{~V}$ ), sinal da radiação gama e a diferença destes sinais. 
A Figura 44 apresenta a resposta do fotodiodo S3590-04(A) a nêutrons térmicos com conversor de ${ }^{10} \mathrm{~B}$, mas sem polarização reversa, a resposta à radiação gama e a diferença destes dois sinais.

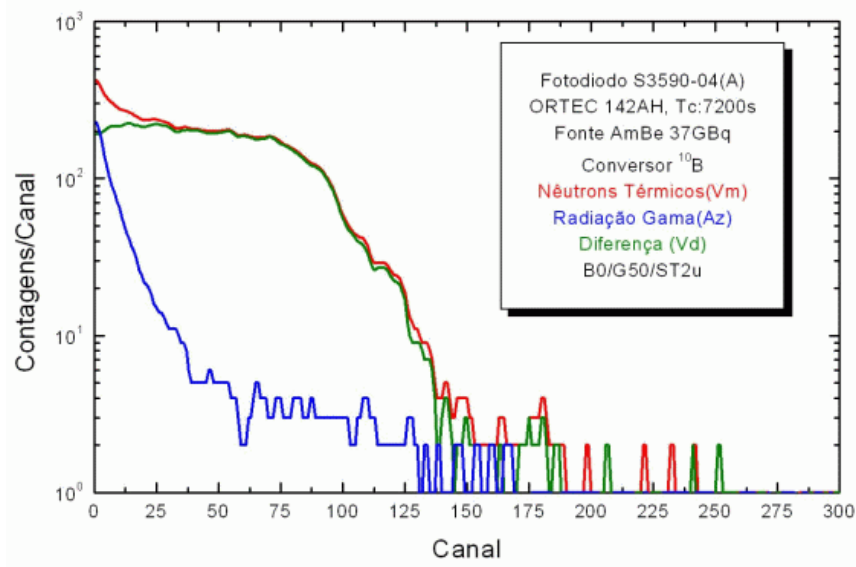

Figura 44: Resposta do fotodiodo (sem polarização reversa) para nêutrons térmicos, à radiação gama (detector coberto por cádmio) e a diferença dos dois sinais.

A Figura 45 apresenta a resposta do fotodiodo S3590-04(A) aos nêutrons térmicos utilizando a lâmina de polietileno borado como conversor e uma polarização reversa de $15 \mathrm{~V}$.

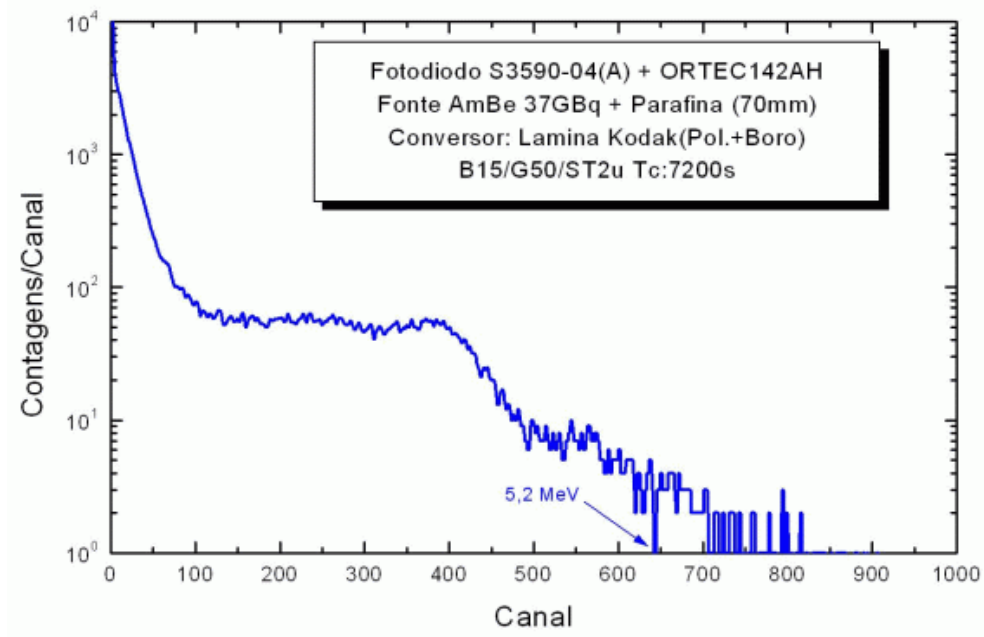

Figura 45: Reposta do fotodiodo aos nêutrons moderados utilizando uma lâmina de polietileno borado, com uma polarização de $15 \mathrm{~V}$. 
A Figura 46 mostra a resposta do fotodiodo (exposto) sem conversor, o sinal correspondente à radiação gama e a diferença dos dois sinais (espectro real correspondente aos nêutrons térmicos).

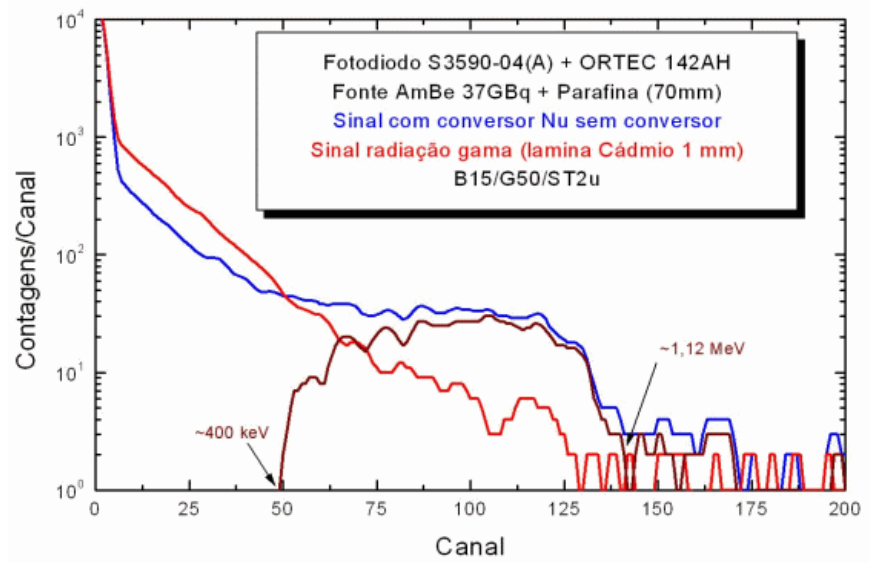

Figura 46: Resposta do fotodiodo nu (sem conversor) aos nêutrons térmicos, a resposta do detector coberto com cádmio e a diferença destes sinais.

A Figura 42 mostra o resultado da detecção de nêutrons térmicos para o fotodiodo S3590-04(A). Observa-se na Figura duas regiões: a primeira em um intervalo de energia entre 145 e $670 \mathrm{keV}$ e outra entre $670 \mathrm{keV}$ e $1,12 \mathrm{MeV}$. O tempo de aquisição foi de $36000 \mathrm{~s}$.

A Figura 43 mostra a resposta do fotodiodo aos nêutrons térmicos usando um conversor, a resposta apenas ao sinal de gama, obtida cobrindo o detector com uma lâmina de cádmio, e a diferença entre estes dois sinais. Este sinal de diferença foi analisado para obter os parâmetros de eficiência do detector e o desvio padrão da medição. O intervalo de energia utilizado para a determinação destes parâmetros foi de 0,1 até 1,0 MeV).

A Figura 44 mostra a resposta para o fotodiodo $\mathrm{S} 3590(\mathrm{~A})$ aos nêutrons térmicos usando conversor de ${ }^{10} \mathrm{~B}$, mas sem polarização reversa, a resposta à radiação gama e a diferença destes dois sinais. Nota-se que a resposta à radiação gama é baixa, isto devido ao fato que sem polarização reversa a camada de depleção do fotodiodo está no seu valor mínimo e esta radiação atravessa o volume sensível do fotodiodo sem grandes interações no silício. $\mathrm{O}$ limite de energia foi de $1,12 \mathrm{MeV}$ e o tempo de contagem foi de $7200 \mathrm{~s}$. 
A Figura 45 mostra o resultado da detecção de nêutrons térmicos para o semicondutor S3590-04(A) usando como conversor uma lâmina de polietileno borado (Kodak). Pode-se observar que a curva obtida tem uma resposta até uma energia de 5,2 $\mathrm{MeV}$ aproximadamente.

A Figura 46 apresenta a resposta para nêutrons térmicos do fotodiodo S3590-04(A)* exposto sem qualquer tipo de conversor. $O$ intervalo útil de energia situa-se entre $400 \mathrm{keV}$ e $1,12 \mathrm{MeV}$ aproximadamente.

\subsection{Detecção de nêutrons rápidos}

\subsubsection{Medições no Laboratório CENF usando os diodos TMF-1 e S3590-04(A).}

A janela destes detectores foi coberta por uma fôlha de polietileno com espessuras que variavam de 0,055 a $1 \mathrm{~mm}$. A Figura 47 apresenta a resposta do detector TMF-1 para nêutrons rápidos utilizando como conversor uma fôlha $0,12 \mathrm{~mm}$ de espessura e polarização de $40 \mathrm{~V}$.

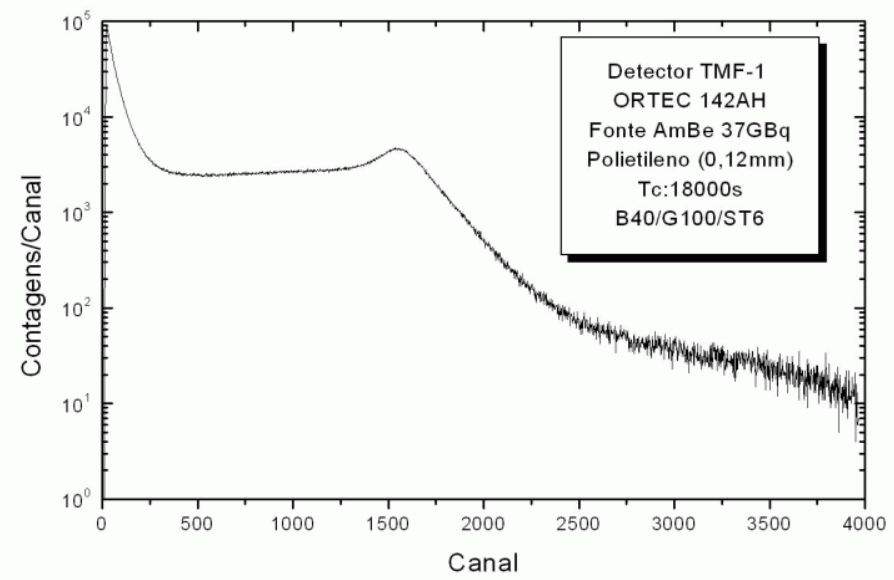

Figura 47: Espectro de nêutrons para o detector TMF-1 com conversor de polietileno $(0,12 \mathrm{~mm}$ de espessura) para fonte de AmBe.

* Neste capítulo se utiliza a notação (A) para o fotodiodo S3590-04 da HAMAMATSU, devido a que foi o primeiro fotodiodo usado nas experiências. A partir da seção 6.9.3.2 se utiliza a notação (B) devido a que a parte experimental do trabalho foi finalizada usando um segundo diodo, contudo os dois fotodiodos são do mesmo tipo. 
A Figura 48 apresenta a resposta do fotodiodo S3590-04(A) utilizando uma lâmina de polietileno de $1 \mathrm{~mm}$ de espessura e polarização de $15 \mathrm{~V}$.

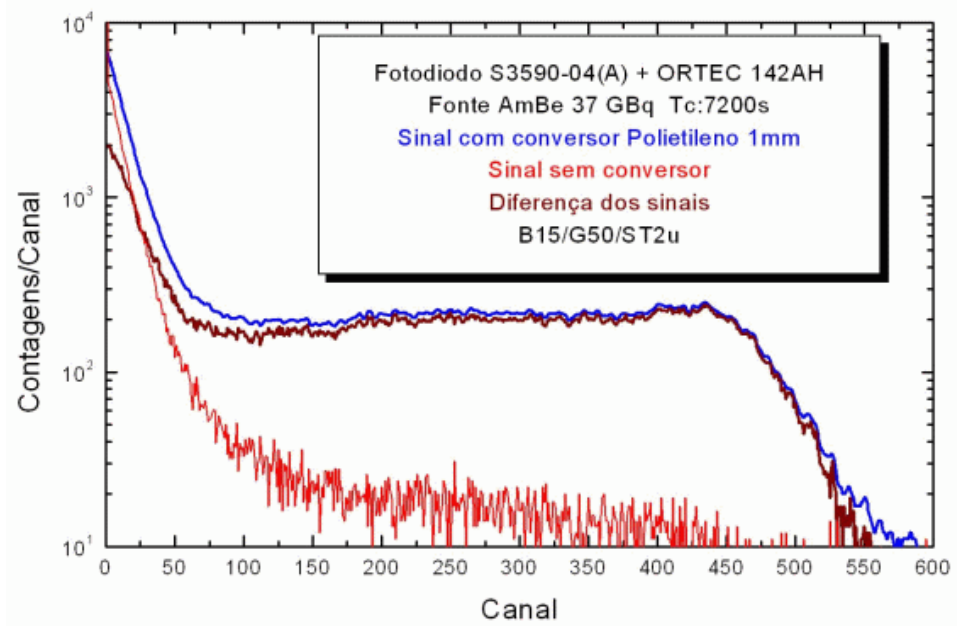

Figura 48: Espectro de nêutrons para o fotodiodo S3590-04(A) com conversor de polietileno (1 $\mathrm{mm}$ de espessura) para fonte de AmBe.

A Figura 49 apresenta as respostas do fotodiodo S1223-01 a nêutrons rápidos, usando conversor de polietileno de $1 \mathrm{~mm}$ de espessura e polietileno borado (Kodak), com polarização de 0 e $24 \mathrm{~V}$.

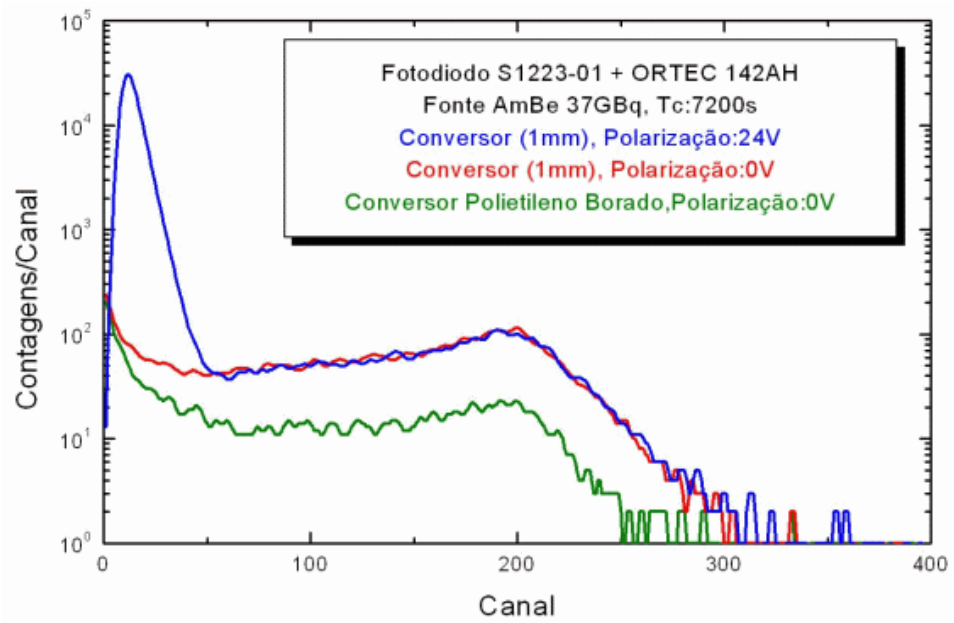

Figura 49: Resposta do fotodiodo S1223-01 para nêutrons rápidos utilizando conversor de polietileno e polietileno borado e polarização de 0 e $24 \mathrm{~V}$ 


\subsubsection{Medições no Reator IPEN/MB-01 (UCRI).}

Neste experimento, para ambos semicondutores, foi usada uma fôlha de polietileno (0,12 $\mathrm{mm}$ de espessura) como gerador de prótons de recuo através da reação (n,p). Estes semicondutores foram instalados dentro de um tubo (perfil retangular) experimental (um de cada vez) e este inserido em uma posição adequada (360 mm da parte ativa do núcleo) para melhor incidência de fluxo neutrônico, no núcleo do reator.

Os resultados foram obtidos para potências de 1, 2, 4, 5 e $10 \mathrm{~W}$ térmicos, como mostram as Figuras 50 e 51 para o detector TMF-1 e o fotodiodo S3590-04(A) respectivamente. Ambos os detectores foram polarizados com $40 \mathrm{~V}$.

Não foram repetidas estas experiências para polarizações reversas de $0,15,24,40$ ou 60 Volts, pois se procurou preservar na medida do possível a integridade dos semicondutores devido ao alto fluxo de irradiação.

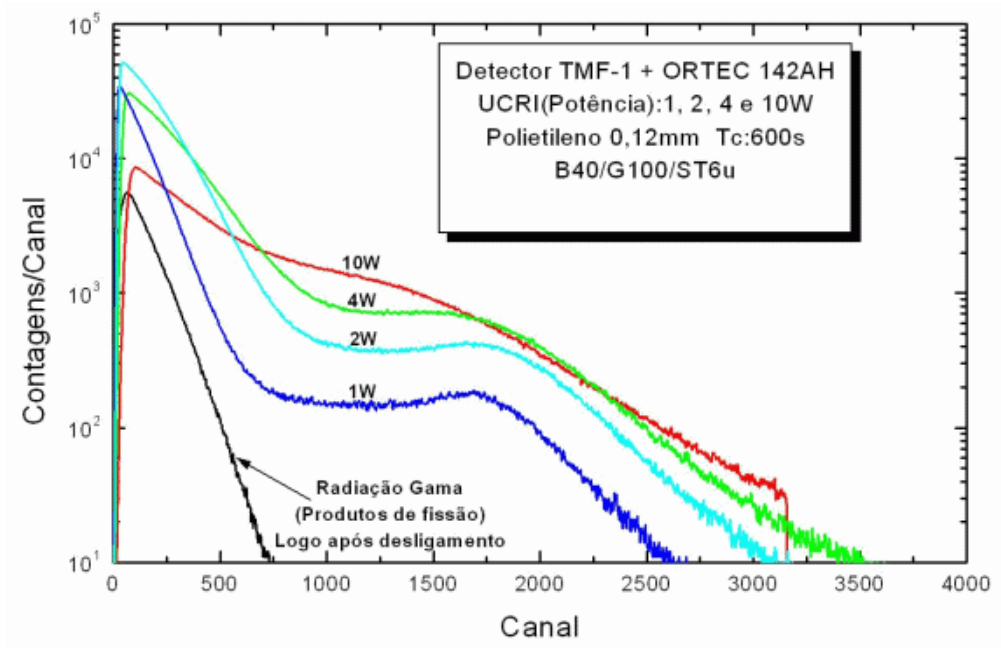

Figura 50: Resposta (espectro) do detector TMF-1 na Unidade Critica para potências de $1,2,4$ e $10 \mathrm{~W}$. 


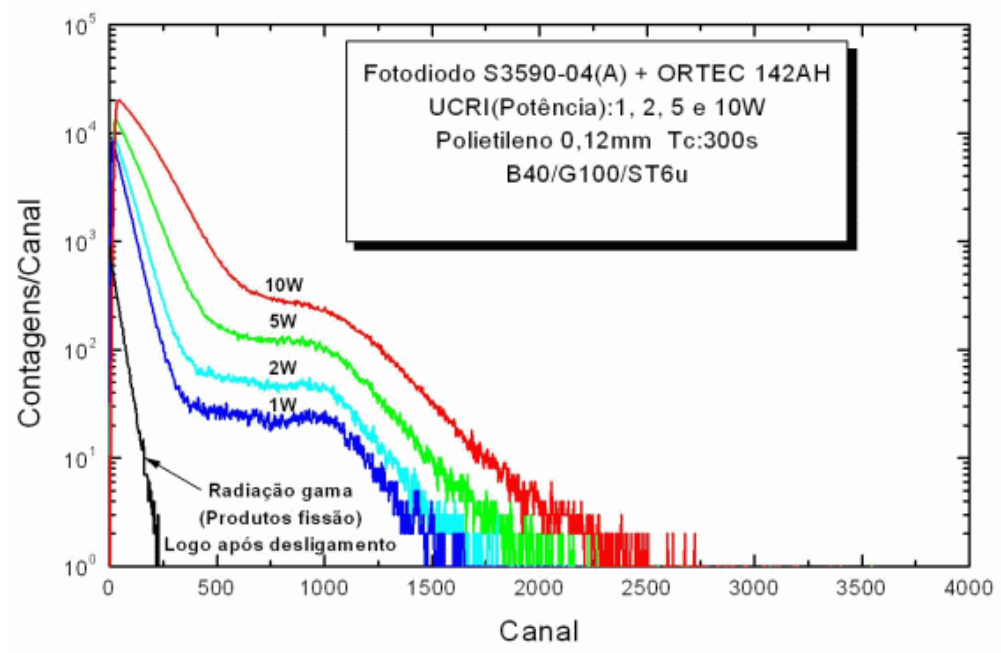

Figura 51: Resposta (espectro) do fotodiodo S3590-04(A) na Unidade Critica para potências de $1,2,5$ e $10 \mathrm{~W}$.

No caso dos nêutrons rápidos a espessura da camada de depleção foi otimizada experimentalmente ajustando a polarização reversa do detector com o fim de minimizar o limite inferior de energia de nêutrons detectáveis, que e dada pela contribuição dos elétrons secundários gerados pelas interações de fótons com o invólucro do detector. Este requisito foi conseguido situando a polarização em 15 V (fotodiodos S3590-04(A) e S3590-04(B)).

Nos espectros obtidos observa-se que existe um rápido decremento do intervalo de energias baixas para intermediarias, seguido de uma distribuição suave que se estende até a energia máxima depositada na camada de depleção como mostrado nas Figuras 47 e 48. A região uniforme até a energia máxima depositada é devida aos prótons de recuo gerados pelo conversor. A baixas energias a resolução do espectro se perde pela sobreposição do sinal correspondente aos elétrons secundários gerados pelos fótons que interagem com o invólucro do detector e não aos que incidem perpendicularmente na superfície do fotodiodo. Em termos de detecção isto limita a energia mais baixa detectável, resultando em torno de $250 \mathrm{keV}$ e $400 \mathrm{keV}$ para o detector TMF-1 e o fotodiodo S3590-04(A) respectivamente.

A influência destes fótons pode ser minimizada reduzindo a espessura da camada de depleção, ou seja, diminuindo o volume sensível de detecção, porém uma camada de depleção mais fina impõe uma limitação na energia máxima detectável. Neste trabalho as energias 
mínimas e máximas detectáveis foram estabelecidas em 0,1 e $5 \mathrm{MeV}$ (detecção de nêutrons rápidos).

A Figura 47 apresenta a resposta para o detector TMF-1 utilizando uma fôlha de polietileno de 0,12 $\mathrm{mm}$ de espessura como geradora de prótons de recuo. O intervalo de energia para definição de parâmetros foi entre 0,5 e $1 \mathrm{MeV}$.

A resposta para o fotodiodo S3590-04(A) é mostrada na Figura 48. Desta vez foi utilizado um conversor de polietileno de $1 \mathrm{~mm}$ de espessura e o intervalo para definição de parâmetros foi entre $1 \mathrm{MeV}$ e $2 \mathrm{MeV}$.

Na Figura 49 nota-se a influência da tensão de polarização reversa na resposta do fotodiodo S1223-01. Nas regiões de energias baixas, com o fotodiodo operando sem polarização, a resposta à radiação gama é quase nula, mas o limite de alta energia alcança até os 2,5 MeV aproximadamente.

As Figuras 50 e 51 apresentam as respostas do detector TMF-1 e do fotodiodo S3590-04(A) respectivamente. A linearidade da resposta (contagens vs. potência) só se manteve até uma potência de $5 \mathrm{~W}$. Para potência maior $(10 \mathrm{~W})$ a resposta aumentou excessivamente. Analisando os gráficos através do software Maestro nota-se que o Tempo Morto da aquisição aumenta conforme a frequência indicando uma saturação do sinal devido a (talvez) um efeito de empilhamento (pile-up). Como o intuito da experiência era a de apenas avaliar os componentes não foram repetidas as experiências para preservar a integridade dos componentes a danos por irradiação. 
6.9.3 Medições na Instalação de Neutrongrafia - nêutrons térmicos e epitérmicos.

6.9.3.1 Resposta dos detectores para nêutrons térmicos e epitérmicos com o reator operando a uma potência de 2 MW térmicos.

Nesta instalação foi obtido o espectro para nêutrons térmicos e epitérmicos, embora o fluxo de nêutrons seja de predominância de nêutrons térmicos, com o reator IEA-R1 operando a uma potência de 2 MW. A Figura 52 mostra os espectros correspondentes aos detectores TMF-1 e S3590-04(A) utilizando um conversor de polietileno de 0,12 $\mathrm{mm}$ de espessura e uma polarização reversa de $40 \mathrm{~V}$ para ambos semicondutores.

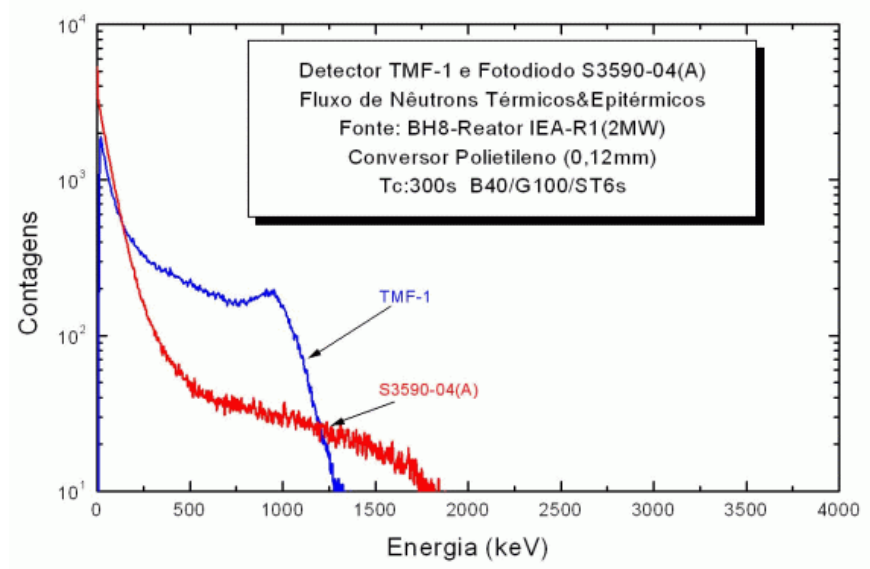

Figura 52 Espectro de nêutrons térmicos e epitérmicos para o detector TMF-1 e o fotodiodo S3509-04 para uma potência térmica do reator de 2 MW.

6.9.3.2 Resposta do detector S3590-04(B) para nêutrons térmicos e epitérmicos e uma potência do reator de 3,5 $\mathrm{MW}$.

Neste caso foi obtido o espectro para nêutrons térmicos e epitérmicos utilizando um conversor de ${ }^{10} \mathrm{~B}$, com o reator operando a uma potência de 3,5 MW e um fluxo total de nêutrons de $2,110^{6} \mathrm{n} \cdot \mathrm{cm}^{-1} \cdot \mathrm{s}^{-1}$ como mostra a Figura 53. Nesta figura aparece também o nível de radiação gama detectado utilizando uma lâmina de cádmio cobrindo o detector por inteiro, bloqueando o sinal correspondente aos nêutrons térmicos. 


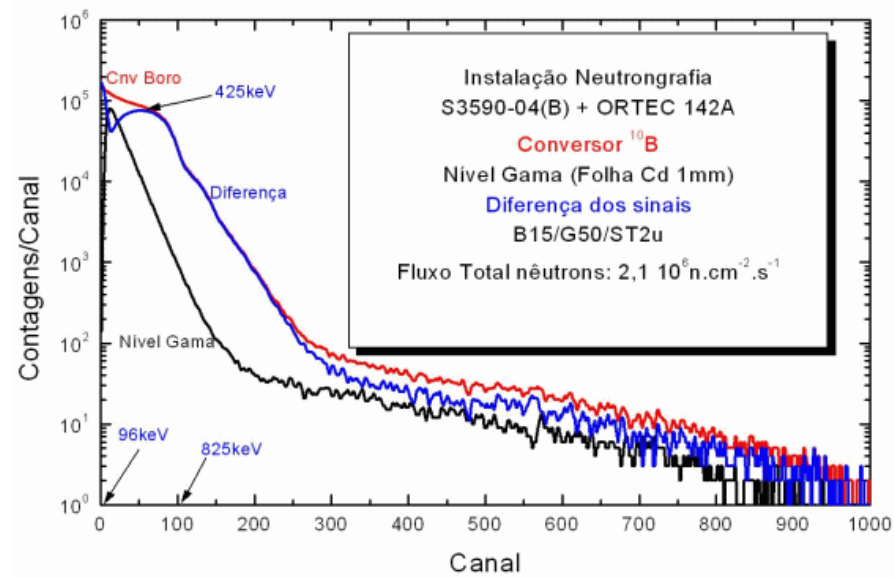

Figura 53: Resposta do fotodiodo S3590-04(B) para um fluxo de nêutrons térmicos e epitérmicos usando conversor de ${ }^{10} \mathrm{~B}$.

Para a mesma potência do reator foi obtida a resposta do fotodiodo S3590-04(B) utilizando um conversor de polietileno ( $1 \mathrm{~mm}$ de espessura) como mostrado na Figura 54.

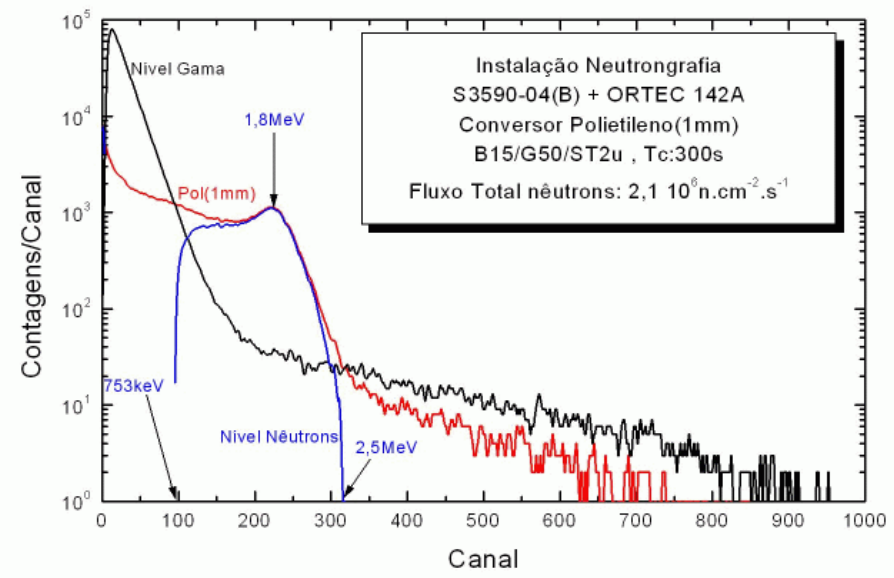

Figura 54: Resposta do fotodiodo S3590-04(B) para um fluxo de nêutrons térmicos e epitérmicos usando conversor de polietileno ( $1 \mathrm{~mm}$ de espessura).

Da mesma maneira as medições foram realizadas usando, desta vez, como conversor, uma fôlha de polietileno borado, a resposta é mostrada na Figura 55. 


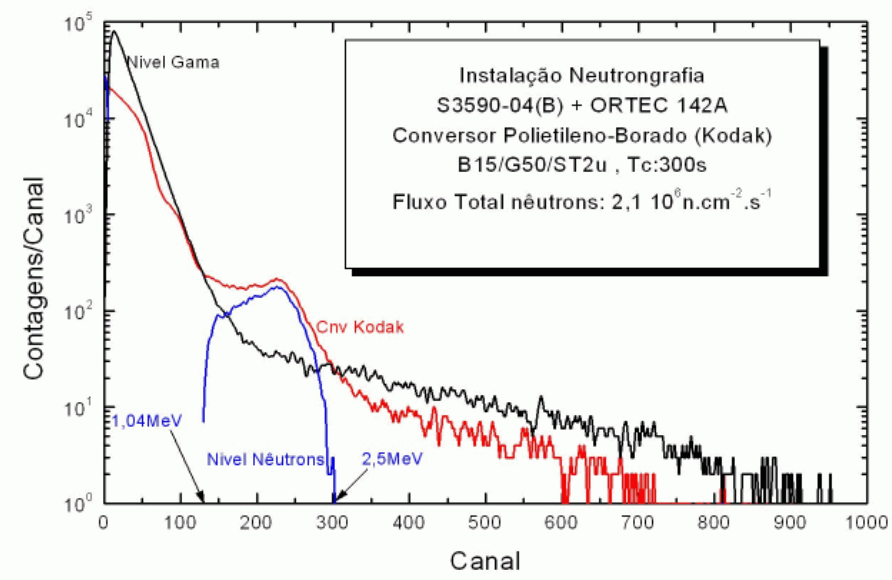

Figura 55: Resposta do fotodiodo S3590-04(B) para um fluxo de nêutrons térmicos e epitérmicos usando conversor de polietileno borado.

A Figura 56 apresenta as respostas do detector S3590-04(B) correspondentes a cada situação, conforme o tipo de conversor usado, mas sem o sinal correspondente à radiação gama, que foi subtraída de cada um dos espectros obtidos.

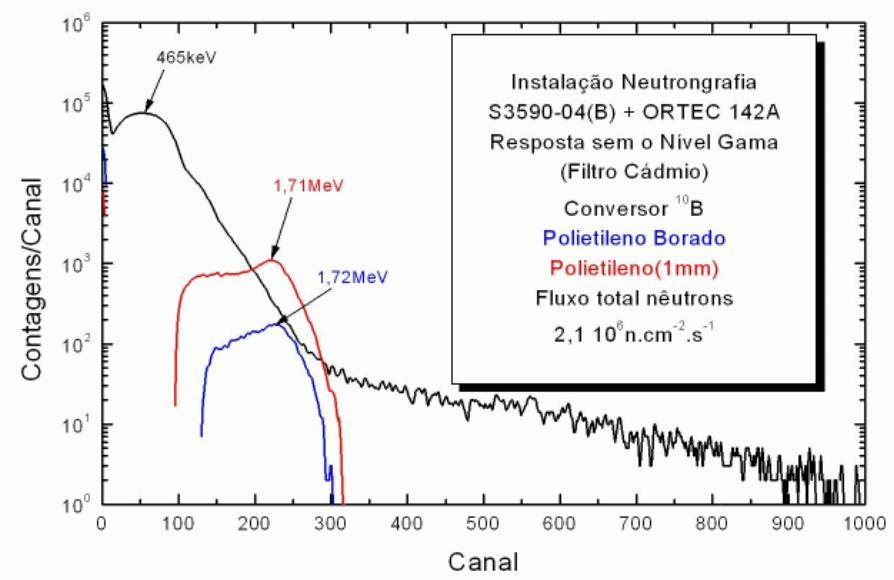

Figura 56: Resposta do detector S3590-04(B) para um fluxo de nêutrons térmicos e epitérmicos usando os três tipos de conversores sem o sinal de radiação gama (subtraído).

A Figura 57 apresenta as respostas do detector S3590-04(B) correspondentes a cada situação, conforme o tipo de conversor usado, incluindo o sinal correspondente à radiação gama. 


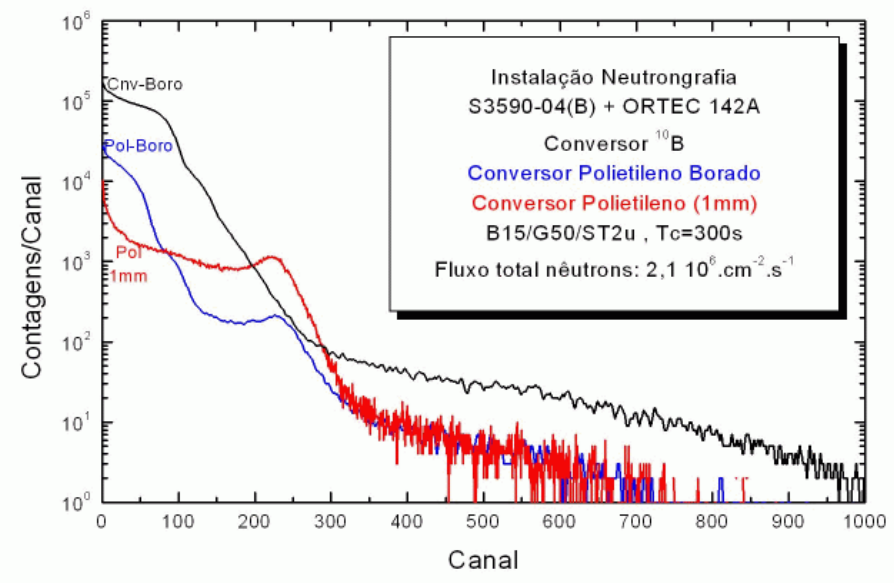

Figura 57: Resposta do detector S3590-04(B) para um fluxo de nêutrons térmicos e epitérmicos usando os três tipos de conversores com o sinal de radiação gama incluído.

A resposta do detector TMF-1 usando uma fôlha de polietileno de 0,12 $\mathrm{mm}$, para a geração de prótons de recuo, é mostrada na Figura 52, mostrando o pico característico que aparece nas medições de nêutrons com energias maiores que $100 \mathrm{keV}$ [25]. Cabe salientar que esta resposta foi obtida quando dos testes preliminares. Nessa situação o Analisador Multicanal não se encontrava calibrado em energia com fonte padrão mista de três nuclídeos $\left({ }^{239} \mathrm{Pu}+{ }^{241} \mathrm{Am}+{ }^{244} \mathrm{Cm}\right)$.

A Figura 53 mostra a resposta do fotodiodo S3590-04(B) sob irradiação de nêutrons térmicos e epitérmicos utilizando um conversor de ${ }^{10} \mathrm{~B}$, a resposta ao sinal gama, obtido cobrindo o detector com uma fôlha de cádmio, e a diferença dos dois sinais. Como no caso anterior para fonte de $\mathrm{AmBe}$, este sinal de diferença foi usado para obter os parâmetros de eficiência e desvio padrão. $\mathrm{O}$ intervalo de energia para os cálculos foi definido de $100 \mathrm{keV}$ até $1 \mathrm{MeV}$.

A Figura 54, como no caso anterior, mostra este fotodiodo usando um conversor de polietileno de $1 \mathrm{~mm}$ de espessura, sua resposta ao gama e a diferença destes sinais, que foi usada para definir a eficiência e o desvio padrão. Neste caso os limites do intervalo a ser utilizado para definição da eficiência e o desvio padrão foram de 0,75 a $2,5 \mathrm{MeV}$ aproximadamente. 
A resposta do fotodiodo S3590-04(B) usando um conversor de polietileno-borado (Kodak) é apresentada na Figura 55, mostrando as curvas para os sinais de nêutrons, gama e sua diferença. A eficiência e o desvio padrão foram obtidas usando o mesmo procedimento anterior e o intervalo de energia para determinação destes parâmetros foi de 1 até $2,5 \mathrm{MeV}$ aproximadamente. Como nos casos anteriores esta diferença foi usada para a determinação da eficiência e o desvio padrão.

As Figuras 56 e 57 são meramente ilustrativas, apresentando a forma das curvas incluindo a radiação gama e os espectros correspondentes apenas aos nêutrons.

6.10 Cálculo de um fator de conversão Contagens para Dose para dosimetria utilizando um diodo.

Para o cálculo de um fator de conversão de contagens para dose foram utilizados os dados obtidos na parte experimental, relacionando-os com os valores de fluxo de nêutrons (obtidos através da técnica de ativação de fôlhas) e a dose equivalente (obtida por meio de instrumento Monitor Portátil calibrado).

Para esta abordagem resulta conveniente classificar os nêutrons conforme sua energia cinética. Cabe salientar que esta classificação é arbitrária, existindo nos limites de cada uma delas uma superposição de categorias adjacentes de acordo com este formalismo. Podem-se classificar os nêutrons da seguinte forma:

- nêutrons lentos, com energias inferiores a $1 \mathrm{keV}$, inclui os nêutrons térmicos, caracterizados pelo equilíbrio energético dos nêutrons com os átomos do meio material. A distribuição de energia dos nêutrons térmicos, frequentemente, pode ser aproximada por uma distribuição de Maxwell, no intervalo de 0 a $1 \mathrm{eV}$;

- nêutrons epitérmicos, com energias entre $0,5 \mathrm{eV}$ e $210^{6} \mathrm{eV}$, cujas colisões elásticas com os átomos do moderador possibilitam o processo de moderação; suas energias excedem as permitidas pela distribuição de Maxwell para a temperatura do moderador;

- nêutrons rápidos, com energias entre $500 \mathrm{keV}$ e $20 \mathrm{MeV}$, são aqueles emergentes de reações nucleares; 
- nêutrons ultra-rápidos, com energias superiores à $20 \mathrm{MeV}$, não são encontrados em reatores nucleares, uma vez que só podem ser obtidos por meio de reações nucleares utilizando aceleradores de partículas. [110]

6.10.1 Dados necessários para o cálculo de fator de conversão de Contagens para Dose (fonte AmBe)

Os dados necessários para os cálculos são os seguintes:

a) as contagens (valor bruto) correspondentes aos nêutrons incidentes (térmicos ou rápidos) procedentes da fonte de $\mathrm{AmBe}(37 \mathrm{GBq})$. $\mathrm{O}$ sinal correspondente à radiação gama e ruído de fundo (BG) foi subtraído de cada sinal correspondente quando da utilização de conversor, seja ${ }^{10} \mathrm{~B}$, polietileno ou polietileno borado (vide Figuras 44, 48 e 56).

b) a taxa de dose equivalente em mSv.h ${ }^{-1}$ obtida através de instrumento Monitor Portátil (Survey Meter) como indicado no APÊNDICE C (página 109) para o caso de nêutrons térmicos e rápidos usando uma fonte de $\mathrm{AmBe}(37 \mathrm{GBq})$.

6.10.2 Dados necessários para o cálculo de fator de conversão Contagens para Dose (instalação de Neutrongrafia).

Como no caso anterior são necessários os valores de contagens (valor bruto) e a taxa de dose equivalente correspondente (neste caso) aos nêutrons epitérmicos. Para o cálculo do fluxo de nêutrons e taxa de dose equivalente foi utilizada a metodologia descrita no APÊNDICE D (página 110).

Na época da instalação desta bancada experimental as taxas de dose equivalente foram obtidas através de instrumentos calibrados (Teletector fabricado pela Nuclear Enterprises Modelo MK27-NRM e Monitor Portátil fabricado pela LUDLUM para radiação gama e para nêutrons respectivamente) e conversões correspondentes resultando em uma taxa de dose equivalente de $70 \mathrm{mSv} \cdot \mathrm{h}^{-1}$ e $20 \mathrm{mSv} \cdot \mathrm{h}^{-1}$ para a componente dos nêutrons e da radiação gama respectivamente para um fluxo total de nêutrons de $1,7510^{6} \mathrm{n} \cdot \mathrm{cm}^{-2} \cdot \mathrm{s}^{-1}$ com o reator operando a 2 MW [96].

Assumindo uma relação linear entre os fluxos obtidos e a relação entre nêutrons epitérmicos e térmicos $(0,306)$ tem-se como resultado uma taxa de dose de $58,3 \mathrm{mSv}^{-1} \mathrm{~h}^{-1} \mathrm{e}$ 25,7 mSv.h ${ }^{-1}$ para nêutrons térmicos e epitérmicos respectivamente, para um fluxo de 
nêutrons de 2,1 $10^{6} \mathrm{n} \cdot \mathrm{cm}^{-2} \cdot \mathrm{s}^{-1}$ com o reator operando a uma potencia de 3,5 MW. O APÊNDICE D (página 110) mostra em detalhe os cálculos para obter estes valores.

Como o objetivo é obter um fator de conversão de contagens para dose, este é calculado através da relação seguinte:

$$
F=\frac{\text { Dose }}{C_{c n t}} \mu \text { Sv.contagens }{ }^{-1}
$$

onde $D$ é igual à taxa de dose equivalente $\left(\mathrm{mR} \cdot \mathrm{h}^{-1}\right.$ ou $\left.\mathrm{mSv} \cdot \mathrm{h}^{-1}\right)$ obtida através de medição usando um instrumento Monitor Portátil e $C_{c n t}$ é o número de contagens obtido através do software Maestro (vide considerações no APÊNDICE E (página 111) [19 e 68].

A Tabela 7 mostra os dados obtidos com o fotodiodo S3590-04, conforme os dados mostrados no APÊNDICE F (página 113). Estes dados foram utilizados para obter o Fator de Conversão em microSievert por contagens ( $\left.\mu S v \cdot C_{c n t}^{-1}\right)$.

Tabela 7: Valores utilizados para a obtenção do fator de conversão de contagens para dose.

\begin{tabular}{|c|c|c|c|}
\hline $\begin{array}{c}\text { Fotodiodo } \\
\text { S3590-04 }\end{array}$ & $\begin{array}{c}\text { Fonte AmBe } \\
\text { Conv. }{ }^{\mathbf{1 0}} \mathbf{B}\end{array}$ & $\begin{array}{c}\text { Fonte AmBe } \\
\text { Polietileno }\end{array}$ & $\begin{array}{c}\text { Neutrongrafia } \\
\text { Polietileno }\end{array}$ \\
\hline $\begin{array}{c}\text { Taxa de Dose } \\
\left(m S v \cdot h^{-1}\right)\end{array}$ & 4,96 & 850 & 25,7 \\
\hline $\begin{array}{c}\text { Contagens por hora } \\
\left(C_{c n n t} \cdot h^{-1}\right)\end{array}$ & 8950 & 39808 & 1526016 \\
\hline $\begin{array}{c}\text { Fator de conversão } \\
\left(\mu S v \cdot C_{c n t}^{-1}\right)\end{array}$ & 0,5542 & 0,022 & 0,017 \\
\hline
\end{tabular}




\subsection{Eficiência global da detecção.}

Para a determinação da eficiência $\left(\varepsilon_{g}\right)$ foi assumido que a eficiência intrínseca para prótons de recuo é igual a 1 (todos os prótons que incidem na área sensível do fotodiodo produzem um pulso na saída do preamplificador). Neste trabalho foi utilizada a relação entre o número de contagens registrado pelo analisador multicanal dividido pelos número de nêutrons incidentes na área sensível do sistema conversor-detector, sendo esta igual a:

$$
\varepsilon_{g}=\left(N^{\circ} \text { contagens }\right) /\left(N^{\circ} \text { nêtrons incidentes }\right)
$$

Foi considerado apenas o sinal diferença (nêutrons menos radiação gama) das respostas do fotodiodo S3590-04(A) e (B) aos nêutrons térmicos, epitérmicos e rápidos nas diversas situações: usando conversor de ${ }^{10} \mathrm{~B}$, polietileno ou polietileno-borado.

A Tabela 8 apresenta um resumo dos resultados do desvio padrão e da eficiência do detector TMF-1 e o fotodiodo S3590-04(A) e (B) com base nos dados fornecidos pelo software Maestro (ORTEC) e valores de fluxo de nêutrons obtidos através do código de Monte Carlo.

Tabela 8 Resumo dos valores de desvio padrão e eficiência para o detector TMF-1 e o fotodiodo S3590-04(A) e (B) para nêutrons térmicos e rápidos procedentes da fonte de $\mathrm{AmBe}$, e nêutrons térmicos e epitérmicos da instalação de Neutrongrafia utilizando os dados obtidos através do software Maestro.

\begin{tabular}{|c|c|c|c|c|}
\hline Semicondutor & Contagens & Desvio Padrão & Eficiência (T) & Eficiência (R) \\
\hline $\begin{array}{c}\text { TMF-1 } \\
(\mathrm{AmBe})\left(\mathrm{P}_{\mathrm{o}}\right)\end{array}$ & 76,9 & 8,77 & ----- & $0,23 \%$ \\
\hline $\begin{array}{c}\mathrm{S} 3590-04(\mathrm{~A}) \\
(\mathrm{AmBe})\left({ }^{10} \mathrm{~B}\right)\end{array}$ & 2,48 & 1,58 & $0,25 \%$ & ----- \\
\hline $\begin{array}{c}\mathrm{S} 3590-04(\mathrm{~A}) \\
(\mathrm{AmBe})(\mathrm{Pol} .)\end{array}$ & 10,9 & 3,3 & ---- & $0,1 \%$ \\
\hline $\begin{array}{c}\text { S3590-04(B) } \\
\left(\text { Neutrongrafia - }{ }^{10} \mathrm{~B}\right)\end{array}$ & 19010 & 138 & $3,88 \%$ & - \\
\hline $\begin{array}{c}\text { S3590-04(B) } \\
(\text { Neutrongrafia - Pol. })\end{array}$ & 423,88 & 20,6 & - & $0,086 \%$ \\
\hline
\end{tabular}


Os valores de fluxo utilizados para a fonte de AmBe foram de 994 n.cm ${ }^{-2} \cdot \mathrm{s}^{-1} \mathrm{e}$ $10500 \mathrm{n} . \mathrm{cm}^{-2} \cdot \mathrm{s}^{-1}$ para nêutrons térmicos e rápidos respectivamente. No caso da instalação de Neutrongrafia foi utilizado um valor de fluxo epitérmico de $0,4910^{6} \mathrm{n} \cdot \mathrm{cm}^{-2} \cdot \mathrm{s}^{-1}$.

Comparando os resultados entre o detector TMF-1 e o fotodiodo S3590 foi comprovado que a eficiência do detector será maior quanto maior for a probabilidade de interação. Esta probabilidade aumenta com o tamanho do detector. Mas o aumento do tamanho do detector tem um limite, pois a contagem devido ao BG aumenta proporcionalmente com o tamanho da área do semicondutor, e em alguns casos é impraticável confeccionar detectores grandes.

Para uma melhor aproximação dos valores mínimo e máximo de energia é necessário se dispor de um gerador de nêutrons monoenergéticos (aceleradores de partículas) e de simulações usando o código de Monte Carlo (código FLUKA). Alguns grupos de pesquisas têm desenvolvido experiências com nêutrons rápidos desenvolvendo uma teoria para a simulação usando esta ferramenta [65].

\subsection{Análise de incertezas.}

Todas as medições de qualquer classe e tipo levam associado ao seu valor uma incerteza. Nas medições de radiações ionizantes aparecem devido a variações nos instrumentos de medição e os procedimentos analíticos, erros humanos, radiação natural de fundo (BG), incertezas nas contagens, variações do componente alvo no médio em que esta sendo analisado e outras fontes.

A incerteza nas contagens é obtida por meio de análise radioativa. Esta incerteza é devida a que os átomos se desintegram de uma maneira randômica, isto quer dizer que não todas as partículas ou energia liberada incidem no detector. Isto significa que se o número de desintegrações de uma amostra é contado varias vezes, cada uma com a mesma duração, o resultado será em torno de um valor médio. A radiação de fundo sempre terá um valor finito, mesmo que a amostra não possua radioatividade [109]. 


\subsubsection{Avaliação de incertezas.}

Todos os gráficos obtidos tanto para nêutrons térmicos quanto para nêutrons rápidos utilizando os três tipos de fontes de nêutrons descritas em 4.1.7 possuem incertezas produto da cadeia de aquisição de dados utilizada neste trabalho.

Estas incertezas estão relacionadas com os seguintes itens:

a) Incertezas na medição do fluxo de nêutrons.

A incerteza do valor de um fluxo de nêutrons obtido experimentalmente (no caso da instalação de Neutrongrafia) é dependente principalmente da eficiência da contagem da fôlha de ativação utilizada, da seção de choque do isótopo alvo e do nível de potência do reator quando da irradiação. No caso deste trabalho a incerteza na determinação da atividade foi assumida como sendo de um valor em torno de 3 e $6 \%$ para o fluxo térmico e epitérmico respectivamente, para um nível de confiança de $68 \%(1 \sigma)$. Esta incerteza inclui a estatística da contagem, o tempo de irradiação e a eficiência do contador para um dado isótopo. Normalmente esta eficiência do contador é determinada irradiando a fôlha (Au) com um campo de nêutrons conhecido, o qual é corrigido devido à perturbação do fluxo pela fôlha. A incerteza da seção de choque de ativação para um dado tipo de fôlha varia em até 10\% [109]. A estimativa da incerteza na potência do reator é de aproximadamente de $6 \%$ para uma potência nominal $2 \mathrm{MW}$ térmicos [110].

A incerteza devida à contagem da atividade $\left(\mathrm{I}_{\mathrm{CF}}\right)$ é igual a:

$$
I_{C F}=\sqrt{I_{c}^{2}+I_{S c(A u)}^{2}}
$$

em que $\mathrm{I}_{\mathrm{c}}$ e $\mathrm{I}_{\mathrm{Sc}(\mathrm{Au})}$ são as incertezas devidas às contagens da atividade e da seção de choque de choque de ativação respectivamente, resultando em uma incerteza $\mathrm{I}_{\mathrm{CF}}$ igual a $11,7 \%$

Assumindo que a incerteza parcial $\left(I_{P}\right)$ neste caso é dada por:

$$
I_{P}=\sqrt{I_{e c}^{2}+I_{\mathrm{Pr}}^{2}}
$$


em que $I_{e c}$ é a incerteza na eficiência da contagem da fôlha de ativação e $I_{P r}$ a incerteza na medição de potência do reator, sendo o valor total acumulado na medição de fluxo de 13,15\% aproximadamente.

\section{b) Incertezas nos componentes da aquisição de dados.}

As incertezas nas medições foram realizadas somente com os dados obtidos na instalação de Neutrongrafia usando os detectores TMF-1 e S3590-04(A) ambos polarizados com uma tensão reversa de $40 \mathrm{~V}$ e conversor de polietileno de $0,12 \mathrm{~mm}$ como gerador de prótons de recuo. Isto, devido ao fato que houve a necessidade de preservar a integridade dos componentes aos danos por irradiação. Os cálculos foram relacionados com os valores de contagens para cada amostra ( 5 em total) em um mesmo intervalo de energia, entre $500 \mathrm{keV}$ e $1 \mathrm{MeV}$. A Tabela 9 apresenta os resultados dos cálculos utilizando os gráficos da Figura 52.

Tabela 9: Resultado da média, desvio padrão (DP) e incerteza para as medições (S1 a S5 em contagens por segundo) realizadas na instalação de Neutrongrafia usando o detector TMF-1 e o fotodiodo S3590-04(A) com conversor de polietileno de 0,12 $\mathrm{mm}$ de espessura.

\begin{tabular}{|c|c|c|c|c|c|c|c|c|}
\hline Diodo & S1 & S2 & S3 & S4 & S5 & Média & DP* & Incert** \\
\hline TMF-1 & 379,95 & 382,51 & 388,89 & 385,14 & 385,36 & 384,37 & 19,6 & $5,1 \%$ \\
\hline S3590 & 87,83 & 86,75 & 88,80 & 88,50 & 87,33 & 87,84 & 9,37 & $10,7 \%$ \\
\hline
\end{tabular}

* Desvio Padrão ** Incerteza

Por outro lado, como este trabalho trata de uma avaliação, não foi considerado o erro na atividade nominal das fontes utilizadas para a calibração do canal de aquisição de dados, além disso, foi assumido o erro obtido utilizando o software Maestro, como a incerteza na medição (detecção), ou seja, só foi considerado o desvio padrão nas contagens.

c) Considerações sobre o software Maestro utilizado na aquisição de dados de detecção.

As curvas de Bragg, obtidas pelo software Maestro, indicam os valores de Energia vs Contagens para cada situação. O software permite obter os valores do pico maior de energia e a contagem correspondente, o número bruto de contagens (GA-Gross Area), o número líquido das contagens (NA-Net Area) e seu correspondente desvio padrão, e o valor bruto correspondente às contagens por segundo (cps), conforme o tempo de contagem $\left(\mathrm{T}_{\mathrm{c}}\right)$, obtido através do valor de GA dividido pelo tempo $\left(\mathrm{T}_{\mathrm{c}}\right)$ em segundos [111]. O APÊNDICE E (página 111) mostra o detalhe para avaliação de desvio padrão do software Maestro. 
Como exemplo, a Figura 58 mostra a janela operacional do software Maestro. Tem-se a curva de resposta para nêutrons térmicos e epitérmicos do detector TMF-1 na instalação de Neutrongrafia, polarizado com $40 \mathrm{~V}$ e usando conversor de polietileno de 0,12 $\mathrm{mm}$. Esta janela mostra os parâmetros de: número bruto de contagens (GA), o número real de contagens (NA) e a taxa de contagens (cps) para o tempo de aquisição em segundos.

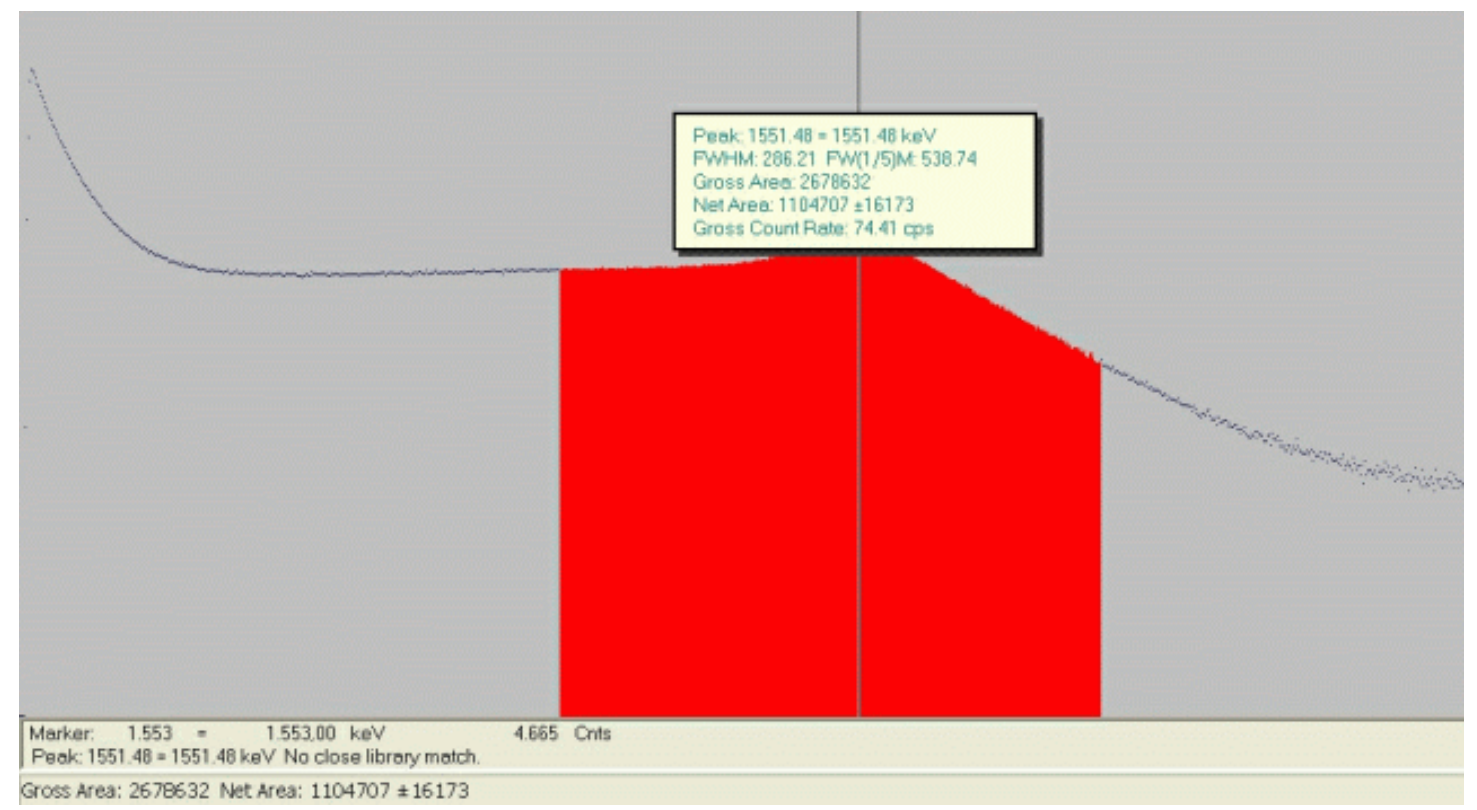

Figura 58: Exemplo da janela operacional do Software Maestro mostrando o número bruto de contagens (GA), o número real de contagens (NA) e a taxa de contagens em cps.

Cabe salientar que o valor de desvio padrão indicado para as situações de detecção de nêutrons térmicos e rápidos depende do intervalo de energia considerado.

A Tabela mostrada no APÊNDICE F (página 113) indica os valores do número bruto de contagens (Gross Area), o número líquido ou real de contagens (Net Area) e o valor bruto correspondente aos impulsos por segundo (ips), o tempo de contagens $\left(\mathrm{T}_{\mathrm{c}}\right)$ e o desvio padrão ou incerteza padrão da medição [111].

Existe também um valor de erro relativo no cálculo (usando MCNP) do fluxo que emerge do moderador constituído pela parafina e do fluxo de nêutrons rápidos que incide no sistema conversor-detector, sendo estes de $0,016 \%$ e $0,1 \%$ respectivamente. 


\subsubsection{Resultado das incertezas.}

Para a instalação de Neutrongrafia utilizando os dados indicados nos itens 6.12.1 e da Tabela 9 tem-se que:

a) incerteza na medição e cálculo do fluxo de nêutrons térmicos e epitérmicos da instalação igual a $13,15 \%$

b) incerteza $\left(\mathrm{I}_{\mathrm{M}}\right)$ no canal de aquisição de dados (Tabela 9) igual a 5,1 e 10,7 para o detector TMF-1 e o fotodiodo S3590-04(A) respectivamente, isto como resultado da análise do exemplo indicado.

A incerteza total de detecção ( $\left.\mathrm{I}_{\mathrm{DT}}\right)$ neste caso é dada por:

$$
I_{D T}=\sqrt{I_{T}^{2}+I_{M}^{2}}
$$

A incerteza total na detecção $\left(\mathrm{I}_{\mathrm{DT}}\right)$ é igual a $14,1 \%$ e $17 \%$ para o detector TMF-1 e o fotodiodo S3590-04(A) respectivamente.

\subsection{Dosimetria de nêutrons.}

Considerando os resultados obtidos no desenvolvimento da parte experimental, este trabalho teve como objetivo final uma abordagem para a dosimetria de nêutrons baseada na utilização de dois diodos.

\subsubsection{Dosimetria utilizando dois fotodiodos "pareados".}

Embora na prática não fosse implementada a utilização de dois diodos devido ao requisito fundamental de que os diodos devem possuir características idênticas, o que é difícil de obter com componentes comercializados normalmente, existe a possibilidade de se implementar um instrumento de medições dosimétricas para nêutrons com componentes PIN especiais fabricados pela HAMAMATSU, por exemplo.

No APÊNDICE G (página 114) deste trabalho é feita uma proposta de pesquisa para a implementação desta técnica utilizando dois diodos [112]. 


\section{7. - DISCUSSÃO GERAL}

\subsection{Considerações finais}

Com referência à calibração em energia, os três fotodiodos da Hamamatsu apresentaram uma resposta similar, mas sua sensibilidade resultou bem diferente. Isto é devido a diferenças na área sensível de cada componente (Figura 37). Conforme a resposta apresentada, o detector S1336-18BR poderia ser utilizado para estudos em microdosimetria pela sua área de $0,012 \mathrm{~cm}^{2}$, mas o tipo $\mathrm{S} 1223-01$ seria mais adequado pois sua camada de depleção pode ser ajustada até $8 \mu \mathrm{m}$, para o diodo sem polarização. Além disso, este fotodiodo apresentou uma baixíssima resposta aos gamas quando polarizado com $0 \mathrm{~V}$ e sua resposta para nêutrons rápidos foi similar em termos de energia (até 2,5 $\mathrm{MeV}$ aproximadamente nos dois casos). Todos os fotodiodos PIN apresentaram uma resolução similar em torno de $8 \%$.

Os resultados com os componentes de Barreira de Superfície da ORTEC não foram satisfatórios. Na resposta usando uma fonte de ${ }^{241} \mathrm{Am}$ percebeu-se a dificuldade para se trabalhar com este tipo de detector, embora o tipo TMF-1 fabricado no IPEN apresentou de uma forma geral a melhor sensibilidade na resposta a nêutrons térmicos e rápidos, sendo isto coerente com sua área sensível, maior que a dos outros componentes. O detector S3590-04 apresentou também uma boa resposta e foi este componente o utilizado para finalizar a parte experimental da avaliação dos componentes semicondutores.

A resposta para nêutrons térmicos do fotodiodo S3590-04 foi satisfatória para o esquema de medição de nêutrons térmicos tendo resultados similares a outros trabalhos semelhantes para este tipo de detecção [23, 25 e 50].

Para nêutrons rápidos os resultados dos detectores TMF-1 e S3590-04 foram semelhantes, embora o TMF-1 apresenta-se melhor sensibilidade e suas respostas foram também similares às de trabalhos sobre detecção de nêutrons rápidos utilizando fôlhas de polietileno [56, 65, 86, e 113].

Para uma melhor aproximação dos valores mínimo e máximo de energia é necessário dispor de um gerador de nêutrons monoenergéticos (aceleradores) e de simulações usando o código de Monte Carlo (código FLUKA). Alguns grupos de pesquisas têm desenvolvido 
experiências com nêutrons rápidos estabelecendo uma teoria para a simulação usando esta ferramenta [65].

Com referência à eficiência global de detecção de nêutrons (fonte de $\mathrm{AmBe}$ ):

a) para nêutrons rápidos a resposta do TMF-1 $\left(3,14 \mathrm{~cm}^{2}\right.$ de área), utilizando o polietileno $(0,12 \mathrm{~mm}$ de espessura) como gerador de prótons de recuo, foi igual a 0,23\% Para o fotodiodo PIN de $1 \mathrm{~cm}^{2}$ de área a eficiência de detecção de nêutrons rápidos usando fôlha de polietileno de $1 \mathrm{~mm}$ de espessura (prótons de recuo) foi igual a $0,1 \%$.

b) A eficiência de detecção para nêutrons térmicos com o uso do conversor ${ }^{10} \mathrm{~B}$ foi de $1 \%$ e de $0,25 \%$ para o detector TMF-1 e o fotodiodo S3590-04(A) respectivamente.

c) a espessura ideal de polietileno para gerar prótons de recuo pela incidência de nêutrons rápidos de uma fonte de $\mathrm{Am}-\mathrm{Be}$ foi de $0,58 \mathrm{~mm}$ determinada experimentalmente, mas na parte experimental foi utilizado uma lâmina de $1 \mathrm{~mm}$ de espessura.

d) Para aplicação em monitoramento de potência em ambiente de reator experimental de baixa potência (UCRI) o conversor de polietileno apresenta-se adequado, considerando a altura de pulso dos sinais gerados pelos prótons de recuo e da radiação gama de fundo. Neste caso os semicondutores mostraram a viabilidade de utilizá-los como uma ferramenta de suporte quando da calibração de potência de operação de um reator experimental deste tipo, embora uma análise através de códigos de simulação (MCNP) seja necessária para otimizar a espessura do polietileno para geração de prótons de recuo considerando o fluxo do reator a diversas potências (de 1 a $100 \mathrm{~W}$ ).

Para uma melhor análise dos espectros obtidos é necessário desenvolver um algoritmo usando o código de Monte Carlo. Em termos de detecção este fotodiodo HAMAMATSU mostra a viabilidade de se implementar um espectrômetro baseado em conversores de nêutrons rápidos para prótons de recuo em um intervalo de energia limitado $(1,0$ a 5,0 MeV).

Para minimizar a contribuição de fótons e aprimorar a exatidão do espectro de nêutrons pode ser usada a técnica de discriminação por forma de pulso (Pulse-shape discrimination). A vantagem desta técnica é que permite trabalhar com o diodo configurado 
na sua máxima depleção, embora seja necessário, para esta aplicação, uma instrumentação eletrônica mais sofisticada no que diz respeito do número de módulos NIM (Nuclear Instrumentation Modules) e do requisito de uma excelente calibração do canal de aquisição de dados [114-116]. 


\section{8. - CONCLUSÕES}

O projeto implementado cumpriu com os objetivos programados e os resultados mostraram a viabilidade de se trabalhar em detecção de campos mistos e estimativas de dose utilizando componentes semicondutores. $\mathrm{O}$ desenvolvimento foi centralizado na detecção de nêutrons térmicos epitérmicos e rápidos utilizando o fotodiodo S3590-04 (HAMAMATSU).

Os resultados indicaram que os componentes de barreira de superfície (ORTEC e IPEN) e os fotodiodos (HAMAMATSU) são adequados para o desenvolvimento experimental junto com o preamplificador 142AH (ORTEC)

Foi utilizado o código de simulação Monte Carlo para definir o fluxo de nêutrons térmicos emergentes do moderador a parafina $(70 \mathrm{~mm})$ para termalizar os nêutrons rápidos de uma fonte de $\mathrm{AmBe}(37 \mathrm{GBq})$. Os resultados mostraram sua aplicabilidade como uma ferramenta de trabalho de suporte.

Em comparação ao fotodiodo S3590-04 (A e B) o detector de Barreira de Superfície TMF-1 tem uma melhor resposta devido à maior sensibilidade, sendo isto coerente com sua área $\left(3,14 \mathrm{~cm}^{2}\right)$ e sua camada de depleção (460 $\mu \mathrm{m}$ para $40 \mathrm{~V}$ de polarização). $\mathrm{O}$ fotodiodo S3590-04(A) teve um desempenho semelhante e resposta proporcional a sua área $\left(1 \mathrm{~cm}^{2}\right)$ em comparação com o detector TMF-1.

As respostas da detecção de nêutrons térmicos e rápidos (usando o fotodiodo S3590-04 e o detector TMF-1) foram similares às de trabalhos de outros grupos de pesquisas envolvendo a utilização de conversores de ${ }^{10} \mathrm{~B}$ e fôlhas de polietileno para a detecção de prótons de recuo.

A eficiência global de detecção de nêutrons utilizando o polietileno como gerador de prótons de recuo no detector TMF-1 $\left(3,14 \mathrm{~cm}^{2}\right.$ de área) foi igual a 0,23\%. Para o fotodiodo S3590-04(B) a eficiência de detecção foi de 0,1 \%. Para nêutrons térmicos a eficiência (usando conversor de ${ }^{10} \mathrm{~B}$ ) foi de $1 \%$ e $0,25 \%$ para o detector TMF-1 e para o fotodiodo S3590-04(B) respectivamente. 
A resposta aos nêutrons térmicos e epitérmicos desenvolvida na instalação de Neutrongrafia mostrou que o fotodiodo S3590-04(B) pode vir a ser utilizado como componente primário de um sistema de monitoração em campos de irradiação aplicados em BNCT (Terapia de Captura de Nêutrons pelo Boro).

Os fotodiodos S1223-01 e S1336-18BR podem ser utilizados para o desenvolvimento de aplicação em Microdosimetria devido a suas características particulares de área e camada de depleção. Cabe salientar que para este tipo de desenvolvimento é imprescindível o uso de um Contador Proporcional Equivalente ao Tecido (TEPC) para comparação e validação da resposta dos componentes em Microdosimetria.

Dos resultados do fotodiodo S3590-04 utilizando o conversor de polietileno borado pode ser concluído que ele pode servir como elemento primário de detecção em um sistema dosimétrico do tipo diferencial (o sinal correspondente à radiação gama é subtraído do sinal dos nêutrons), permitindo uma discriminação macroscópica da componente dos fótons.

Foram estabelecidas duas abordagens (critérios) para a utilização (como exemplo) dos dados obtidos na parte experimental para obter a dose equivalente de nêutrons.

Os resultados mostraram a viabilidade de se utilizar um sistema de detecção de nêutrons térmicos utilizando um par de diodos PIN como elementos primários de um sistema dosimétrico diferencial, como ilustrado no APÊNDICE G.

Com base em todo o estudo e pesquisas desenvolvidas pode-se afirmar que: o Fotodiodo S3590-04 da Hamamatsu pode ser utilizado como o componente principal de detecção de um sistema dosimétrico para monitoramento de nêutrons em instalações nucleares, como uma ferramenta em verificações de campo em proteção radiológica e verificação em cálculos de blindagens, em culturas biológicas (BNCT) e como uma ferramenta (de baixo custo) para propósitos de ensino (detecção de partículas alfa). 


\section{9. - PROPOSTA DE TRABALHOS FUTUROS}

9.1 Sistema de detecção diferencial a ser aplicado em dosimetria de nêutrons térmicos utilizando dois fotodiodos "pareados".

A implementação do sistema: o primeiro fotodiodo é coberto com um material orgânico dopado com ${ }^{10} \mathrm{~B}$, sendo sensível aos nêutrons e fótons (conversor de polietileno borado); o segundo fotodiodo permanece exposto sem nenhum tipo de conversor ou coberto por uma lâmina de cádmio, sendo menos sensível (quando exposto) aos nêutrons do que aos fótons ou permitindo apenas a passagem da radiação gama quando coberto com cádmio. No APÊNDICE D mostra-se o esquema de desenvolvimento desta técnica [112-117].

9.2. Sistema dosimétrico para determinar a dose equivalente usando fotodiodo como elemento primário de detecção e instrumento rastreado (padrão de calibração).

Outra proposta (abordagem) para se utilizar um fotodiodo como elemento primário de um sistema dosimétrico, é realizar uma aquisição de dados com este fotodiodo e relacioná-la com a dose medida por um instrumento rastreado (calibrado com padrão secundário, pelo menos). Para isto é necessário submeter o fotodiodo a campos de radiação neutrônicos, por exemplo, de um Laboratório de Calibração e comparar as taxas de contagens obtidas com as taxas de doses medidas com um instrumento calibrado para o equivalente de dose ambiente H*(10), por exemplo o Berthold LB 6411, para uma serie de distâncias entre 5 e $150 \mathrm{~cm}$. A comparação resultará em uma relação (equação) entre a taxa de contagem (c.min ${ }^{-1}$ ) e a taxa de equivalente de dose ambiente $\mathrm{H}^{*}(10) \mathrm{em} \mathrm{Sv}^{-1}$ [68].

9.3 Desenvolvimento de uma metodologia para a obtenção de uma estimativa de equivalente de dose (dosímetro individual) utilizando os dados de detecção de nêutrons obtidos com semicondutores fotodiodos.

Para obter uma estimativa de equivalente de dose, somam-se os valores, por exemplo, de equivalente de dose correspondentes aos nêutrons térmicos até $1 \mathrm{MeV}\left(\mathrm{H}_{\mathrm{t}}\right)$ e os correspondentes aos nêutrons rápidos acima de $1 \mathrm{MeV}\left(\mathrm{H}_{\mathrm{r}}\right)$. $\mathrm{O}$ equivalente de dose total $\left(\mathrm{H}_{\mathrm{T}}\right)$ é expresso da maneira seguinte:

$$
H_{T}=H_{r}+H_{t}=a C_{r}=b C_{t}
$$


onde $C_{r}$ e $C_{t}$ são as contagens obtidas dos dois detectores acima do corte de raios- $\gamma$ e os coeficientes $a$ e $b$ são dados pela expressões seguintes [118]

$$
\begin{gathered}
a=\frac{\int_{1 M e V} h_{10}(E) \phi(E) d E}{\int_{1 M e V} R_{r}(E) \phi(E) d E} \\
b=\frac{\int_{t e ́ r m i c o s}^{1 M e V} h_{10}(E) \phi(E) d E}{\int_{\text {térmicos }}^{1 M e V} R_{t}(E) \phi(E) d E}
\end{gathered}
$$

onde $R_{r}(E)$ e $R_{t}(E)$ são as respectivas funções respostas dos detectores para nêutrons rápidos e térmicos e $h_{10}(E)$ é o fator de conversão de fluência para equivalente de dose dado pela ICRP 51 [118]. Os dados para a estimativa de equivalente de dose são mostrados no APENDICE VII (Tabela 9).

9.4 Caracterização completa de um elemento sensor (semicondutor), moderadores $e$ conversores sob campos mistos nêutron-gama usando simulação por código de Monte Carlo.

9.5 Módulo de monitoração de nêutrons de área utilizando fotodiodos e comunicação de dados via Ethernet e sem fio (wireless).

9.6 Desenvolvimento de medições eletrônicas na detecção da radiação em campos mistos nêutrons-gama utilizando a técnica de discriminação por forma de pulso.

9.7 Projeto de Medidor de Rotina (Survey Meter) baseado em componentes semicondutores para aplicações em proteção radiológica. 


\section{APÊNDICE A}

Modelagem da fonte de AmBe e do moderador (parafina) utilizado para os cálculos de fluxo térmico usando o código de Monte Carlo.

Caso 1: Cálculo da termalização de nêutrons procedentes de uma fonte de $\mathrm{AmBe}(37 \mathrm{GBq})$ utilizando parafina como elemento moderador obedecendo o esquema da Figura A1.

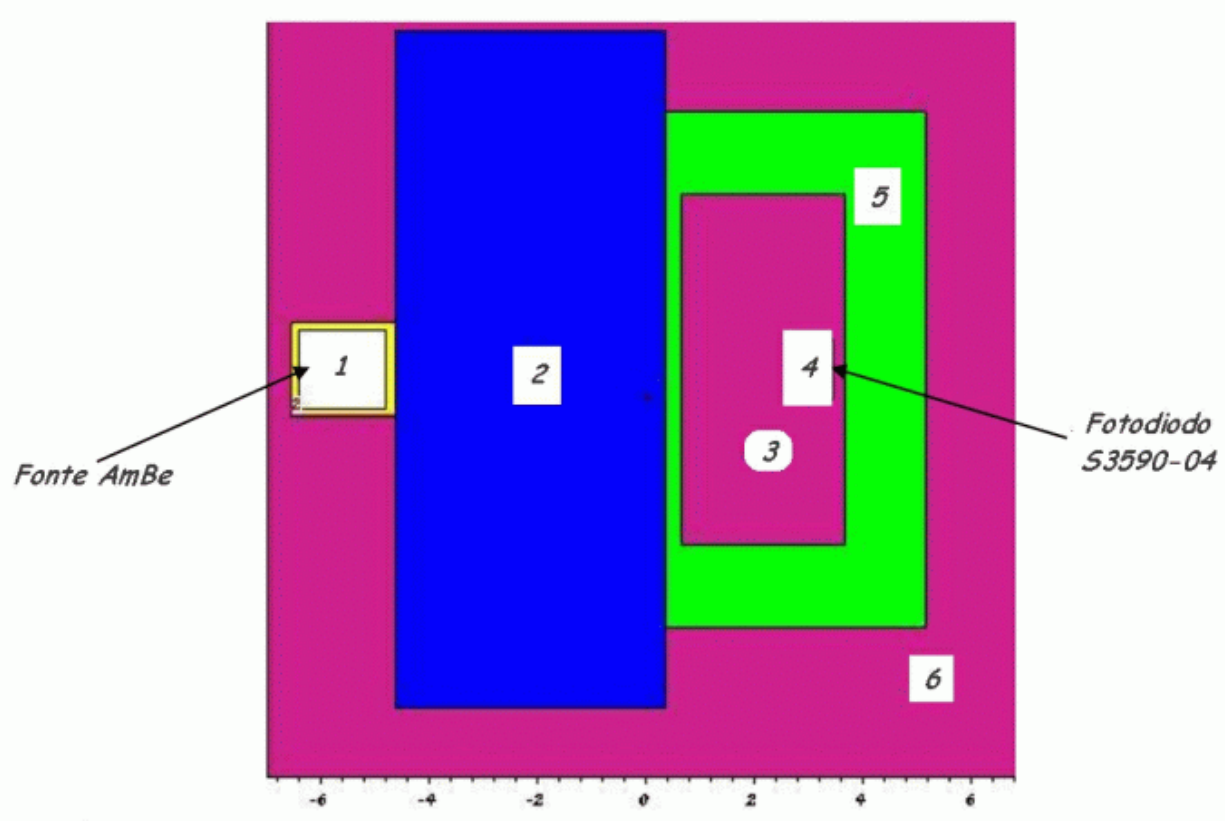

Figura A1: Esquema da modelagem (MCNP) da fonte de nêutrons e o moderador (parafina).

Em que:

1: Fonte de AmBe (com invólucro de aço (cor amarela))

2: Moderador (parafina)

3: Ar, dentro do invólucro do detector

4: Fotodiodo (detector)

5: Invólucro de alumínio.

6: Ar, sala ambiente

Foram modelados a fonte de AmBe e a parafina como moderador para obter o fluxo de nêutrons emergentes que incidem no conversor de ${ }^{10} \mathrm{~B}$ (sem considerá-lo) que cobre a face sensível do sensor. 
Caso 2: Cálculo do fluxo de nêutrons rápidos procedentes de uma fonte de $\mathrm{AmBe}(37 \mathrm{GBq})$ que incidem no elemento sensor (sem considerar qualquer conversor), a uma distância de $30 \mathrm{~mm}$, conforme o esquema mostrado na Figura A2.

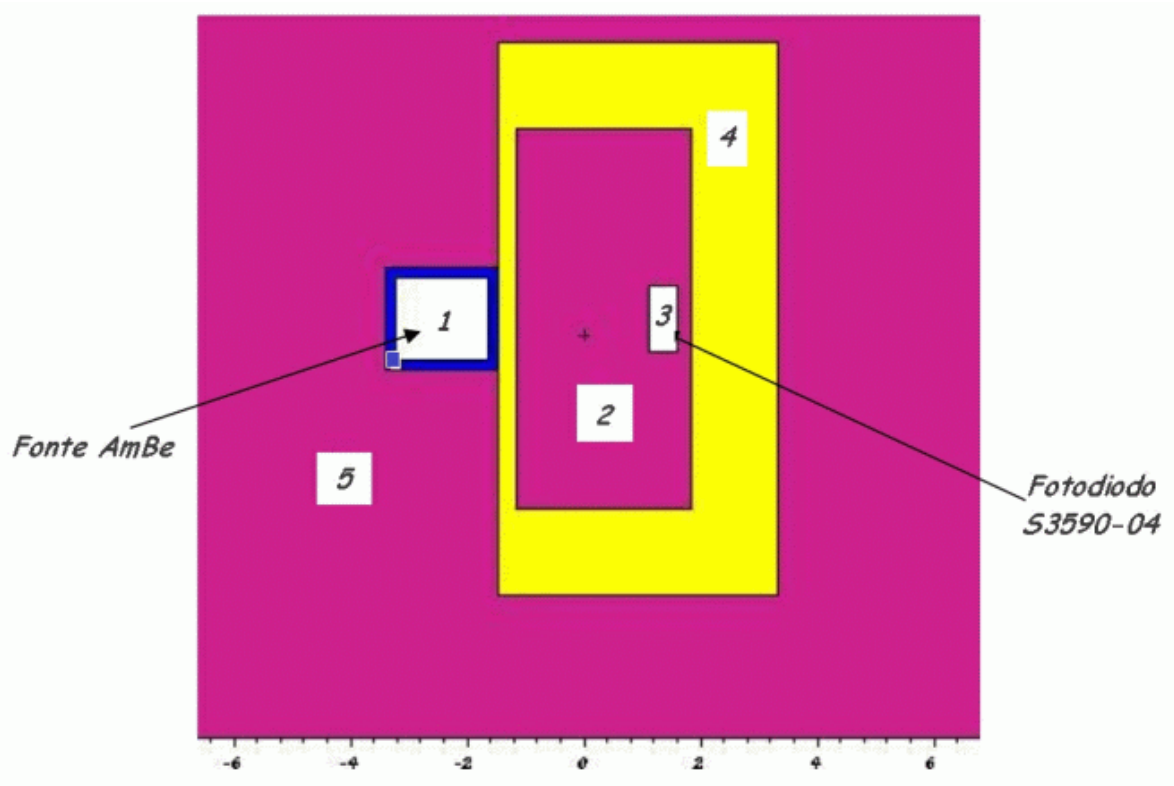

Figura A2: Esquema da modelagem (MCNP) da fonte de nêutrons sem o moderador.

\section{Fonte $\mathrm{AmBe}$}

2. Ar, dentro do invólucro de alumínio do detector

3 Fotodiodo (detector)

4. Alumínio

5. Ar, sala ambiente

Os dados de entrada para a simulação foram os correspondentes à parafina e à fonte de AmBe, que possuía na época (Junho de 2009) uma atividade de 0,940 Ci e uma emissão de nêutrons de 2,07 $10 \mathrm{n} \cdot \mathrm{s}^{-1} \cdot \mathrm{Ci}^{-1}$. A 


\section{APÊNDICE B}

Dados referentes às medições de fluxo na instalação de Neutrongrafia.

Fonte de nêutrons: Canal de Irradiação BH-8 - Filtro de Bismuto $(25 \mathrm{~cm})$

Potência do Reator IEA-R1: 4,2 MW térmicos.

\section{Data e hora das irradiações:}

Fôlha-A : 15/03/2004 as 15:45 hrs a 16/03/2004 às 07:00 hrs

Fôlha-B : 15/03/2004 as 15:45 hrs a 16/03/2004 às 07:00 hrs

Fôlha-C : 16/03/2004 as 07:53 hrs a 16/03/2004 às 15:38 hrs

Fôlha-D : 16/03/2004 as 07:53 hrs a 16/03/2004 às 15:38 hrs

Reação utilizada: ${ }^{197} \mathrm{Au}(\mathrm{n}, \gamma){ }^{198} \mathrm{Au}$

Tipo de Amostra: Au puro - diâmetro 12 mm

Tabela de resultados das medidas de fluxo de nêutrons na instalação de Neutrongrafia

\begin{tabular}{|c|c|c|c|c|c|c|}
\hline $\begin{array}{c}\text { Irradiação } \\
\text { Fôlhas }\end{array}$ & $\begin{array}{c}\text { Fluxo } \\
\text { Térmico } \\
\left(10^{6} \mathrm{~cm}^{-2} \cdot \mathrm{s}^{-1}\right)\end{array}$ & $\begin{array}{c}\text { Incerteza } \\
\text { Absoluta } \\
(\%)\end{array}$ & $\begin{array}{c}\text { Incerteza } \\
\text { Relativa } \\
(\%)\end{array}$ & $\begin{array}{c}\text { Fluxo } \\
\text { Epitérmico } \\
\left(10^{5} \mathrm{~cm}^{-2} \cdot \mathrm{s}^{-1}\right)\end{array}$ & $\begin{array}{c}\text { Incerteza } \\
\text { Absoluta } \\
(\%)\end{array}$ & $\begin{array}{c}\text { Incerteza } \\
\text { Relativa } \\
(\%)\end{array}$ \\
\hline $\mathrm{A}-1$ e 4 & 1,93 & $+43 /-13$ & 3,0 & 5,9 & 60 & 6,0 \\
\hline $\mathrm{B}-3$ e 6 & 0,604 & $+43 /-13$ & 3,0 & 1,95 & 60 & 6,0 \\
\hline $\mathrm{C}-5$ e 8 & 2,02 & $+43 /-13$ & 3,0 & 6,2 & 60 & 6,0 \\
\hline $\mathrm{D}-7$ e 10 & 0,312 & $+43 /-13$ & 3,0 & 1,55 & 60 & 6,0 \\
\hline & & & & & & \\
\hline
\end{tabular}

Nível de confiança: $68 \%$

Obs: Temperatura do moderador considerada em $40{ }^{\circ} \mathrm{C}$.

FONTE: Certificado de calibração de densidade de fluxo de nêutrons ( ${ }^{\circ}$ : F-03/2004)

Laboratório de Metrologia Nuclear - IPEN/CNEN-SP

Responsáveis: Dr. Mauro S. Dias e Dra. Marina Koskinas 


\section{APÊNDICE C}

Medições dosimétricas com instrumento Medidor Portátil (Survey meter) fabricado pela LUDLUM MEASUREMENTS modelo 2363.

Caso 1: Taxa de dose de nêutrons térmicos (nêutrons rápidos da fonte de $\mathrm{AmBe}$ de $37 \mathrm{GBq}$ termalizados com bloco de parafina de $70 \mathrm{~mm}$ de espessura e $100 \mathrm{~cm}^{2}$ de área) Nêutrons térmicos: $496 \mathrm{mrem} \cdot \mathrm{h}^{-1}\left(4,96 \mathrm{mSv} \cdot \mathrm{h}^{-1}\right)$

Radiação gama: $9,5 \mathrm{mrem} \cdot \mathrm{h}^{-1}\left(0,095 \mathrm{mSv} \cdot \mathrm{h}^{-1}\right)$

As medições foram realizadas a uma distância de $50 \mathrm{~mm}$ da parte inferior do bloco de parafina.

Caso 2: Taxa de dose de nêutrons rápidos da fonte de AmBe de $37 \mathrm{GBq}$ sem qualquer moderação.

Nêutrons rápidos: $85 \mathrm{mrem} \cdot \mathrm{h}^{-1}\left(850 \mu \mathrm{Sv} \cdot \mathrm{h}^{-1}\right)$

Radiação gama: $2 \mathrm{mrem} \cdot \mathrm{h}^{-1}\left(20 \mu \mathrm{Sv} \cdot \mathrm{h}^{-1}\right)$

As medições foram realizadas a uma distância de $50 \mathrm{~mm}$ da fonte de nêutrons. 


\section{APÊNDICE D}

Metodologia para a definição do Fator de Conversão Contagens para Dose (Neutrongrafia).

Com os valores de fluxo de nêutrons para uma potência do reator de 2 e 4,2 MW e a taxa de dose equivalente obtida para o reator operando a 2 MW obtém-se os valores de taxa de dose equivalente para nêutrons térmicos e epitérmicos. No caso da instalação de Neutrongrafia utiliza-se a taxa de dose equivalente correspondente a um fluxo epitérmico. Devido a que a taxa de dose para nêutrons epitérmicos é dada em $\mathrm{mSv}^{-1}{ }^{-1}$ e a taxa de contagens é dada em contagens/segundo, deve-se transformar este valor para contagens em um período de uma hora e utilizar a relação indicada em 6.10.2 para obter o Fator de Conversão.

$$
F_{c n v}=\frac{\text { Dose }}{C_{c n t}} \mu \text { Sv.contagens }{ }^{-1}
$$

Dados disponíveis:

Fluxo total do reator a 4,2 MW $=2,5210^{6}=\mathrm{FNT}+\mathrm{FNE}=1,9310^{6}+0,5910^{6}\left[\mathrm{n} \cdot \mathrm{cm}^{-2} \cdot \mathrm{s}^{-1}\right]$

Fluxo total $[96]=1,7510^{6} \rightarrow$ Taxa Dose $=\mathrm{TDN}+\mathrm{TDG}=70 \mathrm{mSv} \cdot \mathrm{h}^{-1}+20 \mathrm{mSv} \cdot \mathrm{h}^{-1}$

Relação de fluxo epitérmico para térmico $=0,59 / 1,93=0,306$

Fluxo reator a $3,5 \mathrm{MW}=($ Fluxo a 4,2 MW $) \cdot(0,833)=2,110^{6}$ [n.cm.s]

Relação entre Fluxos = 2,1 10 $/ 1,7510^{6}=1,2$

Para Fluxo de 2,1 $10^{6}$ tem-se uma Taxa de Dose de Nêutrons $=(70 \mathrm{mSv} \cdot \mathrm{h}) \cdot(1,2)$

Taxa total de dose nêutrons $=$ TDNE + TDNT $=84 \mathrm{mSv} \cdot \mathrm{h}^{-1}$

Taxa de dose de nêutrons epitérmicos $(\mathrm{TDNE})=\left(84 \mathrm{mSv} \cdot \mathrm{h}^{-1}\right) \cdot(0,306)=25,7 \mathrm{mSv} \cdot \mathrm{h}^{-1}$

TDNE $=25,7 \mathrm{mSv} \cdot \mathrm{h}^{-1}$

Taxa de dose de nêutrons térmicos $($ TDNT $)=\left(84 \mathrm{mSv}^{-1} \mathrm{~h}^{-1}\right)(0,694)=58,3 \mathrm{mSv} \cdot \mathrm{h}^{-1}$

\section{TDNT = 58,3 mSv.h . $^{-1}$}

Em que:

FNT = Fluxo de nêutrons térmicos

$\mathrm{FNE}=$ Fluxo de nêutrons epitérmicos.

TDN = Taxa de dose equivalente correspondente aos nêutrons.

$\mathrm{TDG}=$ Taxa de dose equivalente correspondente à radiação gama.

TDNE $=$ Taxa de dose equivalente de nêutrons epitérmicos.

TDNT $=$ Taxa de dose equivalente de nêutrons térmicos.

\section{APÊNDICE E}


Considerações na aquisição de dados utilizando o software Maestro.

Os sistemas de aquisição de dados em espectroscopia utilizam uma fração de tempo, usualmente em torno de 1 a $70 \mu \mathrm{s}$, para processar os pulsos procedentes do detector. Enquanto os módulos amplificadores de espectroscopia e conversão analógica-digital processam um pulso, existe a possibilidade de um outro pulso não ser processado neste período de tempo. Neste caso diz-se que a "eletrônica do sistema está morta" ou inoperante para os pulsos entrantes, sendo isto conhecido como "Tempo Morto" (DT). Em situações em que as taxas de pulsos entrantes são pequenas (menores que uma centena de contagens por segundo) e constantes, existe uma pequena probabilidade que o primeiro pulso não seja processado completamente antes que um outro pulso incida no detector.

Entretanto, em algumas aplicações, a taxa de contagens pode ser alta ou variar rapidamente (de uma baixa até uma alta taxa de contagens em menos de $100 \mathrm{~s}$ ), no ponto onde o processamento de um pulso se sobrepõe ao tempo de incidência do pulso subseqüiente. Nestes casos a probabilidade de perdas por tempo morto resulta bem maior [114].

O software Maestro, além de gerar os gráficos, inclui vários parâmetros úteis para uma análise de Tempo Morto (DT - Dead Time), Tempo de Aquisição de Dados (LT - Live Time), Tempo de aquisição Real (RT - Real Time) e o relógio do tempo de coleta de dados (LTC Live Time Clock).

O cálculo do Tempo Morto é dado pela relação:

$$
D T=1-\frac{L T}{R T}
$$

Um conhecimento apurado do tempo de aquisição das contagens permite os cálculos para resultados estatísticos em termos das taxas de contagens. Uma forma simples de expressar a taxa de contagens para qualquer pico de energia é a seguinte:

$$
P=\frac{\text { Área }}{L T}
$$


em que a área considerada é a correspondente abaixo da curva no intervalo de energia estabelecido. A incerteza nesta taxa de contagem no pico de energia é dada por:

$$
\sigma_{P}=\sqrt{\frac{A ́ \text { rea }}{L T}}
$$

devido ao fato que os eventos registrados nestas áreas seguem uma relação estatística de Poisson. 


\section{APÊNDICE F}

Parâmetros de detecção dos semicondutores utilizados (TMF-1 e S3590-04(A)) obtidos através da analise das curvas obtidas usando o software Maestro.

Tabela 10: Parâmetros obtidos usando o software de aquisição de dados Maestro (ORTEC) na detecção de nêutrons térmicos e rápidos usando os semicondutores TMF-1 e S3590-04(A).

\begin{tabular}{|c|c|c|c|c|c|c|}
\hline Detector & $\begin{array}{c}\text { Fonte } \\
\text { Nêutrons }\end{array}$ & $\begin{array}{c}\text { Tempo } \\
\text { Aquisiçãa } \\
\text { (s) }\end{array}$ & $\begin{array}{c}\text { Contagem } \\
\text { Bruta }\end{array}$ & $\begin{array}{l}\text { Cont. por } \\
\text { segundo } \\
\text { (cps) }\end{array}$ & $\begin{array}{c}\text { Desvio } \\
\text { Padrão } \\
(\sigma)\end{array}$ & $\begin{array}{c}\text { Tempo } \\
\text { Morto } \\
(\%)\end{array}$ \\
\hline $\begin{array}{c}\text { TMF-1 } \\
\text { Cnv- }{ }^{10} \mathrm{~B}\end{array}$ & $\mathrm{AmBe}$ & 18000 & 568992 & 31.6 & 5,62 & 0,24 \\
\hline $\begin{array}{l}\text { TMF-1 } \\
\text { Cnv-P }_{0}\end{array}$ & $\mathrm{AmBe}$ & 36000 & 2770496 & 76,9 & 8,77 & 0,75 \\
\hline $\begin{array}{c}\mathrm{S} 3590 \\
\mathrm{Cnv}-{ }^{10} \mathrm{~B}\end{array}$ & $\mathrm{AmBe}$ & 7200 & 17899 & 2,49 & 1,58 & 0,01 \\
\hline $\begin{array}{l}\text { S3590 } \\
\text { Cnv-P }_{o}\end{array}$ & $\mathrm{AmBe}$ & 7200 & 78617 & 10,9 & 3,3 & 0,05 \\
\hline $\begin{array}{l}\text { TMF-1 } \\
\text { Cnv-P }\end{array}$ & $\begin{array}{l}\text { Nêutron } \\
\text { grafia }\end{array}$ & 200 & 108344 & 541,72 & 23,27 & 4,52 \\
\hline $\begin{array}{c}\mathrm{S} 3590 \\
\mathrm{Cnv}-{ }^{10} \mathrm{~B}\end{array}$ & $\begin{array}{l}\text { Nêutron } \\
\text { grafia }\end{array}$ & 300 & 5712801 & 19042,67 & 137,9 & 52,32 \\
\hline $\begin{array}{l}\mathrm{S} 3590 \\
\mathrm{Cnv}^{-P_{o}}\end{array}$ & $\begin{array}{c}\text { Nêutron } \\
\text { grafia }\end{array}$ & 300 & 127168 & 423,9 & 20,6 & 6,11 \\
\hline $\begin{array}{l}\text { TMF-1 } \\
\text { Cnv-P }\end{array}$ & $\begin{array}{l}\text { UCRI } \\
(4 \mathrm{~W})\end{array}$ & 600 & 367756 & 612,9 & 24,75 & 30,71 \\
\hline $\begin{array}{l}\text { S3590 } \\
\text { Cnv-Po }\end{array}$ & $\begin{array}{l}\text { UCRI } \\
(5 \mathrm{~W})\end{array}$ & 300 & 35605 & 118,68 & 10,9 & 11,97 \\
\hline
\end{tabular}

Conv- ${ }^{10} \mathrm{~B}=$ conversor $\mathrm{de}{ }^{10} \mathrm{~B}$

Conv- $\mathrm{P}_{\mathrm{o}}=$ conversor de polietileno 


\section{APÊNDICE G}

\section{Dosimetria utilizando dois fotodiodos "pareados" (matched).}

Embora na prática não fosse implementada a utilização de dois diodos devido ao requisito fundamental de que os diodos devem possuir características idênticas, o que é difícil de obter com componentes comercializados normalmente, existe a possibilidade de se implementar um instrumento de medições dosimétricas para nêutrons com componentes PIN especiais fabricados pela HAMAMATSU, por exemplo.

Os resultados deste trabalho mostraram a viabilidade de se utilizar um sistema de detecção de nêutrons térmicos utilizando um par de diodos PIN como elementos primários de um sistema dosimétrico diferencial baseado em trabalhos desenvolvidos por alguns autores [54-59]. O primeiro fotodiodo é coberto com um material orgânico dopado com ${ }^{10} \mathrm{~B}$, sendo sensível aos nêutrons e fótons (conversor de polietileno borado). O segundo fotodiodo permanece exposto sem nenhum tipo de conversor ou coberto por uma lâmina de cádmio, sendo menos sensível (quando exposto) aos nêutrons do que aos fótons ou permitindo apenas a passagem da radiação gama quando coberto com cádmio. Estes diodos são colocados muito perto um do outro em um ângulo normal ao campo de radiação.

A reação $\mathrm{H}(\mathrm{n}, \mathrm{p})$ com os núcleos dos átomos de hidrogênio produzirá prótons de recuo, em que o ângulo de emissão destes prótons será dependente da direção e energia dos nêutrons incidentes.

A reação ${ }^{10} \mathrm{~B}(\mathrm{n}, \alpha){ }^{7} \mathrm{Li}$ do ${ }^{10} \mathrm{~B}$ produzirá partículas alfa com um ângulo de emissão isotrópico.

As partículas carregadas secundárias perdem sua energia: no próprio conversor, na camada morta do diodo e finalmente na camada sensível. A Figura G1 ilustra uma proposta para um dosímetro usando esta técnica de detecção. Através da diferença dos sinais tem-se o valor real apenas do espectro correspondente a nêutrons térmicos [54-59]. 


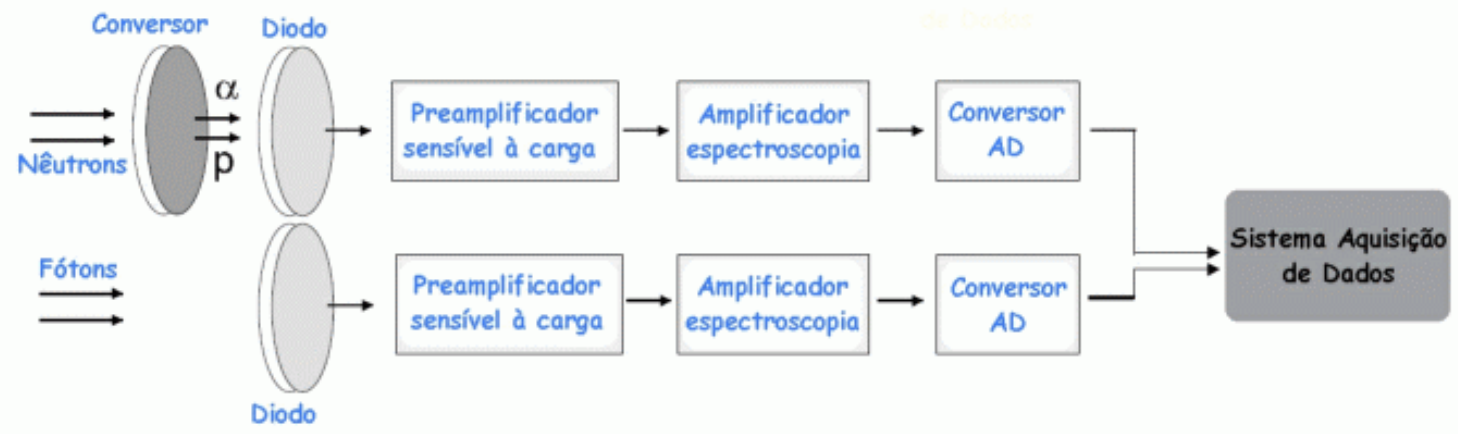

Figura G1: Esquema da proposta de dosímetro usando a técnica de detecção diferencial.

Através da diferença dos sinais tem-se o valor real apenas do espectro correspondente a nêutrons térmicos. Com este resultado e os dados obtidos através da abordagem sugerida neste trabalho este tipo de semicondutor pode constituir o elemento primário de um sistema dosimétrico para dose equivalente em ambientes de alto fluxo de nêutrons. 


\section{APÊNDICE H}

Metodologia para a obtenção de uma estimativa de equivalente de dose (dosímetro individual) utilizando os dados de detecção de nêutrons obtidos com semicondutores fotodiodos.

Tabela 11: Valores de contagens por segundo (cps), intervalos de energia de nêutrons, fluxo correspondente a cada tipo de medição e a eficiência do detector com conversor.

\begin{tabular}{|c|c|c|c|c|c|}
\hline Fonte & $\begin{array}{c}\text { Nêutrons } \\
0,5-1 \mathrm{MeV} \\
(\mathrm{cps})\end{array}$ & $\begin{array}{c}\text { Nêutrons } \\
1-6 \mathrm{MeV} \\
(\mathrm{cps})\end{array}$ & $\begin{array}{c}\text { Fluxo } \\
\mathrm{n} \cdot \mathrm{cm}^{-2} \cdot \mathrm{s}^{-1} \\
0,5-1 \mathrm{MeV}\end{array}$ & $\begin{array}{c}\text { Fluxo } \\
\mathrm{n} \cdot \mathrm{cm}^{-2} \cdot \mathrm{s}^{-1} \\
1-6 \mathrm{MeV}\end{array}$ & $\begin{array}{c}\text { Eficiência } \\
\mathrm{cntgs.n}^{-1} \cdot \mathrm{cm}^{2}\end{array}$ \\
\hline $\begin{array}{c}\text { AmBe } \\
\left(\text { Conv. }{ }^{10} \mathrm{~B}\right)\end{array}$ & 2,21 & ----- & 994 & ----- & 0,22 \\
\hline $\begin{array}{c}\text { AmBe } \\
(\text { Conv. Poliet } \\
1 \mathrm{~mm})\end{array}$ & ----- & 8,87 & ----- & 10500 & 0,084 \\
\hline $\begin{array}{c}\text { Neutrongrafia } \\
\left(\text { Conv. }{ }^{10} \mathrm{~B}\right)\end{array}$ & 8070 & ----- & $0,4910^{6}$ & ----- & 1,65 \\
\hline $\begin{array}{c}\text { Neutrongrafia } \\
(\text { Conv. Poliet } \\
1 \mathrm{1mm})\end{array}$ & ----- & 577,8 & ---- & $0,4910^{6}$ & 0,118 \\
\hline
\end{tabular}

A função resposta, ou seja, a eficiência de detecção, foi obtida pela soma de todos os pulsos de nêutrons além do corte de gama e dividindo este valor pela fluência de nêutrons expressando o resultado em contagens. $\mathrm{n}^{-1} \cdot \mathrm{cm}^{2}$.

Os gráficos úteis para se obter os parâmetros envolvidos nas estimativas de dose são os seguintes:

a) para nêutrons térmicos, os correspondentes às Figuras 43, para nêutrons no intervalo de energia de $145 \mathrm{keV}$ a $1 \mathrm{MeV}$ (curva da diferença entre nêutrons e radiação gama) usando o conversor de ${ }^{10} \mathrm{~B}$ e fonte de AmBe,

b) para nêutrons rápidos, os correspondentes à Figura 48 para nêutrons rápidos no intervalo de 1 a $4 \mathrm{MeV}$ (curva da diferença entre nêutrons e radiação gama) usando conversor de polietileno (1mm) e fonte de AmBe,

c) a Figura 53 (curva de cor azul), usando o conversor de ${ }^{10} \mathrm{~B}$ e o alto fluxo de nêutrons da instalação de Neutrongrafia para nêutrons no intervalo de energia de $100 \mathrm{keV}$ a $1 \mathrm{MeV}$ e 
d) a Figura 54 (curva na cor azul, diferença de nêutrons e radiação gama) na mesma instalação, usando conversor de polietileno $(1 \mathrm{~mm})$, no intervalo de $753 \mathrm{keV}$ a $2,5 \mathrm{MeV}$.

A resposta dos detectores para nêutrons rápidos e térmicos à fluência em função da energia deve ser calculada usando o código de Monte Carlo. Estes resultados são aplicados nas equações (15) e (16) obtendo os valores de $a$ e $b$ os quais, aplicados na equação (14), resultam no equivalente de dose total $\left(\mathrm{H}_{\mathrm{T}}\right)$. 


\section{REFERÊNCIAS BIBLIOGRÁFICAS}

[1] ORLIC, M., LAZAREVIC, V. and BORELLI, F. "Microdosimetric counters based on semiconductors detectors”. Radiation Protection and Dosimetry, Vol 29, pp. 21-22, 1989.

[2] BARTLETT, D.T., TANNER, R.J.and THOMAS, D.J. “Active neutron personal dosemeters- Current Status". Radiation Protection Dosimetry, Vol.86, No 2, pp.107-122, 1999.

[3] BRADLEY, P.D., ROSENFELD, A.B. and ZAIDER, M., "Solid State Microdosimetry", Nuclear Instruments and Methods in Physics Research, B 184, pp.135-157 (2001).

[4] PEURRUNG, A. J. "Recent developments in neutron detection". Nuclear Instruments and methods in Physics Research, A Vol.443, pp. 400-415, 2002.

[5] DRNDAREVIC, V. "A very low-cost alpha particle espectrometer". School of Traffic Engineering, Belgrade University, Belgrade, Serbia. Measurement Science and Technology, 19, 5pp, 2008.

[6] SANTOS, P. G. "Desenvolvimento de um Sistema de Dosimetria por Diodos para o Controle de Qualidade de Unidades de Teleterapia”, Dissertação de Mestrado, IPEN, Brasil, 2003 .

[7] KHOURY, J.L., MELO, F deA, LIRA, C.A.B. Utilização de Fotodiodos como Detectores de Radiação Ionizante. Anais do $2^{\circ}$ Congresso Brasileiro de Físicos em Medicina, p 82-85, São Paulo, 1987.

[8] TOBIAS, C.C.B., GONÇALVES, J.A.C., SANTOS, S.D., "The performance of low-cost commercial photodiodes for charged particle and X-ray spectrometry". Nuclear Instruments and Methods in Physics Research", A 371, pp. 460-464, 1996.

[9] KHOURY, H.J., HAZIN, C.A., MASCARENHAS, A.P. and SILVA da, E.F. "Low Cost silicon photodiode for electron dosimetry". Radiation Protection Dosimetry, Vol 84, Nos 1-4, pp, 341-343,1999. 
[10] INSTITUTO NACIONAL DO CÂNCER. "Revista Estimativa 2010: Incidência do Câncer no Brasil", 2009.

[11] KLIGERMAN, J. “EDITORIAL” Revista Brasileira de Cancerologia, 48(2), 2002.

[12] SILVA, da, A.B. "Desenvolvimento de um Contador Proporcional Equivalente-Tecido para separação de campos mistos nêutron-gama”. Dissertação de Mestrado, Universidade Federal de Minas Gerais, Belo Horizonte-MG, Brasil, 1991.

[13] AWWAL, M.L. "Determinação da dose absorvida e do fator de qualidade para neutrons e gamas em Microdosimetria”, Dissertação de Mestrado, Escola de Engenharia, UFMG, Brasil, 1994.

[14] WAMBERSIE A et al, "The role of Microdosimetry in Radiotherapy" Radiation. Protection. Dosimetry, Vol 31, pp 421-432, 1990.

[15] ARO, A.C.A. "Microdosimetry relevant to beutron and proton cancer therapy", Ph.D. Thesis, University of Birmingham, Faculty pf Science, U.K., 1992.

[16] MECCA, F. "miniCurso de Proteção Radiológica". INCA - Instituto Nacional do Câncer, 2003.

[17] ICRP 21: Data for Protection Against Ionizing Radiation from External Sources Supplement to ICRP Publication 15, April, 1971.

[18] ICRU 26, "Neutron Dosimetry for Biology and Medicine”, 1977.

[19] JAHAN, Q.M. "Characterization of neutron dosimeters containing perforated neutron detectors". Master of Science Thesis, Department of Mechanical and Nuclear Enginnering, Kansa State University, KS, USA, 2008.

[20] ICRP Publication 60. "Recommendations of the International Commission on Radiological Protection”. Annals of the ICRP 21 (1-3). 
[21] NCRP, Report No. 116, “Limitation of Exposure to Ionizing Radiation”, 1993.

[22] ICRU REPORT 66 "Determination of operational dose equivalent quantities for neutrons", Bethesda, MD, USA, 2001.

[23] ALBERTS, W.G., BORDY, J.M., CHARTIER, J.L., JAHR, R., KLEIN, H., LUSZIKBHADRA, POSNY, F., SCHUHMACHER, H. and SIEBERT, B.R.L. "Neutron Dosimetry". Radioprotection, Vol. 31, 1, pp.37-65, 1996.

[24] WIElUnSKI, M., SCHUZT, R., Fantuzzi, E., Pagnamenta, A., WAHL, W. and J. PALFALVI, J., ZOMBORI, P., A. ANDRASI, A., H. STADTMANN, H. And Ch. Schmitzer, $\mathrm{CH}$. "Study of the sensitivity of neutron sensors consisting of a converter plus Si chargedparticle detector". Nuclear Instruments and Methods in Physics Research A 517, PP. 240253, 2004.

[25] FILHO, T.M. "Desenvolvimento de Detector de Neutrons usando sensor tipo Barreira de Superficie com conversor (n,p) e conversor $(n, \alpha)$ ". Tese de Doutoramento, Instituto de Pesquisas Energéticas e Nucleares, Universidade de São Paulo, São Paulo, Brasil, 1999.

[26] SALGIR T. and WAKER, J. "Neutron spectra of Am-Be sources by use of proton recoil from a shaped converter foil". In Neutron Monitoring, August 29 - September 02, Vienna, Austria, Proceeding-IAEA, pp. 261-268, 1966.

[27] KNOLL, G.F., "Radiation detection and measurement". 3.ed. New York: John Wiley \& Sons, 1989.

[28] ICRU 13, "Neutron Fluence, Neutron Spectra and Kerma", 1969.

[29] IAEA, "Neutron monitoring for radiological protection". IAEA Technical Report series, $\mathrm{N}^{\circ} 252,1985$.

[30] ATTIX, F.H. "Introduction to radiological physics and radiation dosimetry" New York: John Wiley\& Sons, 1986. 
[31] IAEA, 1990 "Compendium of neutron spectra and detector responses for radiation protection purposes”. IAEA Technical Report series, $N^{\circ} 318,1990$.

[32] BLANC, D. "Les rayonnements Ionisants: Detection, Spectrometrie et Dosimetrie”. Ed. Masson, France, 1990.

[33] BAKALI, M. "Espectrometria Neutrônica en Plantas Nucleares utilizando Esferas Bonner". Tesis de Doctorado-Facultad de Ciencias, Departamento de Fisica, Universidade Autonoma de Barcelona, 2001.

[34] ROSSI, H. and ZAIDER, M. "Elements of Microdosimetry"- Medical Physics, 18(6), pp. 1085-1092, 1991.

[35] RIKNER, G. , GRUSELL, E. “General specifications for silicon semisonductors for use in radiation dosimetry". Physics in Medicine and Biology, Vol 32, No 9, pp. 1109-1117, 1987.

[36] RIKNER, G., GRUSELL, E. - "Patient dose measurements in photon fields by means of silicon semiconductor detectors”. Medical Physics, 14(5), pp. 870-873, 1987.

[37] ROSENFELD, A.B., CAROLAN, M.G., KAPLAN, G.I., ALLEN, B.J., KHIVRICH, V. "Mosfet Dosimeters: The role of encapsulation on dosimetric characteristics in mixed Gamma-Neutron and megavoltage X-rays fields” IEEE Transactions on Nuclear Science, Vol 42, No 6 , pp. 1870-1877, 1995.

[38] BARTHE, J. "Electronic dosemeter based on solid state detectors". Nuclear Instruments and Methods in Physics Research, B 184, pp. 158-189, 2001.

[39] BARTESAGHI, G. "Real Time Detectors for Radiotherapic Beams". Doctoral Thesis, Universita degli studi dell'Insubria, Facolta di Scienze Matematiche, Fisiche e Naturali, Anno Accademico 2005-2006, Italia.

[40] SCHRODER O. SCHMITZ T. "Microdosimetric Dosimeters for individual monitoring based on semiconductor detectors”, Rad. Prot. Dosim., Vol 52, pp 431-434, 1994. 
[41] ROSENFELD A. B. , et Al "Simultaneous macro-micro dosimetry with MOSFET's" IEEE Trans. Nucl. Sci. , Vol 43, Nº 6, pp. 2693-2700, 1996.

[42] PODGORSAK, E.B. "Radiation oncology physics - Handbook for teachers and students" IAEA, Vienna, Austria, 2005.

[43] EVELING J. N. et Al "Commissioning a p-type silicon diode for use in clinical eletron beams" (Hospital LANE, Leeds, U.K). Medical physics, 26(1), pp. 100-107, 1999.

[44] RIKNER G.,GRUSELL, E., "Linearity with dose rate of low resistivity p-type silicon semiconductor detectors," Phys. Med. Biol. 38, pp 785-792, 1993.

[45] RIKNER G., GRUSELL E. "Evaluation of temperature effects in p-type silicon detector" Phys. MED. Biol. No 38, 785-792, 1986.

[46] ROSENFELD, A. "Electronic dosimetry in radiation therapy". Radiation Measurements, Vol 41, s134-s153, 2007.

[47] COSTA, F. "Desenvolvimento de conjunto detector cintilador com sistema de contagens e aquisição de dados para medidas de vazão utilizando traçadores radioativos”. Dissertação de Mestrado, Instituto de Pesquisas Energéticas e Nucleares, Universidade de São Paulo, São Paulo, Brasil, 2001.

[48] BIRK, M., GOLDRING, G., HILLMAN, P. "Fast neutron spectroscopy with solid state detectors”. Nuclear Instruments and Methods, 21, pp. 197-201, 1963.

[49] KOVACEVIC, K.,STIPICIC, N., PAIC, G.,SLAUS,I., EMAN, B., PECAR,V. and ANTIC, M. "Use of Photodiodes for Neutron Dosimetry", Nuclear Instruments and Methods, 148, pp.291-298, 1978.

[50] EISEN, Y., ENGLER, G., OVADIA, E., SHAMAI, Y. “A combined real time wide energy range neutron dosemeter and survey meter for high neutron dose rates with Si Surface Barrier Detectors”. Nuclear Instruments and Methods, 211, pp.171-178, 1983. 
[51] MATSUMOTO, T. and NOZAKI, T. "A new monitoring system for the thermal neutron fluence rate and gamma dose rate in boron neutron capture therapy". Physics in Medecin and Biology, Vol 33, N4, pp. 427-435, 1988.

[52] SHIRAISHI, F., TAKAMI, Y., HASIMOTO, T. and HATORI, K. "A new type personnel neutron dosemeter with thin Si detectors". IEEE Transactions on Nuclear Science, Vol 35, No 1, 1988.

[53] NAKAMURA, T., HORIGUCHI, M., SUZUKI, T. and YAMANO, T. “A real time wide energy range personal neutron dosemeter with two silicon detectors". Radiation Protection and Dosimetry, Vol.27, 3, pp.149-156, 1989.

[54] BARELAUD, M, DECOSSAS, J.L., MAKOVICKA L. and VAREILLE, J.C. "Capteur électronique pour la dosimetrie des neutrons". Radioprotection, Vol 26, pp. 307-328, 1991.

[55] BARELAUD, M, DUBARRY-CHAVANAIS, B., DECOSSAS, J.L., PAUL, D., MAKOVICKA L. and VAREILLE, J.C. "Evolution du capteur électronique pour la dosimetrie des neutrons développé au LEPOFI". Radioprotection, Vol 28, No4, pp. 387-409, 1993.

[56] HOSONO, Y., SJAFRUDDIN, IGUCHI, T., NAKAZAWA, M. "Fast neutron detector using PIN-type silicon photodidode", Nuclear Instruments and methods in Physics Research, A361, pp.554-557, 1995.

[57] ROSENFELD, A.B., KAPLAN, G., CAROLAN, M.G., ALLEN, B.J., MAUGHAN, R., YUDELEV, M., KOTA, Ch., CODERRE, J. “Simultaneous Macro and Micro Dosimetry with MOSFET”, IEEE Transactions on Nuclear Science, Vol 43, No 36, 1996.

[58] BORDY, J.M., LAHAYER, T., LANDRE, F., HOFLACK, C., LEQUIN, S. and BARTHE, J. "Single diode detector for individual neutron dosimetry using a pulse shape analysis”. Radiation Protection Dosimetry, Vol. 70, 1-4, pp.73-78, 1997. 
[59] ROSENFELD, A., KAPLAN, G., CAROLAN, M. "Application of PIN diode and MOSFETs for dosimetry in gamma and neutron radiation fields". Radiation Protection Dosimetry, Vol 84, № 1-4, pp, 349-352,1999.

[60] NAKAMURA, T., SASAKI, M., UEDA, O. And SUZUKI, T. "Characterization of a real-time personal neutron dosemeter with two silicon detectors" Radiation Protection Dosimetry, Vol. 85, № 1-4, pp. 45-48, 1999.

[61] FILHO, M.T., HAMADA, M.M., SHIRAISHI, F., MESQUITA, C.H. "Development of neutron detector using the surface barrier detector with polyethylene $(n, p)$ and ${ }^{10} \mathrm{~B}(\mathrm{n}, \alpha)$ converters" Nuclear Instruments \& Methods in Physiscs Research, A 458, pp. 441-447, 2001.

[62] AgosteO, S., CASTOLDI, A., CASTEllani, L., COlAUTTI, P., D’Angelo, G., De NARDO, L., FAVALLI, L., LIPPI, I., MARTINELLI, TORNELLI, G. and ZOTTO, P. "A feasibility study of a single event spectrometer based on semiconductor devices". Radiation Protection Dosimetry, Vol. 99, Nos 1-4, pp. 343-346, 2002.

[63] MESQUITA, C.H., FILHO, T.M.,HAMADA, M.M. "Development of nêutron detector using the PIN photodiode with polyethylene $(n, p)$ converter". IEEE Transactions on Nuclear Science, Vol 50, No 4, pp. 1170-1174, August 2003.

[64] LEE, B.J., LEE, W., CHO, G., CHANG, S.Y. and RHO, S.R. "Solid-state personal dosemeter using dose conversion algorithm". Nuclear Instruments and Methods in Physics Research, A 505, pp. 403-406, 2003.

[65] AGOSteO, S., BIRATtARI, C., DANGElO, G., DAL CORSO, F., FOGLIO PARA, A., LIPPI, I., POLA, A. and ZOTTO, P. "Neutron spectrometry with a recoil radiator-silicon dector device". Nuclear Instruments and Methods in Physics Research, A515, pp.589-604, 2003.

[66] VOYTCHEV, M., INIGUEZ, M.P., MENDEZ, R. MANANES, A., RODRIGUEZ, R. and BARQUERO, R. "Neutron detection with a silicon PIN photodiode and LiF converter". Nuclear Instruments and Methods in Physics Research, A512, pp.546-552, 2003. 
[67] Agosteo, S., DANGelo, G., FAZZI, A., FOGlio PARA, A., POLA, A., VENTURA, L. and ZOTTO, P. "A recoil-proton spectrometer based on a PIN diode implementing pulse-shape discrimination”. Radiation Protection Dosimetry, Vol. 110, 1-4, pp.509-516, 2004.

[68] ADAMIEC, G., INIGUEZ, M.P., LORENTE, A. VOYTCHEV, M. and GALLEGO, E. "Response of a silicon PIN photodiode to an Am-Be neutron source". Nuclear Instruments and Methods in Physics research", A534, pp.544-550, 2004.

[69] McGREGOR, D.S., BELlingER, D.B., COWLEY, S., ElAZEGUI, M., McNeil W.J., PATTERSON, E., UNRUH, T. "Perforated semiconductor neutron detector modules for detection of spontaneous fission neutrons, SMART Laboratories, Mechanical and Nuclear Engineering, Kansas State University, Manhattan, KS, USA, 2008.

[70] FARAHMAND M. , "A novel tissue equivalent proportional counter based on a Gas Eletron Multiplier", Ph.D. Thesis, The Netherlands, 2004.

[71] ROSSI H.H., ZAIDER M., "Microdosimetry and its Applications" -Springer Verlag Berlin 1996 .

[72] BRADLEY P.D. "The development of a novel silicon microdosimeter for high LET radiation therapy" $\mathrm{Ph} . \mathrm{D}$. Thesis, Department of Engineering Physics, University of Wollongong, Australia, 2000.

[73] ROSSI, H. H., "Specifications of radiation quality”, Radiation Research, 10, pp.522-531 (1959).

[74] ROSSI, H.H., “The role of Microdosimetry in Radiobiology and Radiation 'Protection. Page 1-30, In: Proceeding Third Symposium on Microdosimetry, Ed H. G. Ebert. 4810 (Luxemburg: Commission of the European Communities) (1972).

[75] KELLERER, A. M., ROSSI, H. H., "The theory of Dual Radiation Action”, Curr. Topics Radiation Research, Q. 8, pp.85-158 (1972). 
[76] WAMBERSIE A et al, "The role of Microdosimetry in Radiotherapy" Radiation. Protection. Dosimetry, Vol 31, pp 421-432, 1990.

[77] KLIAUGA, P. "Microdosimetry at middle age: some old experimental problems and new aspirations" Rad. Res., Vol 124, pp. 5-15, 1990.

[78] ZAIDER, M., BARDASH, J., LADIK, J. "Solid State Microdosimetry" Radiation Protection Dosimetry, Vol 85, No 1-4, pp. 443-446, 1999.

[79] DICELLO, J.F., AMOLZ, H.I., ZAIDER, M. AND TRIPARD, G. A comparison of microdosimetric neasurements with spherical proportional counters and solid-state detectors. Radiation Research, 82, pp.441-453, 1980.

[80] ORLIC M. Et Al "Microdosimetric counters based on semiconductors detectors" Rad. Prot. Dosimetry, Vol 29, pp 21-22, 1989.

[81] KADACHI, A., WAHEED, A. and OBEID, M. "Performance of PIN Photodiode in Microdosimetry”. Health Physics, 66 (5), pp.577-580, 1994.

[82] ROSENFELD A. B. , et Al "Simultaneous macro-micro dosimetry with MOSFET's" IEEE Trans. Nucl. Sci. , Vol 43, Nº 6, pp. 2693-2700, 1996.

[83] SCHRODER, O. And SCHMITZ, T. "The application of commercial semiconductor chips for personal neutron dosimetry". Radiation Protecion Dosimetry, Vol.61, 1/3, pp. 9-12, 1995.

[84] KADACHI, A., WAHEED, A., AL-ESHAIKH and OBEID, M. "Use of photodiode in Microdosimetry and evaluation of effective quality factor". Nuclear Instruments and Methods in Physics Research, A404, pp.400-406, 1998.

[85] ROSENFELD A. B. , et Al "A new silicon detector for microdosimetry applications in proton therapy“ IEEE Trans. Nucl. Sci. , Vol 47, N 4, 2000. 
[86] AgosteO, S., FAlliCA, P.G., FAZZI, A., POlA, A., VAlvO, G., ZOTTO, P. “A feasibility study of a solid-state microdosimeter", Applied Radiation and Isotopes, \#63, pp. 529-535, 2005.

[87] CAROLAN, M.G. and ROSENFELD, A.B. "A method for measuring tissue-equivalent dose using a PIN diode and activation foil in epithermal neutron beams with $\mathrm{E}<100 \mathrm{keV}$, Radiation Protection dosimetry, Vol 120, 1/4. Pp. 337-340, 2006.

[88] YORIYAZ, H., "Desenvolvimento de uma metodologia computacional para cálculos em dosimetria interna”. Tese de Doutoramento, Instituto de Pesquisas Energéticas e Nucleares, Universidade de São Paulo, São Paulo, Brasil (2000).

[89] WITLOCK, K. "Monte Carlo Methods - Basics - Vol 1", John Wiley\&Sons, N.Y., USA, 1986.

[90] MORAlleS, M.,GUIMARÃES, C.C., OHUNO, E. “ Monte carlo Simulation of X-ray generation and detection”, Instituto de Fisica, Universidade de São paulo, Brasil, 2002.

[91] VEGA-CARRILO, H.R., MANZANARES-ACUNA, E., HERNANDEZ-DAVILA, V.M., CHACON-RUIZ, A., MERCADO, G.A., GALLEGOS, E. and LORENTE, A. "Monte Carlo based methods to determine the strength of a neutron source". Radiation Effects\&Defects in Solids, Vol. 162, 10-11, pp.771-776, Sept-Oct, 2007.

[92] ORTEC INCORPORATED. "Instruction manual surface barrier detectors". Oak Ridge, Tenn, USA, 1966.

[93] TAKAMI, Y., HASHIMOTO, T. and SHIRAISHI, F. "Quantitative analysis of alpha activities in thick sources using Si dtectors". IEE Transactions on Nuclear Science, V.33(1), pp. 639-642, 1986.

[94] HAMAMATSU PHOTONICS, "Silicon Photodiodes and Charge Sensitive Amplifiers", 1993. 
[95] ABUHOZA, A.A.A. "Comparison study of reflected and trnasmitted thermal neutron flux in water and other moderators". Master of Science Dissertation, The Department of Physics and Astronomy College of Science King Saud University Riyadh, Kingdom of Saudi, 2007.

[96] PEREIRA, M.A.S., "Radiografia com partículas alfa induzida por nêutrons", Tese de Doutoramento, Instituto de Pesquisas Energéticas e Nucleares, Universidade de São Paulo, São Paulo, Brasil (2007).

[97].THOMPSON, M.N., TAYLOR, J.M. "Neutron spectra from Am-a-Be and Ra-a-Be sources". Nuclear instruments and Methods, 37, pp. 305-308, 1965.

[98] MARSH, J.W., THOMAS, D.J. and BURKE, M. "High resolution measurements of neutron energy spectra from Am-Be and Am-B neutron sources". Nuclear Instruments and Methods in Physiscs Research, A366, pp.340-348, 1995.

[99] VEGA-CARRILLO, H.R., MANZANARES-ACUNA, E., BECERRA-FERRERO, A.M. and CARRILLO NUNEZ, A. "Neutron and gamma-ray spectra of PuBe and AmBe". Applied Radiation and Isotopes, 57, pp.167-170, 2002.

[100] CARDENAS, J.P.N. and FRAJNDLICH, R., "Uma contribuição para a implementação do programa do AGEING para o reator IEA-R1" III ENAN - Encontro Nacional de Aplicações Nucleares, Outubro de 1996, Rio de Janeiro-RJ, Brasil.

[101] BITELLI - BH845.- BITELLI, U., ALVES, M. and COELHO, P.R.P., "Mapeamento de fluxo de nêutrons térmicos no canal de irradiação \#8 do reator IEA-R1”, VII ENFIR, Atibaia-SP, São Paulo, Brasil (1991).

[102] PUGLIESI, R., ANDRADE, M.L., PEREIRA, S.M.A., PUGLIESI, F. "Nêutroninduced electron radiography, Nulear Instruments and methods in Physics Research, A 542, pp. 81-86, 2005.

[103] PEREIRA, S.M.A., PUGLIESI, R., PUGLIESI, F. "Neutron-induced alpha radiography” Radiation Measurements”, 43, pp. 1226-1230, 2008. 
[104] BITELli, U., GONÇALVES, L.B., KURAMOTO, R., "Calibration of the nuclear power channels of the IPEN/MB-01 reactor: measurements of the spatial neutron flux distribution in the core using infinitely dilute gold foils", International Nuclear Atlantic Conference - INAC 2007Santos, SP, Brazil (2007).

[105] DELANEY, C.F.G. and FINCH, E.C. "Radiation detectors". Oxford - Clarendon Pr, 1992.

[106] SIRAJUDDIN, D. "Solid State Detectors and Alpha Spectroscopy". Nuclear Engineering and Radiological Sciences Dept., University of Michigan, USA, 2006.

[107] PECEQUILO, B.R.S. e KOSKINAS, M.F. “Caracterização do Espectro de Altura de Pulso de um contador proporcional para nêutrons tipo BF”. Tópicos Avançados de Medidas Nucleares (TNA5733), Pósgraduação, IPEN, 2004.

[108] SARDELlA, F., INVAP S.A., Bariloche, Rio Negro, Argentina, e BASTIDA C., CNEA, Buenos Aires, Argentina, Comunicação Pessoal, Setembro, 2009.

[109] ZIEGLER, J.F. “The stopping power and ranges of ions in matter". Pergamon Press, New York, 1977.

[110] MAIDANA, N.L. "Medida de seções de choque para reações de captura de nêutrons no ${ }^{57} \mathrm{Co},{ }^{137} \mathrm{Cs}$ e ${ }^{241} \mathrm{Am}$ considerando a formação de estados isoméricos”. Tese de Doutoramento, Instituto de Pesquisas Energéticas e Nucleares, Universidade de São Paulo, São Paulo, Brasil, 2000.

[111] PRICE, W.J. "Nuclear radiation detection". McGraw-Hill book Company, New York, NY,USA, 1958.

[112] BLOSSER, T.V and THOMAS, G.E. "Nêutron flux and Nêutron and gamma-ray spectra measurements in HFIR". Neutron Physics Division, ORNL, Oak Ridge, TN, USA, 1968. 
[113] CARDENAS, J.P.N. "Monitoração continua do balanço térmico para determinação da potência do reator IEA-R1”. Dissertação de Mestrado, Instituto de Pesquisas Energéticas e Nucleares, Universidade de São Paulo, São Paulo, Brasil, 2000.

[114] DANIEL U. "Loss free counting with uncertainty analysis using ORTEC's innovative Zero Dead Time Technique". ORTEC Inc, Application Note AN-56, Oak Ridge, TN, USA, 2000.

[115] SASAKI, M., NAKAMURA, T., TSUJIMURA, N., UEDA, O. And SUZUKI, T. "Development and characterization of real time personal neutron dosemeter with two silicon detectors". Nuclear Instruments and Methods in Physics Research, A 418, pp. 465-475, 1998.

[116] RAMIREZ-JIMENEZ, F.J., AGUILERA, E.F., LOPEZ-CALLEJAS, R., BENITEZREAD, J.S. and PACHECO-SOTELO, J. "A novel application of a PIN diode-preamplifier set for the measurement of charged particles". Nuclear Instruments and methods in Physics Research, A545, pp.721-726, 2005.

[117] PAUSCH, G., BOHNE, W. And HILSCHER, D. "Particle identification in solid state detectors by means of pulse-shape analysis - results of computer simulation". Nuclear Instruments and Methods in Physics research, a 337, pp. 573-587, 1994.

[118] CORNELIUS, I. AND ROSENFELD, A. "Improvement of SOI microdosimeter performance using pulse-shape discrimination techniques". Faculty of Engineering, University of Wollongong, 2002.

[119] Agosteo, S., D’Angelo, G., FAZZI, A., FOGLiO PARA, A., POLA, A., VENTURA L. AND ZOTTO, P. "Performance of a nêutron spectrometer base don a PIN diode". RadiationProtection Dosimetry, Vol 116, 1/4, pp. 189-184, 2005.

[120] NUNOMIYA, T., ABE, S., AOYAMA, K. and NAKAMURA, T. "Development of advance-type multi-functional electronic personal dosemeter",. Radiation Protection Dosimetry, Advanced Access, pp. 1-4, 2007. 
[121] LAHAYE, T., CHAU, Q., MENARD, S., NDONTCHUENG-MOYO, M., BOLOGNESE-MILSZTAN and RANNOU, A. "Numerical and experimental results of the operational neutron dosemeter - SAPHYDOSE”. Radiation Protection Dosimetry, Vol.110, 1/4, pp. 201-206, 2004. 